\author{
University of Szeged \\ Faculty of Pharmacy \\ Department of Pharmaceutical Technology \\ Head: Prof. Dr. Habil. Piroska Szabó-Révész DSc.
}

\title{
STUDY OF THE WIDELY USED ETHYLCELLULOSE POLYMER AS FILM FORMING AND MATRIX FORMER AGENT
}

Ph.D. Thesis

\section{Diána Hegyesi}

Pharmacist

Supervisor

Dr. Géza Regdon Jr.

Szeged

2016 


\section{PUBLICATIONS RELATED TO THE THESIS}

I. G. Regdon Jr., D. Hegyesi, K. Pintye-Hódi:

Thermal study of ethyl cellulose coating films used for modified release (MR) dosage forms.

J. Therm. Anal. Calorim. 108, 347-352 (2012)

IF (2012): 1,982

II. D. Hegyesi, T. Sovány, O. Berkesi, K. Pintye-Hódi, G. Regdon Jr.:

Study of effect of plasticizer on the structure and surface characteristics of ethylcellulose free films with FT-IR spectroscopy

Microchemical Journal 110, 36-39(2013)

IF (2013): 3,583

III. D. Hegyesi, K. Süvegh, A. Kelemen, K. Pintye-Hódi, G. Regdon Jr.:

Characterization of ethylcellulose free films by positron annihilation spectroscopy and mechanical testing.

Microchemical Journal 115, 47-50 (2014)

IF (2014): 2,746

IV. D. Hegyesi, M. Thommes, P. Kleinebudde, T. Sovány, P. Kása Jr., A. Kelemen, K. Pintye-Hódi, G. Regdon Jr.:

Preparation and physico-chemical characterization of matrix pellets containing APIs with different solubility via extrusion process.

(manuscript submitted for publication) 


\section{PRESENTATIONS RELATED TO THE THESIS}

I. D. Hegyesi, T. Sovány, O. Berkesi, K. Pintye-Hódi, G. Regdon Jr.

Study of the effect of the plasticizer on the structure and surface characteristics of ethylcellulose free films with FT-IR spectroscopy.

8th World Meeting on Pharmaceutics, Biopharmaceutics and Pharmaceutical Technology.

Istanbul, Turkey, 2012.03.19-2012.03.22.

II. D. Hegyesi, K. Pintye-Hódi, G. Regdon Jr.

Investigation of the thermal behaviour of ethyl cellulose coating films for the purpose of modified release (MR)

8th World Meeting on Pharmaceutics, Biopharmaceutics and Pharmaceutical

Technology.

Istanbul, Turkey, 2012.03.19-2012.03.22.

III. D. Hegyesi, K. Süvegh, K. Pintye-Hódi, G. Regdon Jr.

The study of the incorporation of the plasticizer and the mechanical properties of ethyl-cellulose free films

International Conference on Bio-Based Polymers and Composites 2012.

Siófok, Hungary, 2012.05.27-2012.05.31.

IV. Hegyesi D., ifj Kása P., Hódi K., ifj Regdon G.

Mátrix típusú pelletek formulálása faktoriális kísérlettervezés alkalmazásával.

XVIII. Országos Gyógyszertechnológiai Konferencia és IX. Gyógyszer az

Ezredfordulón Konferencia, Elöadáskivonatok (EA-13) 22 (2012)

Siófok, Hungary, 2012.09.27-2012.09.29.

V. D. Hegyesi, M. Thommes, P. Kleinebudde, T. Sovány, P. Kása Jr., A. Kelemen, K.

Pintye-Hódi, G. Regdon Jr.

Preparation and characterization of matrix pellets via extrusion process

5th BBBB International Conference 2013.

Athen, Greece, 2013. 09.26-2013.09. 28. 


\section{Hegyesi Diána}

Mátrixpelletek formulálása kétcsigás extruderrel (szóbeli előadás)

XI. Clauder Ottó Emlékverseny

Budapest, 2013. 10.17-18.

VII. D. Hegyesi, T. Sovány, A. Kelemen, M. Thommes, P. Kleinebudde, K. Pintye-Hódi, G. Regdon Jr.

Effects of extrusion-spheronization parameters on the structural properties of matrix pellets

9th World Meeting on Pharmaceutics, Biopharmaceutics and Pharmaceutical

Technology.

Lisbon, Portugal, 2014.03.31-2014.04.03.

VIII. D. Hegyesi, T. Sovány, A. Kelemen, M. Thommes, P. Kleinebudde, K.Pintye-Hódi, G. Regdon Jr.

Az extrudálási-szferonizálási paraméterek hatása mátrixpelletek szerkezeti tulajdonságaira

$X V$. Congressus Pharmaceuticus Hungaricus

Budapest, Hungary, 2014. 04. 10- 2014. 04. 12.

\section{OTHER PRESENTATION}

IX. G. Regdon Jr., D. Hegyesi, B. Sipos, I. Oláh, K. Kristó, T. Sovány, S. Barimani, K. Knop, P. Kleinebudde

Investigation of coating processes and of separated polymer films from model solid dosage forms

6th BBBB - Conference on Pharmaceutical Sciences: Startegies to Improve the Quality and Performance of Modern Drug Delivery Systems.

Helsinki, Finnland, 2015.09.10-2015.09.12. Paper 40. 


\section{ABBREVIATIONS}

ACE: Angiotensin Converting Enzyme

API: Active Pharmaceutical Ingredients

AR: aspect ratio

BCS: Biopharmaceutics Classification System

CAP: cellulose acetatephthalate

CPEC: coarse particle ethylcellulose

CR: controlled-release

DSC: Differencial Scanning Calorimetry

EC: ethylcellulose (EC10, EC45)

EM: enalapril-maleate

FPEC: fine particle ethylcellulose

FT-IR: Fourier Transform Infrared Spectroscopy

HCT: hydrochlorothiazide

HEC: hydroxyethylcellulose

HPMC: hydroxypropyl methylcellulose

HPMCP: hydroxypropylmethylcellulose phthalate

MC: methylcellulose

MCC: microcrystalline cellulose

MFT: Minimum Film forming Temperature

MR: modified release

PALS: Positron Annihilation Lifetime Spectroscopy

PEO: polyethylene oxide

RAS: Renin-Angiotensin System

RH: Relative Humidity

SEM: Scanning Electron Microscope

SEM-MID: Secondary Electron Multiplier - Multiple Ion Detection

SR: slow-release / sustained-release

TEC: triethyl citrate

TG: thermogravimetry

TG-MS: Thermogravimetric Analysis coupled with Mass Spectrometry

XR: extended-release 


\section{STUDY OF THE WIDELY USED ETHYLCELLULOSE POLYMER AS FILM FORMING AND MATRIX FORMER AGENT}

\section{Contents}

1. INTRODUCTION .................................................. 1

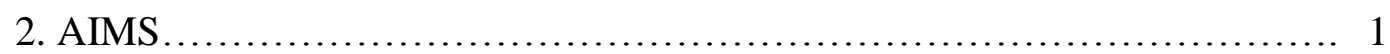

3. LITERATURE SURVEY ......................................... 2

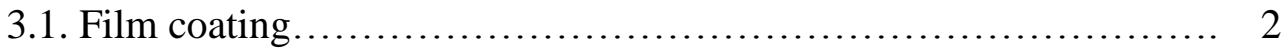

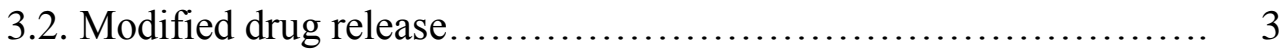

3.3. Film forming mechanism................................... 4

3.4. Ethylcellulose............................................ 5

3.5. Preformulation studies of free films .......................... 6

3.6. Extrusion / spheronization pelletization process............... 7

4. SECTION I. ....................................................... 10

4.1.Materials and methods $\ldots \ldots \ldots \ldots \ldots \ldots \ldots \ldots \ldots \ldots \ldots \ldots \ldots \ldots, 10$

4.1.1. Materials ........................................... 10

4.1.2. Methods ........................................... 10

4.1.2.1. Preparation of solutions ............................ 10

4.1.2.2. Preparation of free films .............................. 10

4.1.2.3. Thermoanalytical measurements..................... 11

4.1.2.4. Mass spectrometric examinations .................... 11

4.1.2.5. Measurement of the contact wetting angle .............. 12

4.1.2.6. Fourier transform infrared spectroscopy (FT-IR) ....... 12

4.1.2.7. Positron annihilation lifetime spectroscopy (PALS)....... 12

4.1.2.8. Mechanical properties of free films ................. 13

4.2. Results............................................. 14

4.2.1. Thermoanalysis................................... 14

4.2.2. Physico-chemical properties of films.................... 18

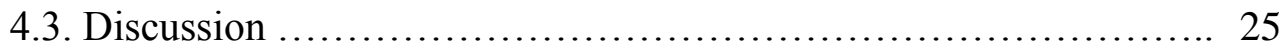


5.1. Materials and methods ....................................... 27

5.1.1. Materials ...................................................... 27

5.1.2. Methods ........................................... 27

5.1.2.1. Experimental plan ................................ 27

5.1.2.2. Preparation of pellets ........................... 28

5.1.2.3. Image Analyser ................................. 28

5.1.2.4. Scanning electron microscope (SEM)................ 29

5.1.2.5. Mechanical properties of pellets ...................... 29

5.1.2.6. Dissolution study .............................. 29

5.2. Results............................................... 30

5.2.1. Characterization of APIs.............................. 30

5.2.2. Characterization of pellets............................ 31

5.2.3. Factorial design................................... 33

5.2.4. Mechanical properties of pellets.......................... 38

5.2.5. Dissolution ........................................... 39

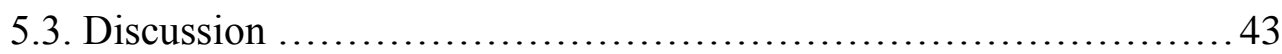

6. FINAL CONCLUSION, NOVELTY, PRACTICAL USEFULNESS ....... 44

7. REFERENCES ................................................. 46

AKNOWLEDGEMENT ............................................ 51 


\section{INTRODUCTION}

With the continuous development of biopharmacy and technology, the possibility arose to make controlled-release release oral systems and with this the potential to control the rate, place or duration of drug release. Accordingly, modified (sustained, retarded, pulsatile) drug release can be achieved; and the one possible way to realize this is to use a properly formed coat ( $\mathrm{pH}$-dependent dissolution, diffusion film, etc.). These solutions require film coats to meet higher expectations [1].

There are several methods to achieve modified drug release (MR). One of the most common way to prepare this dosage form, is film coating [2,3]. Another method is, to formulate a multiparticulate drug delivery system [4].

Multiparticulates involve multiple-unit small systems. They have more advantages compared to single unit systems owing to their small size. They are better distributed in the gastrointestinal transit, therefore cause less side effect.

\section{AIMS}

The two main parts of this work were to investigate the widely used ethylcellulose (EC) polymer as a film forming agent and as a matrix former agent.

In the first section, two ethylcellulose film forming polymers with different chain lengths and different molecular weight (Ethocel Standard Premium 10 ${ }^{\circledR}$, Ethocel Standard Premium $45^{\circledR}$, Colorcon Ltd.) were studied. The investigation of free films is an essential part of the preformulation studies because it is necessary to know weather the given formulation is suitable to coat the corpus or not.

The aim of our research was to investigate the effect of the length of the polymer chain and the effect of the concentration of triethyl citrate (TEC), which was used as a plasticizer, on the thermal stability of the film and as well as on the structure of the ethylcellulose films (EC10 and EC45) used for preparing MR dosage forms. As preformulation, the relationship between surface properties and the structure of EC free film containing different amounts of plasticizer and the relationship between the mechanical properties and the distribution of the plasticizer were studied. The knowledge of these properties is indispensable for preformulation studies. The influence of storage time was studied by monitoring the changes in the thermoanalytical parameters and by performing Termogravimetric Analysis coupled with Mass Spectrometry (TG-MS) examinations. The structure analysis and the incorporation of the plasticizer were performed with the use of Fourier Transform Infrared Spectroscopy (FT-IR). There are 
several methods for the prediction of the polymer-plasticizer interactions [5], but the real microstructure and the incorporated amount of the plasticizer could be studied with the use of FT-IR spectroscopy [6-11]. The distribution of the plasticizer between the chains of the polymer ethylcellulose was determined in order to explain the mechanical properties. The distribution was investigated with positron annihilation lifetime spectroscopy (PALS), and the mechanical properties with breaking hardness tests. The best film former with plasticizer was chosen with the optimal concentration. Selection of the optimum type and concentration of the plasticizer is essential in the formulation of pellets and coated dosage forms.

In the second section, ethylcellulose polymer was used as matrix former excipient. Besides the generally used microcrystalline cellulose (MCC), EC was used as matrix former to achieve modified drug release ensured by diffusion. Innovative, matrix pellets containing capsule dosage forms was developed with combined Active Pharmaceutical Ingredients (API).

The matrix pellets were made by extrusion-spheronization using a twin-screw extruder. Two different APIs with different Biopharmaceutics Classification System (BCS), solubility and particle were used in the course of formulation of monolithical matrix pellets. Some pellet properties (aspect ratio /AR/ 10\% interval fraction, hardness, deformation process) were determined. The aim of our study was to investigate how the two different APIs with different solubility and particle size influence the process.

\section{LITERATURE SURVEY}

\subsection{Film coating}

Film coating is a method widely used for the development of solid dosage forms. In the process of film coating, a thin stable polymer film coat is created on the surface of a solid dosage form, such as tablets, capsules, pellets or crystals. The great number of polymers available for coating ensure different dissolution profiles. With the optimal choice of film forming materials, we provide the possibility that the coating would solve in the optimal part of the gastrointestinal tract, therefore the rate and the place of the drug release can be influenced. Coatings are divided into 3 type:

1. gastrosolvent coating

2. enteric coating

3. permeable coating 
Methylcellulose (MC), hydroxyethylcellulose (HEC) and some polymethacrylate products (e.g. Eudragit ${ }^{\circledR}$ E) are polymers that dissolve in the gastric juice [12]. Cellulose esters, cellulose acetatephthalate (CAP) and hydroxypropylmethylcellulose phthalate (HPMCP) are enteric polymers used to form colonic drug delivery systems [13]. Acryl-Eze ${ }^{\circledR}$, an aqueous system, which contains a 1:1 copolymer of methacrylic acid and methyl methacrylate, is often used for the enteric coating of dosage forms, it means that the drug release happens in the intestines, it is resistant for gastric juice [14-16]. Enteric coating can protect the stomach from the drug, the drug from the stomach, or provides the drug release after stomach.

This way we can not only develop dissolving coatings, but coatings that are insoluble in the gastrointestinal tract, that is to say permeable coatings; such products make the effect sustained by diffusion. Ethylcellulose polymer is able to prepare permeable coating.

\subsection{Modified drug release}

Pharmacists, during their everyday work, meet with abbreviations indicating the modified release properties of that specific medication, which may appear in the brand name or in the descriptive name of the medication.

Tablets and capsules which are designed to provide modified release often have the letter combinations XL, SR, MR, CR, XR, or LA in their names e.g. (in Hungary) Cardura $\mathrm{XL}^{\circledR}$, Xanax SR ${ }^{\circledR}$, Alfetim Uno ${ }^{\circledR}$, Preductal MR ${ }^{\circledR}$, Tegretol $\mathrm{CR}^{\circledR}$, Merckformin $\mathrm{XR}^{\circledR}$, Ritalin LA ${ }^{\circledR}$. The goal of the drug is presaged by these abbreviations.

Modified-release (MR) products include extended-release (XR), prolonged-release, controlled-release (CR), slow-release (SR) and sustained-release (SR). These preparations, by definition, have a reduced rate of release of active substance. In general, these terms are interchangeable. This kind of release offers advantages and disadvantages [17].

This has a great significance in the therapy, where patient compliance could be considerably improved with the use of preparations administered once/twice daily [18]. The improvements of the effectiveness of the therapy and enhanced patient compliance have had an increasing importance in the last decades. This necessitates controlling the rate, place or duration of drug release. One of the many possibilities is the use of coated dosage forms, however, to achieve the required effect ( $\mathrm{pH}$-dependent dissolution, diffusion film, etc.) it is necessary to use a properly formed coat. Besides better compliance there is another advantage, which is the sustained blood level and therefore the attenuation of adverse effects. The disadvantage of the 
modified release product is that they must not be crushed or chewed, since the slow-release characteristics will be lost and this administration method may result in toxicity.

\subsection{Film forming mechanism}

In general the coating liquid is sprayed to the core surface from solution or aqueous dispersion, but the film formation is different from these systems.

From solutions it is relatively easy to create a film coating. However, the atomized droplets should cover the surface totally to create a liquid film. During the atomization the evaporation of the solvent must not increase the viscosity of the droplets. The spreading of droplets is determined by the surface tension between the liquid and the core surface. The contact angle provides valuable and useful information, which is the angle between the surface and the liquid drop. The drops may remain at a certain angle, or sprawled across the surface. In this case the angle is zero. The smaller the angle, the better the droplets spread out on the surface, and as a result the coating is more evenly distributed on the corpus.

After a short time the corpus is covered with a thin polymer film, and then it is important that the film surface must bet wet enough to properly merge the droplets. During drying, the solvent evaporates from the solution, in which the polymer was initially located as separate chains.

The colloidal solutions of polymers have become more concentrated. When the solvent is slowly evaporated, the polymer chains will be closer together and upon reaching a certain concentration an overlap will be formed in between. This is the reciprocal of intrinsic viscosity: therefore $\boldsymbol{\mu}$ expresses the hydrodynamic interactions between polymer and solvent and reflects the ability of the solvent to swell the polymer. This results gel formation, which is converted into a film in the drying progresses [19].

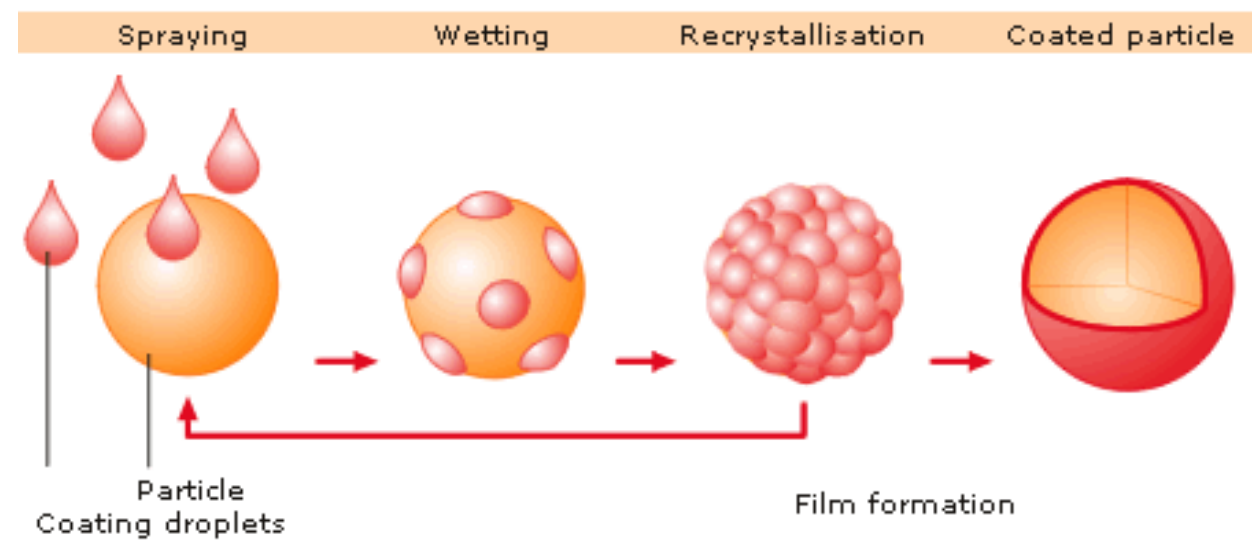

Figure 1.: The mechanism of film formation [20] 
Polymer dispersions can only form a film, when the polymer particles crushed and deformed and permanently unite by beating the repulsive forces between them. As it is apparent from the foregoing, film formation is a prerequisite for certain stickiness and deformability of polymer particles, which in the case of polymers is correlated with temperature. Therefore it includes a Minimum Film forming Temperature (MFT) to all polymer dispersion. MFT means the lowest temperature where a polymer emulsion forms a continuous film. This is not a definite value because it depends on the thickness, the drying speed, the intake capacity of the surface and also on the air movement. Of course the pigments, the filler materials and other additives may change the MFT. Another important factor in the film formation process is the driving force that causes coalescence of the polymers by means of water evaporation and capillary forces. Since the coalescence happens above a certain temperature (MFT) the temperature and the evaporation of the water are the most important factors that affect the film forming properties of the coating materials. When the polymer dispersion has dried below the level of the MFT, after heat treatment we get a transparent film, but it requires higher temperatures than MFT. Thus water plays a significant role in the film forming [21, 22].

Aqueous dispersions are water-dispersible polymers. Several methods are known for their production, which determine excipients contained therein. Film forming polymer dispersions create film coatings with a special mechanism. When the dispersion medium - the water evaporates the latex particles take up the closest spherical arrangement first. During further drying they can stick together if the polymer material is quite soft. This process is called coalescence. In this state, the remaining water is removed, thus obtaining water-insoluble, homogeneous film [23]. Adhesion occurs between the coating and the core, assuring the 'sticking' of the film to the core. The cohesion among the polymers determines the inside structure and the film properties such as porosity, permeability, flexibility and mechanical strength. The occurring forces can be altered with additives, which influence the physical properties of the coating layer [24].

\subsection{Ethylcellulose}

Ethocel (Ethylcellulose polymers) has been widely used in the pharmaceutical industry for over 50 years [25]. Ethylcellulose has been used for choice in pharmaceutical formulations for various purposes, such as taste-masking of bitter actives [26], moisture protection [27], stabilizer [28], extended release multiparticulate coating [29], micro-encapsulation of actives 
[30], extended release binder in inert matrix systems [31], solvent [32] and extrusion granulation [33-35]. The application of EC in wet extrusion processes is limited, since the polymer has considerable elastic properties, but can be successfully used as matrix former in combination with some plasticizing agents $[34,35]$. Mallipeddi et al. used the potential of coarse ethylcellulose (CPEC) and fine particle ethylcellulose (FPEC) as diluent with high molecular weight polyethylene oxide (PEO), which was used as an extrusion aid and a binder. Their results have shown that water is sufficient to prepare a wet granulation product when using FPEC. MCC was included in their formulations to contribute its plasticity to the wetted mass during extrusion and to the extrudate during spheronization.

Ethylcellulose is a water insoluble cellulose ether, which is prepared from cellulose, it is a partly O-ethylated cellulose, its ethoxy content $\left(-\mathrm{OC}_{2} \mathrm{H}_{5}\right)$ is between $44-51 \%$.

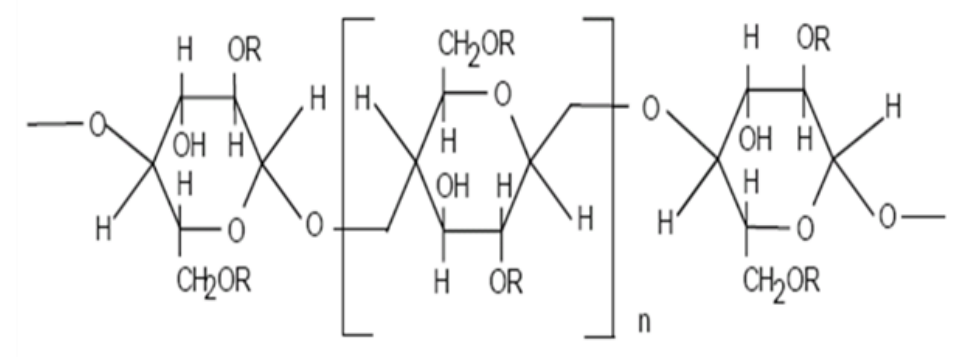

Figure 2.: The atomic formula of ethylcellulose polymer

Ethylcellulose is an ideal polymer for the formation of products allowing modified drug release. It is insoluble at any $\mathrm{pH}$ that occurs in organism, but in the presence of the gastric juice it undergoes swelling. It is then permeable for water and permits extended modified drug release [36-39]. This makes it suitable for improved patient compliance. A small number of ethylcellulose polymers have been approved for general pharmaceutical application and are used in extended release solid dosage formulations. Several types of such ethylcellulose exist, e.g. Ethocel 4, Ethocel 10 and Ethocel 45, which differ in the length of the polymer chains, the rate of dissolution, and the viscosity of their solution. Ethylcellulose is suitable to prepare MR coatings.

\subsection{Preformulation studies of free films}

Before film coating, preformulation studies are necessary in order to study the physicochemical and thermal properties of free films, e.g. the glass-transition temperature, the 
Minimum Film forming Temperature (MFT), the surface properties, the breaking strength, deformability and the structure of the film former polymer.

The polymer film has to form a uniform and continuous coat on the surface of the core to be coated; which is based on the properties of the polymer. However, the special requirements, or the achievement of the best performance or the need to decrease the costs often necessitates the modification of the basic properties of films.

Most of the properties such as the MFT, the surface characteristics and the mechanical properties can be modified with the use of different plasticizers [40-43]. These molecules are built in amongst the polymer chains, thereby preventing their interaction. Therefore, the polymer chains may shift along each other and elasticity will increase, which will reduce the rigidity of the film. Moreover, the functional groups of the plasticizer and the interactions between the materials will affect the surface characteristics and adhesive properties of the films [43, 44]. There are several methods for the prediction of the polymer-plasticizer interactions [5], but the real microstructure and the incorporated amount of the plasticizer could be studied with the use of FT-IR spectroscopy [6-10].

The mechanical properties of the resulting film depend on the distribution of the plasticizer. It is necessary to know its breaking strength, because the film is exposed to intense mechanical stress during the technological process.

In the present work, the distribution of the plasticizer and the supramolecular structure of free films were studied by means of Positron Annihilation Lifetime Spectroscopy (PALS), which furnishes direct information about the dimensions and contents of free-volume holes in amorphous materials. The magnitude of the free volume can be measured with the aid of PALS as electron density changes in the lifetime of the ortho-positron depend on the free volume of the polymer [45-47]. This method is most commonly applied to study polymers. Investigation of cellulose-based polymers by PALS have revealed that substitution on cellulose has little effect on the lifetime, but a major effect on the probability of formation of the ortho-positron (o-Ps) [48, 49].

\subsection{Extrusion / spheronization pelletization process}

In the pharmaceutical industry, pellets can be defined as small, free-flowing, spherical particulates with a diameter between 500 and $1500 \mu \mathrm{m}$, manufactured by the agglomeration of fine powders or granules of drug substances and excipients using appropriate processing equipment [50]. There are several techniques to produce pellets, e.g.: layering in fluid bed 
equipment or direct pelletisation in high shear mixers and rotary processors. The extrusionspheronization is an established technique to produce pellets of a high density and narrow size distribution.

The process of extrusion/spheronization is applied in the pharmaceutical industry to manufacture many types of dosage forms. During the preparation of pellets [34, 35, 51], granules [52], implants [53, 54], films [55], and nanocomposite films [56] extruders are used. There are many type of extruders: screw extruders, radial screen and roll extruders, and ram extruders [57]. Ram extruder is the simpliest type ones, but owing to its construction, it is not able to prepare continuous production [58]. Radial screen extruders and roll extruders are suitable for continuous extrusion of pregranulated powders, but the disadvantage of this extruder is that dry powders cannot be used, due to the lack of mixing, which should take place inside the extruder [59, 60, 61]. With the development of technology, screw extruders became more popular. There are two types of screw extruders: the single-screw and twinscrew extruders. Single screw extruders are usually equipped with an axial discharge. The twin screw extruders are available with both axial and radial discharge of the extrudate. Screw extruders are able to continuous extrusion and they also work with prewetted masses. During extrusion, first a uniform mixture of components is made - owing to the liquid binder that prepares the wetted mass - which has the appropriate cohesive properties, thus it can be extruded. The wetted mass is pressed by the screws of the extruder through one or more dies; this way the material gets shaped and the strands of extrudates are formed.

In case of co-rotating screws the mixing, wettening and extruding of the powder initial material can be managed in that one single device. This is allowed by the modular design of the screws, because different processes may be implemented in different parts of the extruder. The starting materials are fed by the input part of the extruder, and during the extrusion process the specific combination of the thickening, mixing or kneading screw elements mix, dilute, cut, and at the end extrudes the mass $[62,63]$.

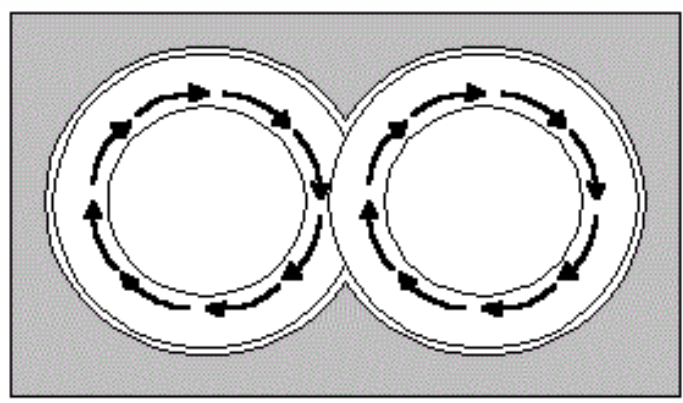

co-rotating screws

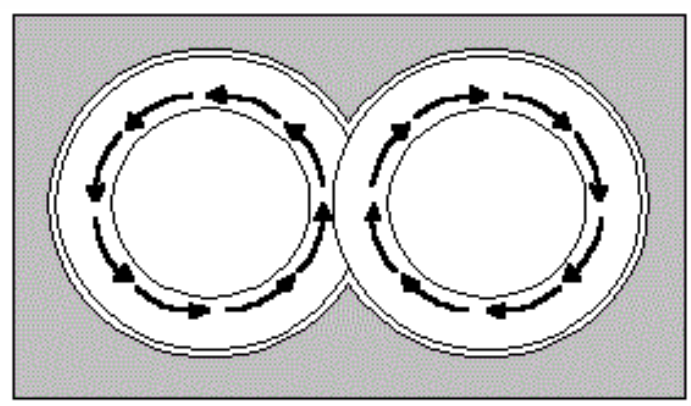

counter-rotating screws

Figure 3.: Type of twin-screw 
The extrusion is followed by spheronization. The result and strands of extrudates must not adhere to each other, and must exhibit plasticity such that the shape imposed by the die is maintained. In case of spheronization, under ideal circumstances, almost sphere-shaped particles are obtained. Special rheological properties of the paste are required for a successful spheronization process. The most important requirements for spheronization of extrudate, are as follows:

(a) the extrudate needs to have enough mechanical strength when wet, but in order to brake down into short lengths in the spheronizer it still needs to be brittle enough, but no so fragile to disintegrate completely

(b) the extrudate needs to have enough plasticity to be rolled into spheres from the cylindrical rods, by the friction plate in the spheronizer

(c) the extrudates must not adhere to each other, in order to enable the particles not to aggregate during spheronization [64-66].

Spheronization is followed by drying. MCC may be regarded as the standard and the most commonly used matrix former material in pellet preparation with extrusion. It has plastic properties, thus it provides the cohesiveness of the wetted mass, which was suitable for extrusion andspheronization. MCC has a large surface area and high internal porosity, therefore introduces the liquid into the matrix to provide a faster liberation of the API [67, 68]. Moreover, in consequence of its large surface area and high internal porosity, it is able to absorb and retain a large quantity of water thereby facilitating extrusion, improving the wetted mass plasticity and enhancing spheronization [33, 69]. Moreover, control of the movement of water through the plastic mass prevents phase separation during extrusion andspheronization. In order to decrease the amount of the used MCC, other pharmaceutical excipients are added and can achieve modified drug release, e.g. hydroxypropyl methylcellulose (HPMC) and hydroxyethyl cellulose (HEC) [70] or karragenan [67] or ethylcellulose (EC) [34-36].

The film formation in the solid polymer matrix significantly influences the texture of the dosage form and hences the liberation of the active agent. 


\section{SECTION I.}

\subsection{Materials and methods}

\subsubsection{Materials}

Two different products of Colorcon Ltd. were used for the experiments, namely ethylcellulose labelled Ethocel Standard Premium $10^{\circledR}$ (EC10), and Ethocel Standard Premium $45^{\circledR}($ EC45) (Colorcon Ltd., Dartford, England), which differ in the viscosity of their solutions and also in the length of the polymer chains. Polymers are best characterized by the viscosity of their solutions, the viscosity of Ethocel Standard Premium $10^{\circledR}$ and Ethocel Standard Premium $45^{\circledR}$ is 9-11 cP and 41-49 cP, respectively. Viscosities were given for 5\% solutions measured at $25^{\circ} \mathrm{C}$ in an Ubbelohde viscosimeter, the solvent was $80 \%$ toluene and $20 \%$ alcohol [71]. As polymers do not dissolve in water, only in organic solvents; we used $96 \%$ alcohol as solvent. Plasticizers have the ability to alter the physical properties of a polymer film.

During our experiments we used triethyl citrate (Ph. Eur.) (TEC) as plasticizer, which is the ethyl ester of citric acid, it belongs in the group of organic esters.

\subsubsection{Methods}

\subsubsection{Preparation of solutions}

For the experiments alcoholic solutions with $10 \%$ polymer content were prepared without plasticizer and with 1-3-5\% triethyl citrate concentration. An MFT bar apparatus (Rhopoint Instrumentation Ltd.) was applied to determine the $M F T$ and the film forming time of a $75 \mu \mathrm{m}$-thick layer of solution at different temperatures. The method for determining film formation was worked in our institute earlier [72]. We performed six parallel measurements.

\subsubsection{Preparation of free films}

The solutions were sprayed on teflon surfaces placed in a rotating vessel; the conditions of spraying are presented in Table 1. The temperature of the drying air was set according to the MFT values presented in Table 2. During spraying, we continuously checked the temperature of the drying air, which was controlled with a laser temperature controller. The properties of the prepared free films were determined after preparation (fresh) and also after 1,2 and 4 weeks of storage $\left(40^{\circ} \mathrm{C} / 50 \mathrm{RH} \%\right)$ in order to monitor changes. 
Table 1: Parameters of the preparation of free films

\begin{tabular}{|c|c|}
\hline PARAMETERS & VALUES \\
\hline Rotation rate of vessel & $22 / \mathrm{min}$ \\
\hline Rate of liquid feeding & $5 \mathrm{ml} / \mathrm{min}$ \\
\hline Pressure of spraying air & $1.5 \mathrm{bar}$ \\
\hline Diameter of nozzle & $0.8 \mathrm{~mm}$ \\
\hline Temperature of drying air & according to MFT \\
\hline
\end{tabular}

Table 2: MFT values of EC10 and EC45 films

\begin{tabular}{|c|c|c|c|c|c|}
\cline { 3 - 5 } \multicolumn{2}{c|}{} & \multicolumn{4}{c|}{ CONCENTRATION OF PLASTICIZERS } \\
\cline { 3 - 6 } \multicolumn{2}{c|}{} & $0 \%$ & $1 \%$ & $3 \%$ & $5 \%$ \\
\hline EC10 films & $M F T\left({ }^{\circ} \mathrm{C}\right)$ & 26.1 & 20.7 & 20.3 & 17.7 \\
\hline EC45 films & $M F T\left({ }^{\circ} \mathrm{C}\right)$ & 24.4 & 13.1 & 16.8 & 18.8 \\
\hline
\end{tabular}

\subsubsection{Thermoanalytical measurements}

The thermoanalytical examinations of the materials were carried out with a Mettler-Toledo DSC $821^{\mathrm{e}}$ and TG/DSC1 instrument. During the Differencial Scanning Calorimetry (DSC) measurements the start temperature was $-40^{\circ} \mathrm{C}$, the end temperature was $300^{\circ} \mathrm{C}$ and the applied heating rate was $10^{\circ} \mathrm{C} \mathrm{min}^{-1}$. Argon atmosphere was used and nitrogen was used as drying gas. $10 \pm 1 \mathrm{mg}$ sample was measured into aluminium pans $(40 \mu \mathrm{l})$. The data were calculated from the average of three parallel measurements and were evaluated with STAR Software.

For the Termogravimetry (TG) measurements the start temperature was $+25^{\circ} \mathrm{C}$, the end temperature was $300^{\circ} \mathrm{C}$, the applied heating rate was $10^{\circ} \mathrm{C} \min ^{-1}$. Nitrogen atmosphere was used. $10 \pm 1 \mathrm{mg}$ sample was measured into aluminium pans $(100 \mu \mathrm{l})$. The data were calculated from the average of three parallel measurements and were evaluated with $\mathrm{STAR}^{\mathrm{e}}$ Software.

\subsubsection{Mass spectrometric examinations}

The stability examination of the films was supplemented with gas analysis. The TG instrument was coupled to a Thermo Star (Pfeiffer) quadruple mass spectrometer (maximum $300 \mathrm{amu}$ ) for gas analysis. The measurements were carried out in nitrogen atmosphere. Ions with various mass numbers were determined with the Secondary Electron Multiplier - 
Multiple Ion Detection (SEM-MID) measurement module of the Quadera software. The obtained results were exported and then plotted in one coordinate system with the TG curves by using the Mettler Toledo Star software.

\subsubsection{Measurement of the contact wetting angle}

Contact wetting angle was examined with Dataphysics OCA-20 equipment, it was determined by means of drop contour analysis. The SCA-20 software belonging to the equipment can be used for calculating the surface/interfacial tension $(\gamma)$ and the surface free energy of solid materials according to Wu's theory, which gives the dispersion and polar components of surface free energy, too. Contact wetting angle was determined in fresh films and in films after storage with sessile drop method. The liquids used for contact-angle measurements were water and diiodomethane/methylene iodide.

\subsubsection{Fourier transform infrared spectroscopy (FT-IR)}

A Bio-Rad Digilab Division FTS65A/896 FT-IR Spectrometer with a Harrick's Meridian'M SplitPea Single Reflection Diamond ATR Accessory was used to record the spectra. The measurements were performed in the range of $4000-400 \mathrm{~cm}^{-1}$ at $4 \mathrm{~cm}^{-1}$ optical resolution and 256 scans were taken to achieve good signal to noise ratio. Three spectra were averaged for each composition, measured at three different places of the same film.

\subsubsection{Positron annihilation lifetime spectroscopy (PALS)}

PALS measures the time for which a positron can exist in a material. This lifetime depending on the properties of the particular material. The method is based on the fact that electrons and positrons annihilate each other to form photons. The properties of the resulting radiation correspond exactly to the relevant properties of the electron and the positron preceding the annihilation. PALS is an important method in the structural characterization of polymers, and its role is currently increasing in pharmaceutical technology [72-74]. Together with other properties, this method measures the size distribution of free-volume holes in polymers.

The use of positrons in polymers is based on the formation of the positronium, a bound state of an electron and a positron, in which the role of the positron resembles that of the proton in a hydrogen atom. The lifetime of the positronium before its annihilation is determined by the properties of the material in which it is formed. The exact dependence can be approximated 
by means of a simple model. The free-volume model regards the free volume in polymers as formed of uniform spherical voids [75]. Although the model is simple, it provides a possibility to derive a connection between the measured lifetime and the size distribution of the free-volume holes:

$$
\tau=\frac{1}{2}\left[1-\frac{R}{R+\Delta R}+\frac{1}{2 \pi} \sin \left(\frac{2 \pi R}{R+\Delta R}\right)\right]^{-1}
$$

where $\tau$ is the lifetime of the ortho-positronium in nanoseconds, $R$ is the radius of the voids in Angströms, and $\Delta R$ is a constant. This formula indicates that $\tau$ increases with $R$. On a molecular scale, the $R$ values correspond well with the BET and neutron scattering results. The positron source applied for the measurements was made of carrier-free ${ }^{22} \mathrm{NaCl}$ with an activity of $10^{5} \mathrm{~Bq}$, sealed between two very thin kapton foils. The source was placed between two pieces of polymeric mixture previously treated identically. Positron lifetime spectra were recorded by a conventional fast-fast coincidence system based on $\mathrm{BaF}_{2} / \mathrm{XP} 2020 \mathrm{Q}$ detectors and Ortec electronics. Spectra were recorded in 4096 channels of a computer-based multichannel analyser card (Nucleus). The time resolution of the spectrometer was $\sim 220$ ps. Each spectrum related to $1.5 \times 10^{6}$ annihilation events. Samples were measured repeatedly and the data given below are averages of the repeated measurements.

\subsubsection{Mechanical properties of free films}

The breaking strength of the films was tested with an indentation hardness tester. This device and the software were developed in our institute. The tester contains a special specimen holder and a jowl. The loading indicates stress in the sample and it can deform. These devices are connected with a computer through an interface. Thus, not only can the ultimate deformation force be measured, but the process (force-time and force-displacement curves) can be followed. The specimen, and hence the free film is located horizontally in the holder and the jowl moves vertically. The range of measurement: 0-200 N, rate of displacement: 20 $\mathrm{mm} / \mathrm{min}$, the sampling rate was $50 \mathrm{~Hz}$, the output was $0-5 \mathrm{~V}$, and the sensitivity was \pm 0.1 digit. The sensor was a Unicell force-measuring instrument, calibrated with the C9B $20 \mathrm{kN}$ cell. 


\subsection{RESULTS}

\subsubsection{Thermoanalysis}

Before the preparation of free films, the Minimum Film forming Temperature (MFT) of EC films of various compositions were determined (Table 2.), so that the temperature of the drying air during spraying could be set accordingly. After the evaluation of the data shown in the Table 2., it was found that the use of plasticizer decreased the value of MFT in each case. The increase of triethyl citrate concentration decreased the MFT value proportionally to concentration in the case of EC10 films and according to the minimum curve in the case of EC45 films.

The condition of the formation of a proper film structure is to know the glass transition temperature of the film forming polymer, which was determined with a DSC instrument. Both the structure and the glass transition temperature of the film are influenced greatly by the properties and concentration of the plasticizers used, therefore their role was studied.

The DSC curves of EC10 fresh films containing various quantities of triethyl citrate are shown in Figure 4. The glass transitions are indicated on the curve and it is clear that the $T_{g}$ value decreases with the increase of the plasticizer concentration.

The numerical data of glass transition are summarized in Table 3. The data clearly reveal that the $T_{g}$ value in fresh films is not yet decreased by $1 \%$ of plasticizer but is definitely decreased by $3 \%$ and $5 \%$ of plasticizer.

Table 3: Changes in the $T_{g}$ values of EC10 fresh films as a function of plasticizer concentration

\begin{tabular}{|c|c|c|c|c|}
\cline { 2 - 5 } \multicolumn{1}{c|}{} & \multicolumn{4}{c|}{ Triethyl citrate concentration } \\
\hline Glass transition temperature $\left(\boldsymbol{T}_{\boldsymbol{g}}\right) /{ }^{\circ} \mathbf{C}$ & $0 \%$ & $1 \%$ & $3 \%$ & $5 \%$ \\
\hline SD & 126.4 & 126.9 & 118.6 & 105.1 \\
& $( \pm 2.22)$ & $( \pm 2.74)$ & $( \pm 7.89)$ & $( \pm 8.95)$ \\
\hline
\end{tabular}

Figure 5. shows the DSC curves of EC45 fresh films containing various quantities of triethyl citrate. The numerical data of glass transition are summarized in Table 4. It is clear from the data that the $T_{g}$ value in fresh films is increased by $3 \%$ plasticizer, but is decreased by $5 \%$ of plasticizer in the case of EC45 films, which is again due to structural changes.

The comparison of the glass transition temperature values of the two film forming polymers shows that the glass transition temperature of films prepared from the shorter-chain EC10 polymer is slightly lower than for longer-chain EC45 films. 


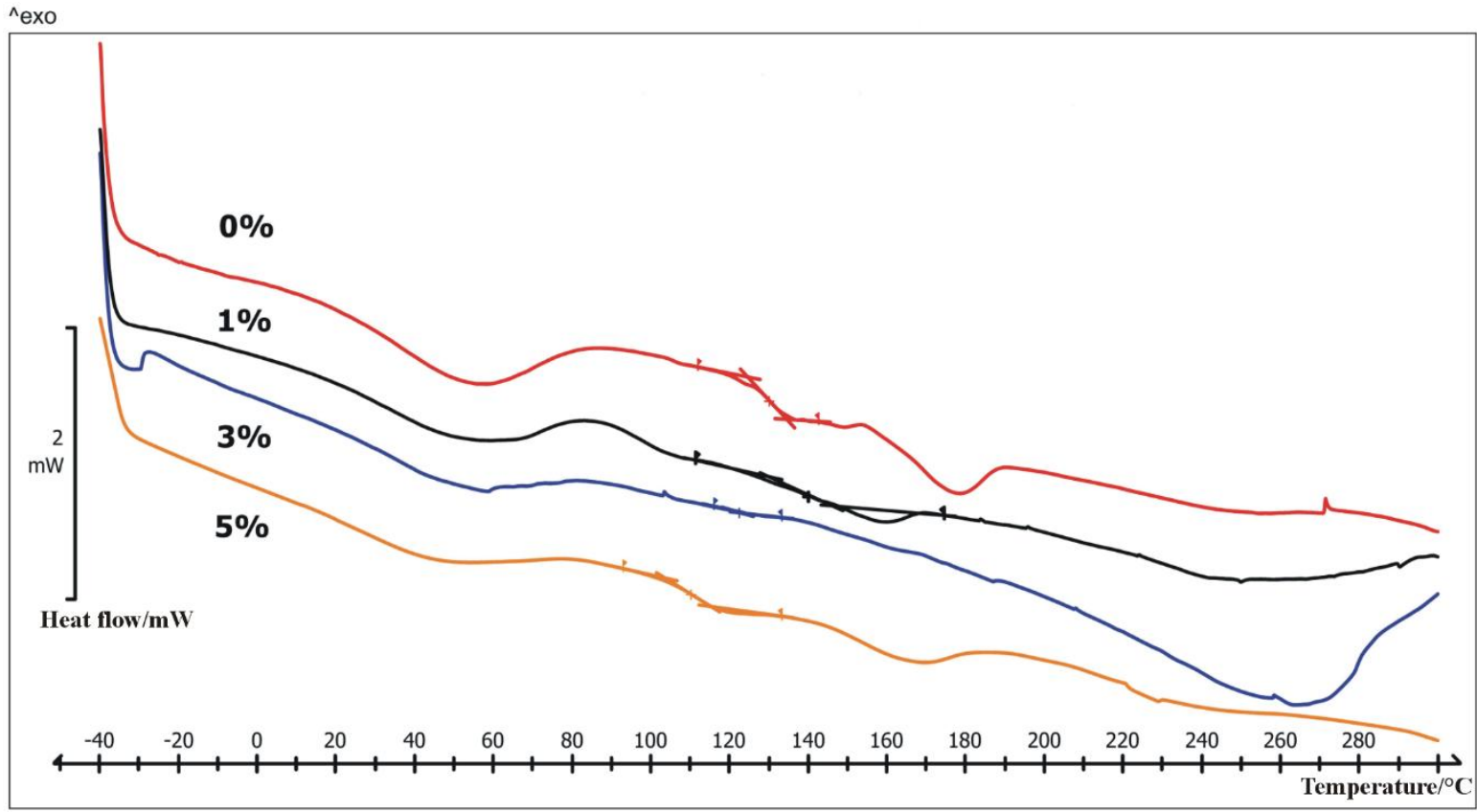

Figure 4.: DSC curves of EC10 fresh films

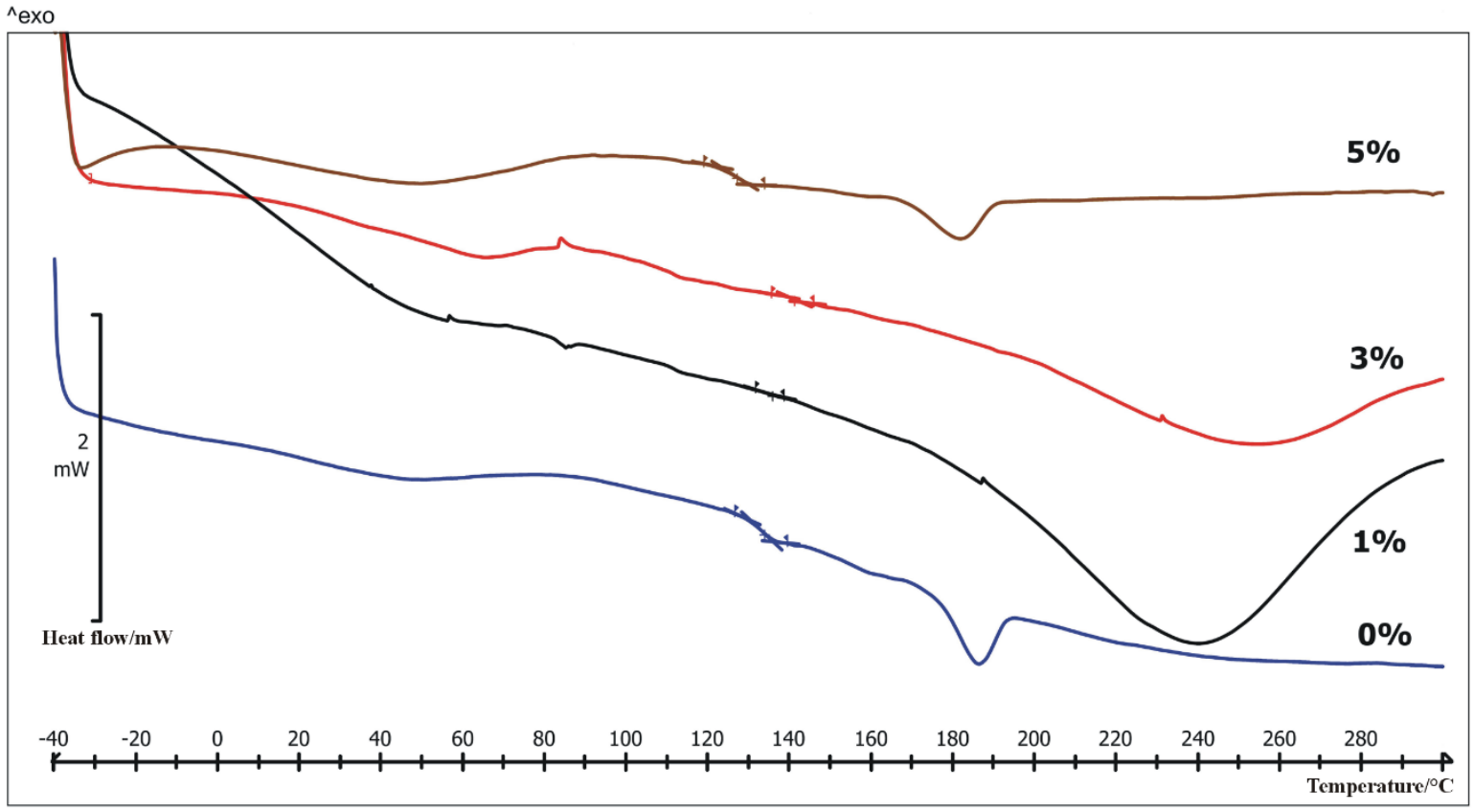

Figure 5.: DSC curves of EC45 fresh films

Table 4: Changes in the $T_{g}$ values of EC45 fresh films as a function of plasticizer concentration

\begin{tabular}{|c|c|c|c|c|}
\cline { 2 - 5 } \multicolumn{1}{c|}{} & \multicolumn{4}{c|}{ Triethyl citrate concentration } \\
\hline Glass transition temperature $(\mathbf{T g}) /{ }^{\circ} \mathbf{C}$ & $0 \%$ & $1 \%$ & $3 \%$ & $5 \%$ \\
\hline$($ SD $)$ & 133.4 & 135.9 & 141.5 & 128.7 \\
& $( \pm 0.56)$ & $( \pm 0.23)$ & $( \pm 0.43)$ & $( \pm 0.91)$ \\
\hline
\end{tabular}


The reason of this is that in the "looser" structure transition can take place at a lower temperature than in the "more compact" structure formed by longer-chain polymers. The numerical data also show that in fresh films containing plasticizer the $T_{g}$ value could be decreased by $3 \%$ plasticizer in the case of "looser" EC10 films prepared from shorter-chain polymers; while 5\% plasticizer was needed for "stronger" EC45 films made from longerchain polymers.

We also investigated whether the glass transition temperature, which is the most typical feature of the film structure, changed as a function of storage time for the free films we prepared.

The time course of the glass transition values is presented for the films without plasticizer and with the highest concentration in the case of both film forming polymers (Table 5.). The data show that EC10 films underwent greater change during storage, they were less stable than EC45 films, so EC10 films are less suitable for forming MR dosage forms.

Table 5: Changes in the $T_{g}$ values of EC10 and EC45 films as a function of storage time

\begin{tabular}{|c|c|c|c|c|}
\hline & \multirow{4}{*}{$\begin{array}{l}\text { Triethyl citrate } \\
\text { concentration }\end{array}$} & \multirow{3}{*}{\multicolumn{3}{|c|}{$\begin{array}{c}\mathrm{Tg} /{ }^{\circ} \mathrm{C} \\
\text { Storage time }\end{array}$}} \\
\hline & & & & \\
\hline & & & & \\
\hline & & fresh & 2 weeks & 4 weeks \\
\hline \multirow{4}{*}{ EC10 films } & $0 \%$ & 121.9 & 126.9 & 107.1 \\
\hline & (SD) & $( \pm 6.4)$ & $( \pm 1.58)$ & $( \pm 2.08)$ \\
\hline & $5 \%$ & 108.3 & 104.2 & 101.1 \\
\hline & (SD) & $( \pm 7.11)$ & $( \pm 6.16)$ & $( \pm 11.1)$ \\
\hline \multirow{4}{*}{ EC45 films } & $0 \%$ & 131.9 & 135.7 & 132.7 \\
\hline & (SD) & $( \pm 1.16)$ & $( \pm 4.85)$ & $( \pm 1.47)$ \\
\hline & $5 \%$ & 127.5 & 127.9 & 128.5 \\
\hline & (SD) & $( \pm 0.74)$ & $( \pm 2.16)$ & $( \pm 0.16)$ \\
\hline
\end{tabular}

The thermal stability values of the fresh films were examined and the results are summarized in Table 6.

The analysis of the TG curves (Fig. 3.) revealed that the two different film forming polymers are thermally stable, a mass decrease of only $0.5 \%$ and $1.2 \%$ could be detected until $100{ }^{\circ} \mathrm{C}$ and $300{ }^{\circ} \mathrm{C}$, respectively. The decomposition process starts only later and a mass loss of about $10-20-30 \%$ can be detected, depending on the concentration of the plasticizer. There is 
practically no difference between the thermal stabilities of the two polymers, so mass change depends only on the plasticizer concentration.

Table 6: Mass change of EC10 and EC45 films as a function of plasticizer concentration

\begin{tabular}{|l|c|c|c|c|c|}
\cline { 3 - 6 } \multicolumn{2}{c|}{} & \multicolumn{4}{c|}{ Triethyl citrate concentration } \\
\hline \multirow{2}{*}{ Mass decrease/\% } & $0 \%$ & $1 \%$ & $3 \%$ & $5 \%$ \\
\cline { 3 - 6 } & EC10 films & 1.12 & 8.94 & 21.23 & 30.16 \\
\cline { 2 - 6 } & EC45 films & 1.22 & 10.56 & 20.48 & 31.70 \\
\hline
\end{tabular}

The thermal behaviour of triethyl citrate and of films containing 5\% plasticizer is shown in Figure 6. The TG curves show that the decomposition of triethyl citrate starts as early as over $120^{\circ} \mathrm{C}$ and becomes more intensive over $200{ }^{\circ} \mathrm{C}$, and the material is fully decomposed before reaching $300{ }^{\circ} \mathrm{C}$. The shape of the curves is a proof for triethyl citrate probably being built in the structure of the ethylcellulose film, because its decomposition from the film starts only later, at about $180-200{ }^{\circ} \mathrm{C}$.

Similarly, the results of the MS examinations are shown in Figure 6., based on the analysis of the gases which evolve from the EC10 film. Carbon dioxide gas $\left(\mathrm{CO}_{2}\right)(\mathrm{m} / \mathrm{z}=44)$ starts to evolve at $200{ }^{\circ} \mathrm{C}$ and reaches its highest concentration at $260-270{ }^{\circ} \mathrm{C}$.

The films were also examined after 4 weeks of storage (see Table 7.) and the results were practically the same as those for the fresh film. The only exception was the EC10 film containing $1 \%$ plasticizer, which is probably due to the inhomogeneity of the sample.

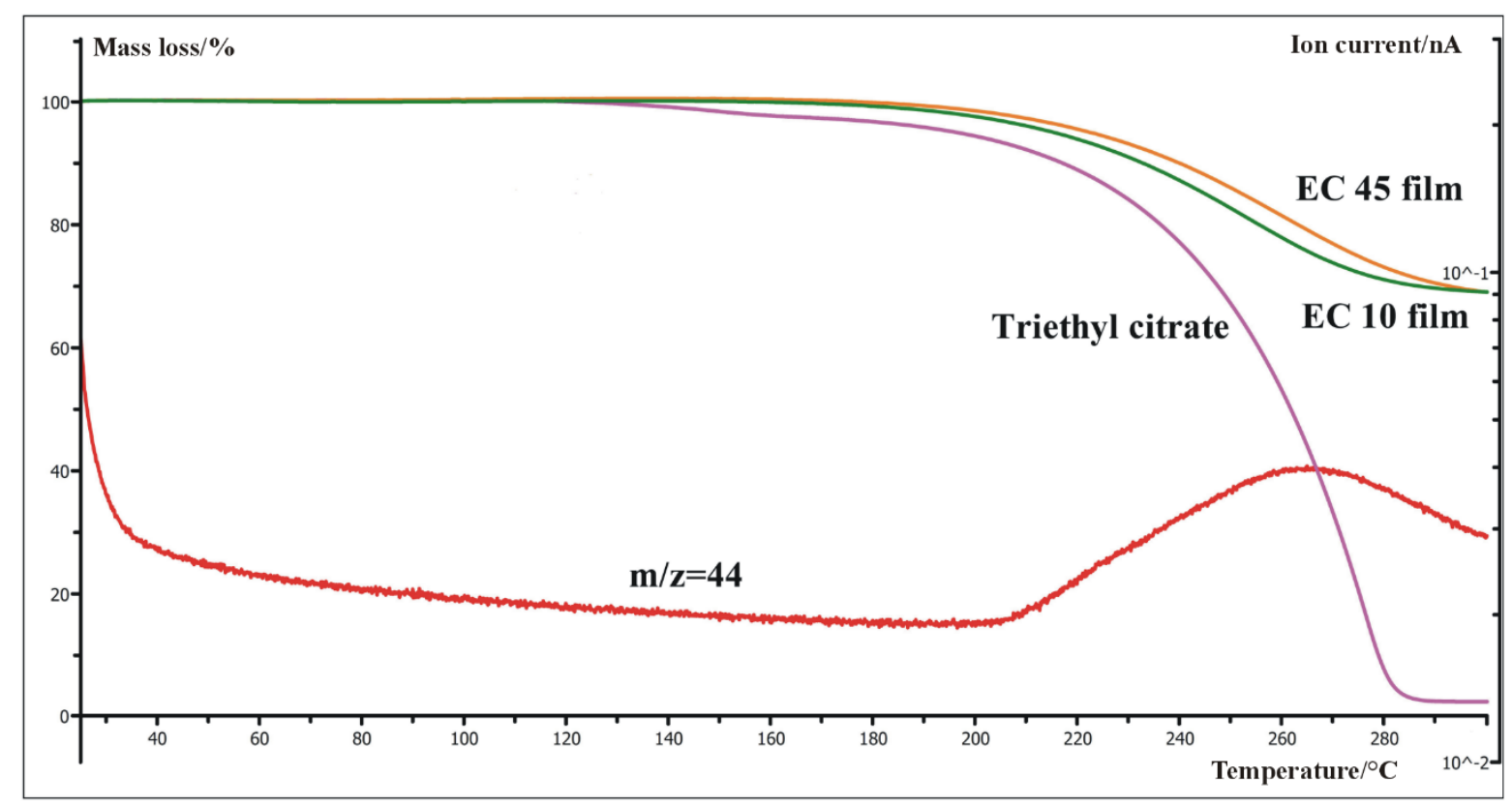

Figure 6.: TG curves of EC10 and EC45 films containing 5\% triethyl citrate and their MS evaluations 
Table 7: Mass change of EC10 and EC45 films as a function of plasticizer concentration after 4 weeks of storage

\begin{tabular}{|l|c|c|c|c|c|}
\cline { 3 - 6 } \multicolumn{2}{c|}{} & \multicolumn{4}{c|}{ Triethyl citrate concentration } \\
\hline \multirow{2}{*}{ Mass decrease/\% } & $0 \%$ & $1 \%$ & $3 \%$ & $5 \%$ \\
\cline { 2 - 6 } & EC10 films & 2.59 & 1.16 & 21.00 & 27.03 \\
\cline { 2 - 6 } & EC45 films & 0.53 & 11.51 & 20.25 & 28.14 \\
\hline
\end{tabular}

As a summary of the thermal investigations it can be stated that the decomposition of the plasticizer from the arising film structure is retarded, and the polymer molecule itself stays stable until $300{ }^{\circ} \mathrm{C}$. A more homogeneous sample, therefore a better film can be prepared from EC45, but mass change depends basically on the material quality of the plasticizer. Mass spectrography performed as a coupled technique also proved that the films stayed stable until approximately $200{ }^{\circ} \mathrm{C}$.

\subsubsection{Physico-chemical properties of films}

The results show that there are considerable differences in the behaviour according to the chain length of the applied polymers. For example, the film integrity and the mechanical properties significantly improve with increasing chain length.

Table 8.: Surface properties of EC films

\begin{tabular}{|c|c|c|c|c|}
\hline & \multicolumn{2}{|c|}{$\gamma(\mathrm{mN} / \mathrm{m})$} & \multicolumn{2}{c|}{ Polarity (\%) } \\
\hline Plasticizer & EC10 & EC45 & EC10 & EC45 \\
\hline \multirow{2}{*}{$\mathbf{0 \%}$} & 56.17 & 49.54 & 28.45 & 22.22 \\
& $( \pm 0.60)$ & $( \pm 0.96)$ & $( \pm 0.90)$ & $( \pm 1.68)$ \\
\hline \multirow{2}{*}{$\mathbf{1 \%}$} & 53.42 & 49.36 & 26.13 & 18.13 \\
& $( \pm 0.55)$ & $( \pm 1.68)$ & $( \pm 0.68)$ & $( \pm 2.38)$ \\
\hline \multirow{2}{*}{$\mathbf{3 \%}$} & 53.92 & 54.71 & 29.95 & 30.31 \\
& $( \pm 1.09)$ & $( \pm 1.03)$ & $( \pm 0.98)$ & $( \pm 1.21)$ \\
\hline \multirow{2}{*}{$\mathbf{5 \%}$} & 53.59 & 53.48 & 28.66 & 27.54 \\
& $( \pm 0.89)$ & $( \pm 1.00)$ & $( \pm 0.98)$ & $( \pm 1.06)$ \\
\hline
\end{tabular}


However, longer chains resulted in higher lipophilicity, probably due to the relatively increased proportion of the ethyl ether groups. The incorporation of triethyl citrate into the structure will affect not only the mechanical and thermal properties but also the surface characteristics of films (Table 8.). The results of the surface energy measurements suggest that the kinetics, and probably the mechanism, of incorporation of the plasticizer differ depending on the chain length of the polymer. A significant change can be observed in the surface properties of films after the addition of $1 \%$ of plasticizer. However, its effect is stabilized after this amount in the case of EC10 films, while in the case of EC45 the stabilization is visible only after $3 \%$. The properties of the fully plasticized films are statistically the same $(p>0.05)$, which suggests that the plasticizer binds differently to the different types of ECs.

To clarify this phenomenon, the structure of the films was investigated by FT-IR spectrometer. Better mechanical properties of the EC45 films provided better quality for the spectra, so the results are explained according to these data. The spectra of the blank and plasticized films have generally the same shape (Fig. 7.), no significant shift of peaks can be observed, only a small widening of the symmetric and asymmetric valence vibration of the ether bonds are present in the $1000-1200 \mathrm{~cm}^{-1}$ wavenumber range. This suggests that the incorporation of the plasticizer is based on secondary bindings. The presence of the plasticizer can be clearly identified based on the bands of the ester groups. The most intensive peaks at $1750 \mathrm{~cm}^{-1}$ belong to the $\mathrm{C}=\mathrm{O}$ valence vibrations.

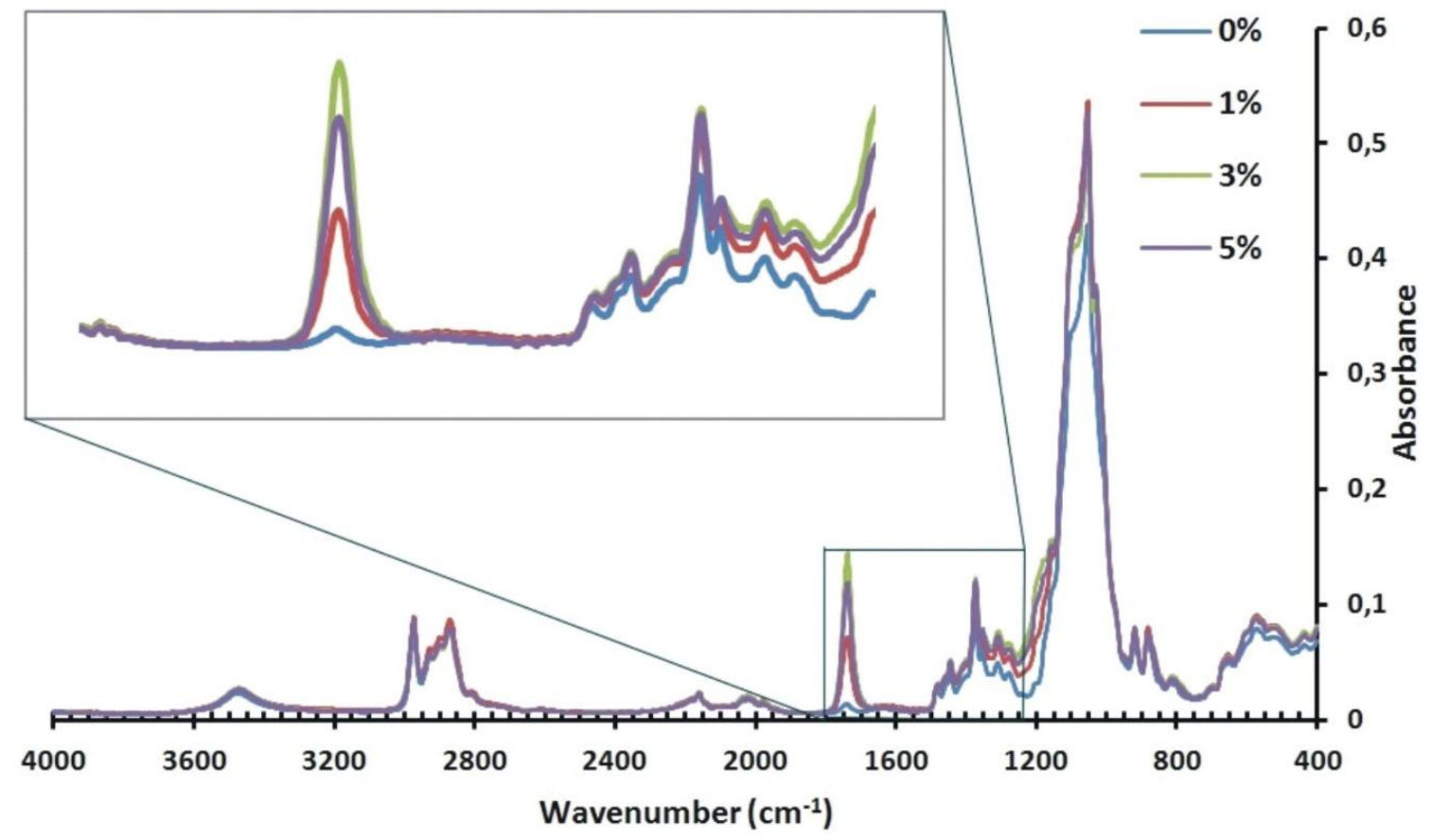

Figure 7.: FT-IR spectra of the EC45 films 
They are clearly present in the original FT-IR spectra. The signs of ternary OH groups at 1200 $\mathrm{cm}^{-1}$ and the COC vibrations of the ether groups are overlapped with the other ether vibration signals, thus they can be identified only in the subtracted spectra (Fig. 8.)

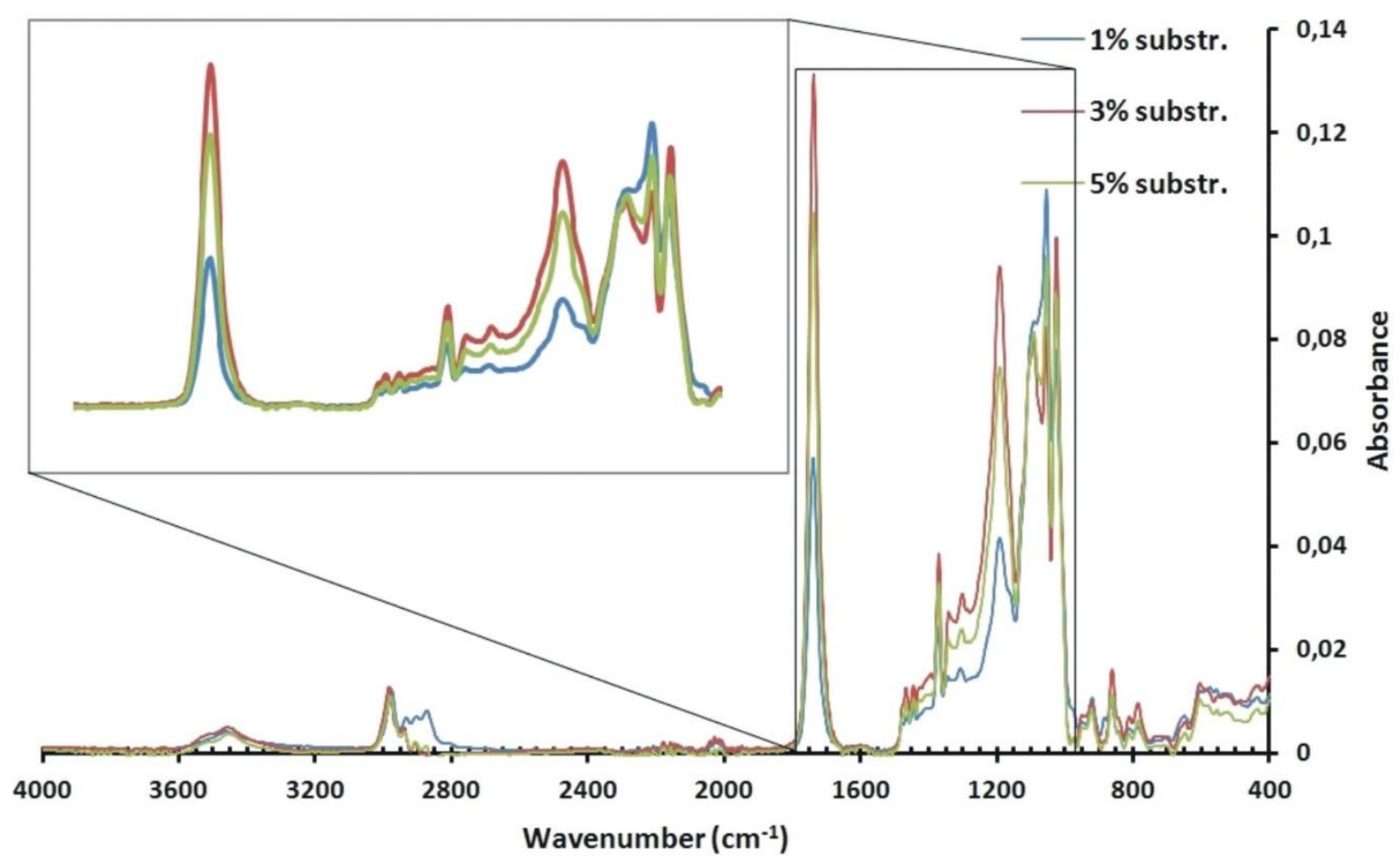

Figure 8.: Subtracted spectra of the plasticized EC45 films

The peaks in the subtracted spectra of EC45 films are significantly increased with increasing the amount of plasticizer from 1 to $3 \%$, but after that a slight decrease can be observed, which is in good agreement with the surface energy measurements and also with the change of the minimal film forming temperature of the samples. This suggests that some of the main characteristics of the films are determined by the bounded fraction of the plasticizer. The slight decrease of the bounded fraction with increasing triethyl citrate amount can probably be due to the mass effect, which means that the increasing amount of the material will change the preferences of the intermolecular bindings, and will hinder the incorporation of the plasticizer into the structure of the polymer film. Meanwhile, there was no sign of inhomogenity inside the film, the unbounded fraction of the plasticzer is probably evaporated from the system with the small droplets of the solvent. These particles could be presented on the surface of the coating pan, but no measurements were performed for the detection of the plasticizer in the pollution. 
The PALS results revealed that there was no significant difference between the two types of ethylcellulose samples (Fig. 9.), which were influenced very similarly by the plasticizer. A significant difference was observed only at the highest concentration of the plasticizer.

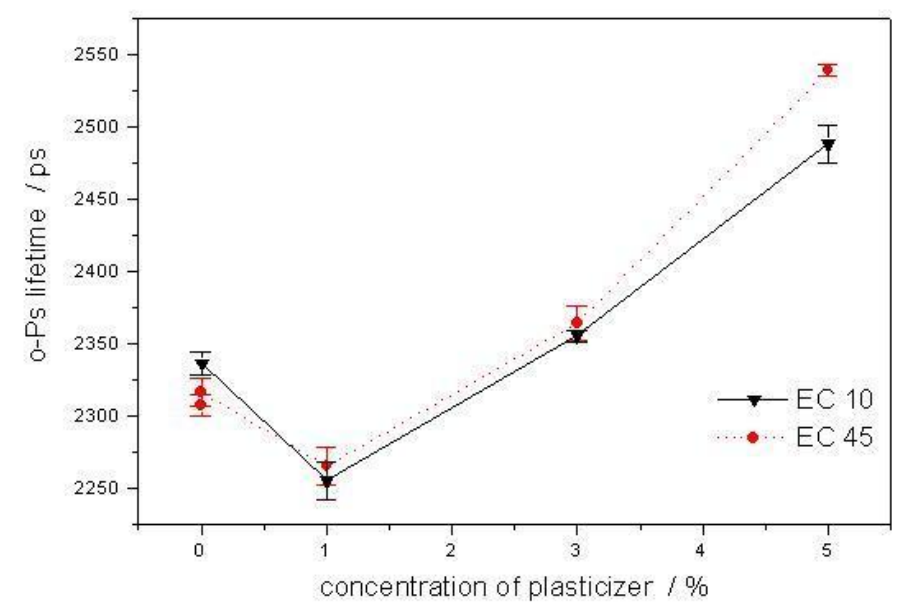

Figure 9.: Positron lifetime plotted against concentration

The positron lifetime initially decreased slightly at the lowest plasticizer concentration. This is a consequence of the distribution of the plasticizer molecules between the polymer chains, filling the free-volume holes, occupying sites formerly available for the positronium atoms, providing a higher electron density. The lifetime of the positronium atoms therefore decreases. The structure of the film was changed as a result of the admixture of the plasticizer. At higher concentrations, the plasticizer initiated a large-scale rearrangement of the polymer chains, leading to the formation of larger free-volume holes, as indicated by the longer lifetimes.

It should be emphasized that the PALS data did not indicate any major structural change up to a plasticizer concentration of $1 \%$. The large-scale rearrangement of the polymer chains necessitated a higher concentration.

The pellet deformation process was evaluated by determining the breaking hardness and studying the deformation curve. The breaking strength results are presented in Table 9. and 10. The addition of $1 \%$ plasticizer to Ethocel 10 resulted in a 2-fold higher breaking strength of the film. The addition of larger amounts of the plasticizer resulted in a decrease in the breaking hardness. The reason for this is the influence of the moisture content of the plasticizer on the elasticity of the film. 
Table 9.: Breaking strength of Ethocel 10 free films

\begin{tabular}{|c|c|c|c|c|}
\cline { 2 - 5 } & \multicolumn{4}{|c|}{ Plasticizer concentration } \\
\cline { 2 - 5 } & $0 \%$ & $1 \%$ & $3 \%$ & $5 \%$ \\
\hline Storage & \multicolumn{4}{|c|}{ Breaking strength (N) } \\
\hline conditions & \multicolumn{4}{|c|}{4.3} \\
\hline Fresh films & 5.66 & 9.62 & 4.68 & $( \pm 1.31)$ \\
\hline \multirow{2}{*}{ After 1 week } & $( \pm 1.55)$ & $( \pm 2.58)$ & $( \pm 1.00)$ & 4.18 \\
& $( \pm 1.83)$ & 9.46 & 4.38 & $( \pm 0.83)$ \\
\hline \multirow{2}{*}{ After 2 weeks } & 5.28 & 9.41 & 4.82 & 4.81 \\
& $( \pm 1.99)$ & $( \pm 2.63)$ & $( \pm 1.66)$ & $( \pm 1.43)$ \\
\hline \multirow{2}{*}{ After 4 weeks } & 5.02 & 9.12 & 4.9 & 4.45 \\
& $( \pm 1.52)$ & $( \pm 2.47)$ & $( \pm 1.6)$ & $( \pm 0.69)$ \\
\hline
\end{tabular}

The addition of $1 \%$ plasticizer to Ethocel 45 resulted in a 3-fold higher breaking strength of the film.

Table 10. Breaking strength of Ethocel 45 free films

\begin{tabular}{|c|c|c|c|c|}
\cline { 2 - 5 } & \multicolumn{4}{|c|}{ Plasticizer concentration } \\
\cline { 2 - 5 } & $0 \%$ & $1 \%$ & $3 \%$ & $5 \%$ \\
\hline $\begin{array}{c}\text { Storage } \\
\text { conditions }\end{array}$ & \multicolumn{4}{|c|}{ Breaking strength (N) } \\
\hline Fresh films & 10.47 & 31.06 & 12.73 & 8.46 \\
& $( \pm 1.94)$ & $( \pm 1.32)$ & $( \pm 2.14)$ & $( \pm 1.5)$ \\
\hline \multirow{2}{*}{ After 1 week } & 11.04 & 34.34 & 13.63 & 8.74 \\
& $( \pm 2.58)$ & $( \pm 3.49)$ & $( \pm 3.06)$ & $( \pm 1.82)$ \\
\hline \multirow{2}{*}{ After 2 weeks } & 10.89 & 32.99 & 12.1 & 8.63 \\
& $( \pm 2.96)$ & $( \pm 3.09)$ & $( \pm 1.82)$ & $( \pm 1.64)$ \\
\hline \multirow{2}{*}{ After 4 weeks } & 10.37 & 30.13 & 12.59 & 8.51 \\
& $( \pm 2.47)$ & $( \pm 3.31)$ & $( \pm 2.11)$ & $( \pm 0.71)$ \\
\hline
\end{tabular}


The breaking strengths of the two kinds of ethylcellulose films are compared in Figure 10. It can be seen that the breaking strengths of the films prepared from the shorter-chain Ethocel 10 polymer with its looser structure were lower than those for the longer-chain, more compact Ethocel 45 films. Ethocel 45 formed a significantly stronger structure.

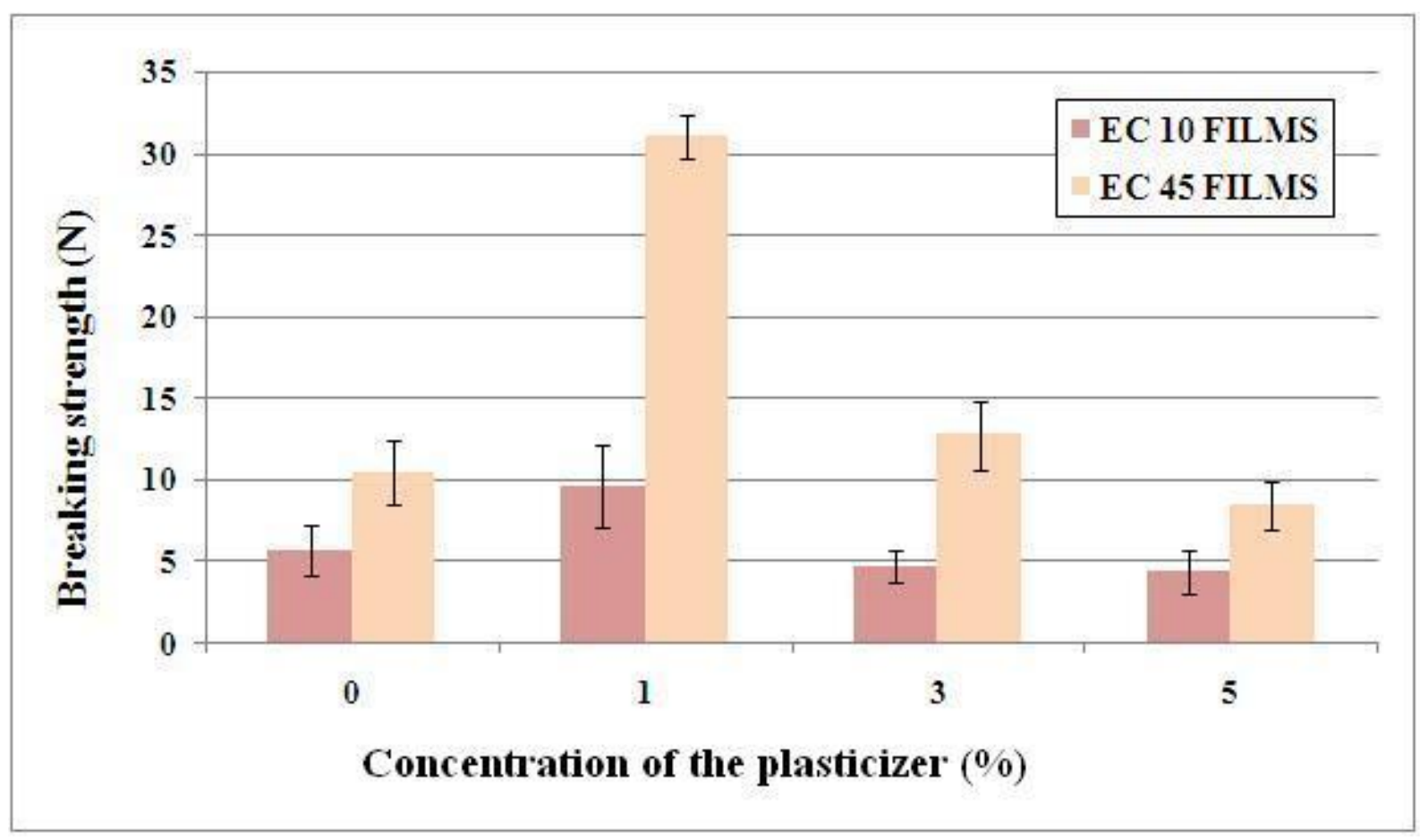

Figure 10.: Breaking strength of EC10 and EC45 free films

The addition of 3\% plasticizer resulted in the small increase of the breaking strength, whereas higher concentrations of the plasticizer caused decreases in the breaking strength. The changes in the breaking strength as a function of time are shown in Tables 9. and 10. In the case of the Ethocel 45 film the breaking strength was highest after 1 week at all plasticizer levels. In contrast, in the case of Ethocel 10 film, similar effect was found only at $1 \%$ plasticizer. The reason for this is the loss of the moisture content from the system. The rate of evaporation of moisture depends on the film structure. The breaking strength of the Ethocel 45 film after 1 week varied linearly with time with a very good correlation, except in the case of the $3 \%$ plasticizer (Table 11.). Figure 10. illustrates the above effects for the Ethocel 45 film containing $1 \%$ plasticizer, with $\mathrm{R}^{2}=0.9998$. Ethocel 10 . films exhibited similar linear property only at a low concentration of the plasticizer. The reason of this is that the breaking strength depends on the moisture content of the system and the length of the polymer chains. 
Table 11.: Fitted results of change in breaking strength in time with the following model:

$$
F(t)=F_{0}+a t
$$

\begin{tabular}{|c|c|c|c|}
\hline $\begin{array}{c}\text { Plasticizer } \\
\text { concentration }\end{array}$ & $\mathbf{F}_{\mathbf{0}}$ & $\mathbf{a}$ & $\mathbf{R}^{\mathbf{2}}$ \\
\hline $\mathbf{0 \%}$ & 11.300 & -0.2286 & 0.9860 \\
\hline $\mathbf{1 \%}$ & 35.77 & -1.41 & 0.9998 \\
\hline $\mathbf{5 \%}$ & 8.80 & -0.0743 & 0.9730 \\
\hline
\end{tabular}

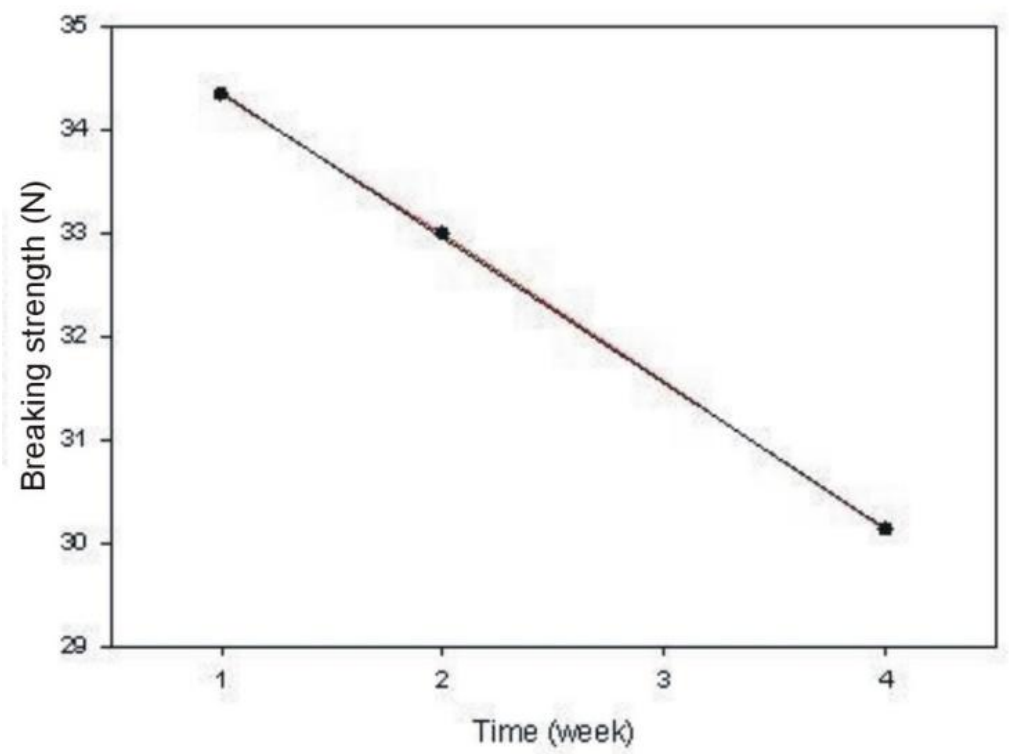

Figure 11.: Fitted hardness curve of EC45 films with 1\% plasticizer

Study of the deformation curve with the aid of our software revealed that the loading did not cause the deformation of the film (Fig. 12., section a). After a very short viscoelastic deformation, when the breaking strength did not change significantly, the breaking curve displayed an elastic tendency (section b). This was followed by a further elastic section (section c), at the end of which breaking occurred. 


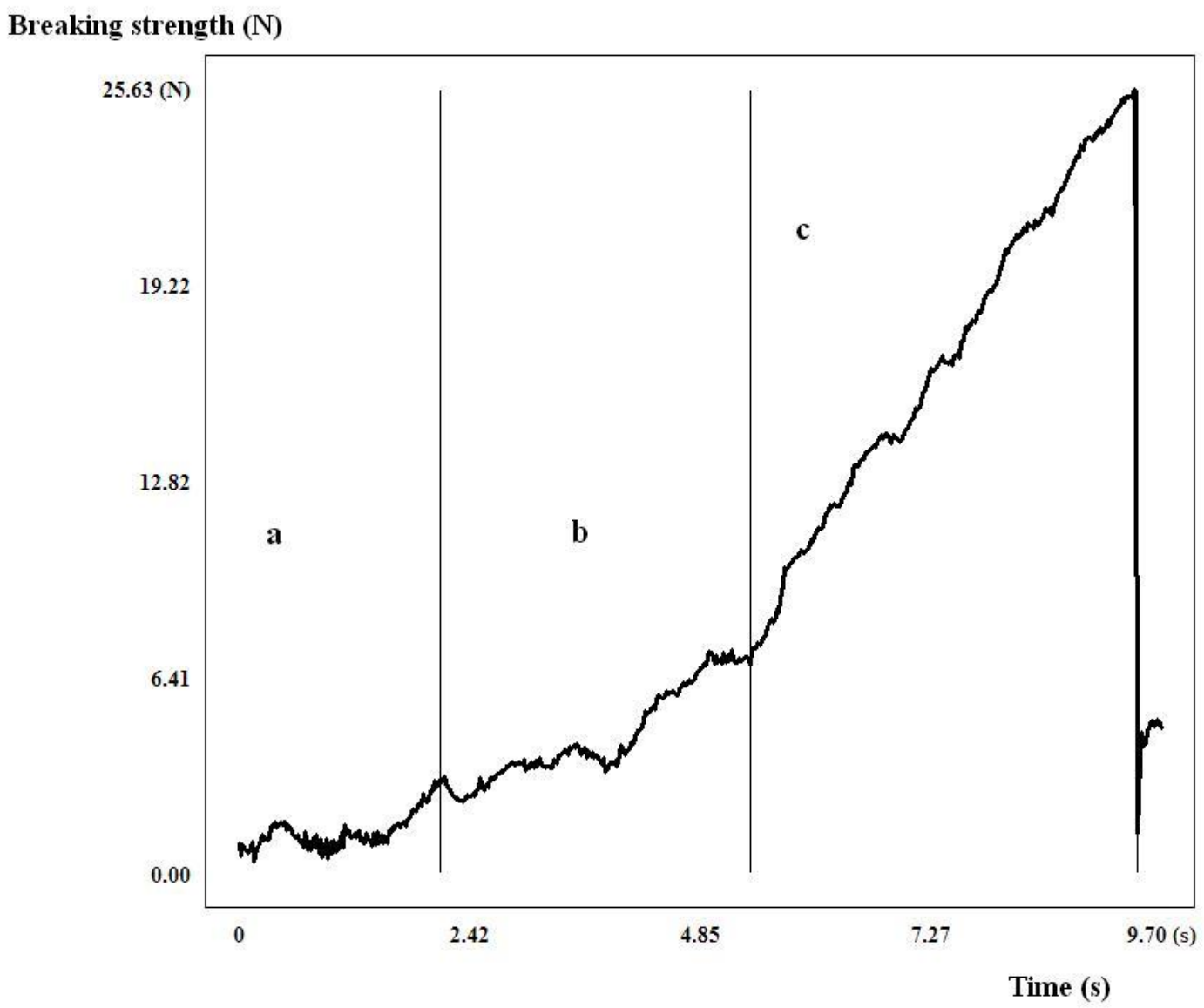

Figure 12.: Deformation curve of the free films

\subsection{DISCUSSION}

It was found that the glass transition temperature of films prepared from the shorter-chain EC10 polymer with a "looser" structure is slightly lower than for longer-chain, more "compact" EC45 films. In fresh films containing plasticizer the $T_{g}$ value could be decreased by $3 \%$ plasticizer in the case of "looser" EC10 films prepared from shorter-chain polymers, while 5\% plasticizer was needed for "stronger" EC45 films made from longer-chain polymers. EC45 films were more stable during storage. The thermal stabilities of the two polymers are approximately the same.

The thermal investigations revealed that the decomposition of the plasticizer from the arising film structure is retarded. A more homogeneous sample, therefore a film of better quality (pore-free, properly elastic) can be prepared from EC45. Mass spectrography performed as a coupled technique also proved that the films stayed stable until approximately $200{ }^{\circ} \mathrm{C}$.

The structure of films and the incorporation of plasticizer can be followed with the use of FTIR. The results support that only a limited amount of plasticizer can be incorporated with 
physico-chemical bindings into the structure of polymer films and this proportion will basically determine some of the main properties of the preparations. The analysis of the film structure can explain some unexpected disturbances in the film properties and can help in the development of suitable preparations.

The mechanical properties of ethylcellulose polymers and the effects of the incorporation of a plasticizer agreed with our expectations and former results. PALS studies demonstrated that up to a concentration of $\sim 1 \%$ the incorporated plasticizer is integrated between the polymer chains. At higher concentrations, the large-scale rearrangement of the polymer chains begins, resulting in larger free-volume holes and lower breaking strengths. The mechanical properties were clearly revealed to depend on the concentration of the plasticizer. These results allow the choice of the better film former polymer: Ethocel 45 with its longer chains. The moisture content of the $1 \%$ plasticizer proved suitable for these ethylcellulose films. After a storage time of 1 week, the breaking strength decreased linearly, the film losing its moisture content continuously.

The ideal concentration of the plasticizer in these film formers was $1 \%$. This concentration resulted in strong, mechanically resistant, stable films. This composition can be used for diffusion coating to obtain a product with modified release. 


\section{SECTION II.}

\subsection{Materials and methods}

\subsubsection{Materials}

Enalapril maleate (EM) is an ACE (angiotensin converting enzyme) inhibitor agent used in the treatment of hypertension. It reduces RAS (renin-angiotensin system) activity in the body, and has cardioprotective and renal-protective effects [76]. It is also used to treat congestive heart failure in adults. This API belongs to Class III of the Biopharmaceutics Classification System (BCS), so it has low permeability and high solubility. The absorption is limited by the permeation rate but the drug dissolves fast. The side effects of the API include allergic reactions, high potassium blood level (hyperkalaemia), dizziness, abdominal pain. To reduce these side effects, enalapril maleate is often combined with diuretics, which reduces the potassium level in blood.

Hydrochlorothiazide (HCT) is a thiazide diuretic medication often used to treat high blood pressure. This API belongs to BCS Class IV, it has low permeability and low solubility. Those compounds have poor bioavailability. Usually they are not well absorbed over the intestinal mucosa and a high variability is expected.

The appropriate preparation can be prepared with the encapsulation of the two API containing pellets. Enalapril maleate and hydrochlorothiazide combination is used to treat high blood pressure. Hydrochlorothiazide reduces the hyperkalaemia caused by enalapril maleate.

Ethocel Standard 10 FP Premium (Colorcon Ltd. Dartford. England) was used as matrix former and MCC type 101 (Avicel 101, FMC Corporation, Philadelphia, USA) as pelletisation aid and deionised water with ethanol and TEC as solvent.

\subsubsection{Methods}

\subsubsection{Experimental plan}

The study dealt with the effect of 3 process parameters - spheronization time $\left(\mathrm{x}_{1}\right)$, the liquid feed rate $\left(\mathrm{x}_{2}\right)$, and the speed of the friction plate $\left(\mathrm{x}_{3}\right)$ - on the pellet properties (shape, tensile strength, breaking force). Mixed 2 and 3 level factorial design was applied to optimize the process parameters and the best composition for the experiments. We examined the liquid feed rate $\left(\mathrm{x}_{2}\right)$ and the speed of the friction plate $\left(\mathrm{x}_{3}\right)$ on 3 levels, while the effect of 
spheronization time on 2 levels. These dependent variables influenced the properties of the pellets. Statistica for Windows 11 AGA (Statsoft. Inc. Tulsa. USA) software was applied to determine the effects of the factors. The effect of the factors was evaluated with the use of Statistica for Windows 11 (AGA software).

\subsubsection{Preparation of pellets}

1500 grams of powder mixture was prepared from $20 \%$ of API (enalapril maleate or hydrochlorothiazide), $30 \%$ of ethylcellulose and $50 \%$ of microcrystalline cellulose.

The powders were combined in a laboratory-scale blender (LM40, Bohle, Ennigerloh, Germany) for $10 \mathrm{~min}$ at $25 \mathrm{rpm}$ and then transferred into the gravimetric powder feeder (B: KT 20, K-Tron Soder, Lenzhard, Switzerland) of the extruder. The co-rotating twin-screw extruder (Mikro 27GL-28D, Leistritz, Nuremberg, Germany) was equipped with an axial screen with 23 dies of $1 \mathrm{~mm}$ diameter and $5 \mathrm{~mm}$ length. The extrusion took place at a constant screw speed of $100 \mathrm{rpm}$, a powder feed rate of $33 \mathrm{~g} / \mathrm{min}$ and a liquid feed rate according to the experimental plan. Deionised water, $96 \%$ ethanol and 1\% TEC were used as granulation liquid supplied by a membrane pump (C. Cerex EP-31, Bran and Luebbe, Norderstedt, Germany) Batches of $40 \mathrm{~g}$ resultant strands of extrudates were collected and spheronized in a spheronizer (Caleva 120, Sturminster Newton, UK) according to the design of experiments. The particles were dried in a fluid bed apparatus (GPCG 1.1., Glatt, Dresden, Germany) for 20 min with an inlet air temperature of $60^{\circ} \mathrm{C}$.

\subsubsection{Image Analyser}

The shape of the pellets was studied with image analysis using a system consisting of a stereo microscope (Leica MZ 75, Cambridge, UK), a ringlight with cold light source (Leica KL 1500, Cambridge, UK), a digital camera (Leica CS 300 F, Cambridge, UK), and an image analysing software (Qwin, Leica, Cambridge, UK). In case of APIs the particle size were analysed with the use of SEM images by ImageJ software.

The images of at least 500 pellets of each sample at a suitable magnification were translated into binary images. Contacting pellets were separated by a software algorithm. For each pellet, 36 Feret diameters were determined and also used to calculate the mean Feret diameter. The ratio of the maximum Feret diameter and the Feret diameter perpendicular to the maximum Feret diameter is used as the aspect ratio (AR). The pellet size and shape were characterized by the mean Feret diameter, aspect ratio and $10 \%$ interval, respectively (Eq.2.). 


$$
d=\frac{\mathrm{d}_{\mathrm{F}}}{\mathrm{d}_{\mathrm{F} 50}}
$$

with the dimensionless diameter $(d)$, mean Feret diameter $\left(d_{F}\right)$ and median of all mean Feret diameters $\left(\mathrm{d}_{\mathrm{F} 50}\right)$. The distribution of the particle size is characterized by the fraction of the particles in the interval $0.9<\mathrm{d}<1.1$. The size distribution is characterized as good if the fraction of the $10 \%$ interval exceeds $50 \%$ and as excellent if it exceeds $75 \%$.

\subsubsection{Scanning Electron Microscope (SEM)}

The surfaces and the structures were tested with a Scanning Electron Microscope (SEM) (Hitachi S4700, Hitachi Scientific Instruments Ltd., Tokyo, Japan). A sputter coating unit (Polaron E5100, VG Microtech, UK) was used to charge the surfaces for the SEM measurements. The air pressure during the analyses was $1.3-13 \mathrm{mPa}$.

\subsubsection{Mechanical properties of pellets}

The breaking strength of 40 pellets was tested. The general technical parameters are in chapter 4.1.2.8. By changing the pressure jowl and the sample holder, the equipment is appropriate for the measurement of the crushing force $(\mathrm{F})$ of pellets. The breaking strength (hardness) value is given by the maximal force corresponding to the peak of the force-time plot.

\subsubsection{Dissolution study}

Pellets containing $100 \mathrm{mg}$ of enalapril maleate and $25 \mathrm{mg}$ of hydrochlorothiazide were filled into size 2 HPMC capsules. The dissolution was tested with USP 1 method, using an automated Erweka DT700 dissolution apparatus. Samples were taken after 5, 15, 35, 60, 90, 120,150 and $180 \mathrm{~min}$. After 2 hours the dissolution media was changed from $\mathrm{pH}=1.2$ artficial gastric juice to $\mathrm{pH}=4.5$ acetate buffer. The concentrations were measured with a MerckHitachi LaChrome D-7000 line HPLC apparatus. The eluent was freshly prepared with the mixing of Acetonitril, Methanol and $\mathrm{pH} 2.5$ o-phosphoric acid buffer 50:25:25 v/v\%, respectively. The flow rate was $0.6 \mathrm{ml} / \mathrm{min}$ and the detection of drugs in the eluates was carried out at $225 \mathrm{~nm}$. 


\subsection{RESULTS}

\subsubsection{Characterization of APIs}

Both APIs have tabular crystal habit (Fig. 13.), and heterodisperse size distribution (Table 12.). The most considerable difference between the APIs is particle size. EM crystals are tenfold bigger than HCT particles.

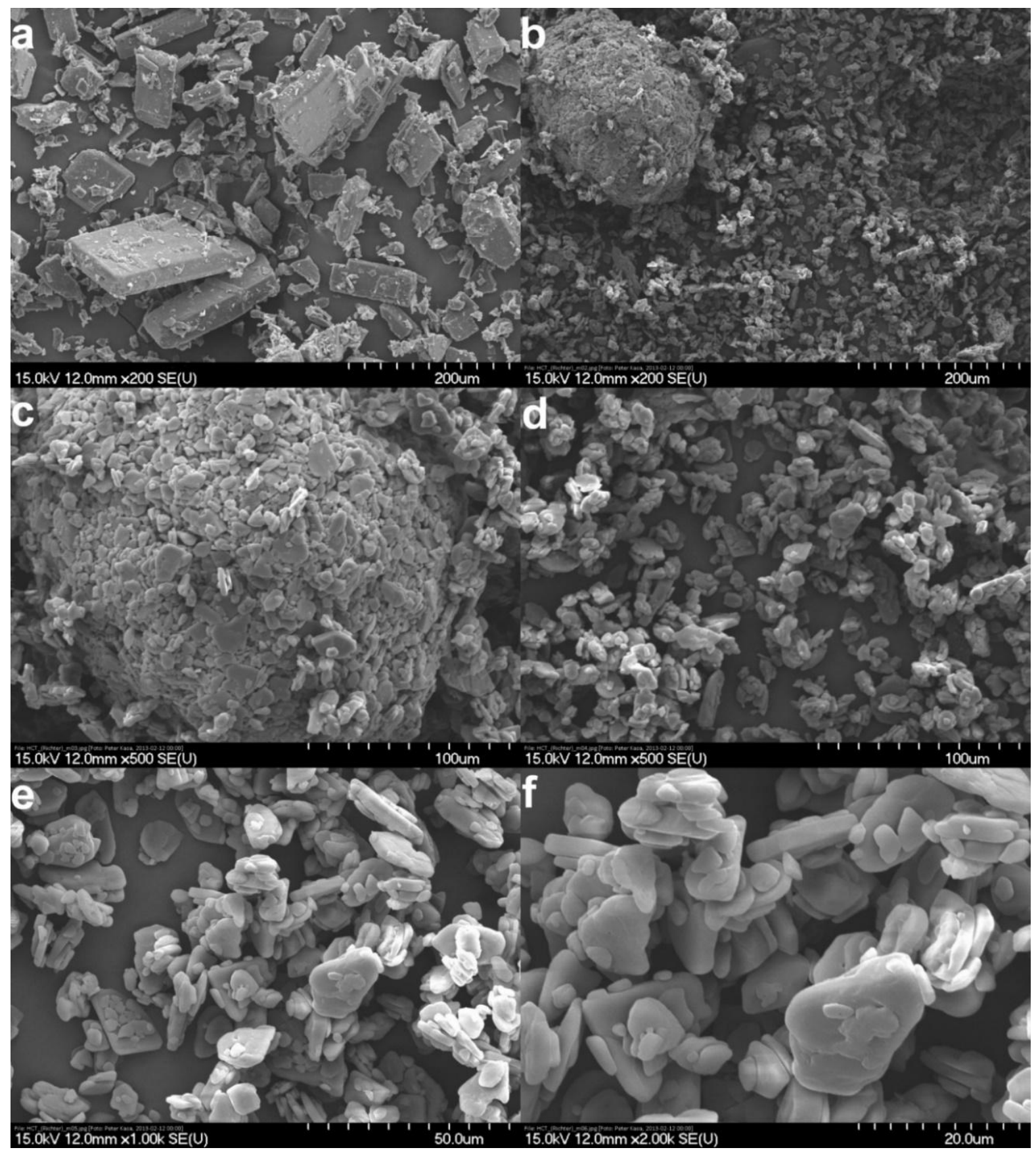

Figure 13.: SEM picture of EM (a), and HCT in magnification 200x (b) 500x (aggregate) (c), $500 \mathrm{x}$ (individual crystals) (d), 1000x (e) and 2000x (f) 
A further difference is that whilst EM crystals are well-developed and sometimes covered by tiny, irregularly-shaped crystal grains (Fig. 13a), the edges and corners of the HCT crystals are rounded (Fig. 13d, e, f). The sticking of smaller particles on the surface of larger crystals, - which suggests a strong cohesion between them is also characteristic for HCT. That is why a number of irregular looking crystals are visible at small magnifications (Fig. 13b), with the presence of some big crystal agglomerates. It is well visible at higher magnifications (Fig. $13 \mathrm{~d}, \mathrm{e}, \mathrm{f})$, that the smaller particles are irregular aggregates of few tabular crystals, while bigger agglomerates are formed from undeveloped particles (Fig. 13c) and behave as individual units in the product.

Table 12.: Properties of APIs

\begin{tabular}{|c|c|c|}
\hline & Enalapril maleate & Hydrochlorothiazide \\
\hline Aspect ratio & 1.866 & 1.829 \\
\hline Roundness & 0.595 & 0.63 \\
\hline $\begin{array}{c}\text { Mean Feret diameter }(\boldsymbol{\mu m}) \\
\text { Aqueous solubility } \\
(\mathbf{m g} / \mathbf{m l})\end{array}$ & $67.4( \pm 43.84)$ & $5.57( \pm 3.96)$ \\
\hline
\end{tabular}

As it can be seen, except for the solubility and particle size, the general physical properties of the APIs are similar, and their mechanical behaviour during the extrusion-spheronization process is expected to be similar too.

\subsubsection{Characterization of pellets}

We can define pellets as spherical, free flowing granules with a narrow size distribution, that typically varies between 0.50 and $1.50 \mathrm{~mm}$. All experimental settings resulted in pellets for both formulations with a mean average Feret diameter from 1.0 to $1.5 \mathrm{~mm}$ (Table 13.). The shorter spheronization time results in larger size particles. The reason for this phenomenon is that the particles do not have enough time to get a rounded shape, and thus "bone" shaped particles are formed during spheronization, the particle size of which is larger as well.

The $10 \%$ interval is used to characterise the particle size distribution., which describes the fraction of pellets within the interval $0.9-1.1$ of the dimensionless diameter. If the fraction in the $10 \%$ interval exceeds $50 \%$ the size distribution is rated as good and if the fraction exceeds $75 \%$ the size distribution is rated as excellent [67]. 
Table 13.: Properties of pellets

\begin{tabular}{|c|c|c|c|c|c|c|c|c|c|c|c|}
\hline \multirow{2}{*}{ Samples } & \multirow{2}{*}{$\begin{array}{c}\mathrm{X}_{1} \\
\text { Spher. } \\
\text { time } \\
\text { (min) }\end{array}$} & \multirow{2}{*}{$\begin{array}{c}\mathrm{X}_{2} \\
\text { Liquid } \\
\text { feed rate } \\
(\mathrm{g} / \mathrm{min}) \\
(\mathrm{EM} / \mathrm{HCT})\end{array}$} & \multirow{2}{*}{$\begin{array}{c}X_{3} \\
\text { Spher. } \\
\text { Speed } \\
(\text { rpm) }\end{array}$} & \multicolumn{2}{|c|}{$\begin{array}{c}\text { Mean Feret } \\
\text { diameter (mm) }\end{array}$} & \multicolumn{2}{|c|}{$\begin{array}{c}10 \% \text { interval } \\
(\%)\end{array}$} & \multicolumn{2}{|c|}{ Aspect ratio } & \multicolumn{2}{|c|}{$\begin{array}{l}\text { Hardness } \\
(\mathrm{N})\end{array}$} \\
\hline & & & & EM & HCT & EM & HCT & EM & HCT & EM & HCT \\
\hline 1. & 2.5 & $25 / 26.3$ & 1000 & $\begin{array}{c}1.31 \\
( \pm 0.06)\end{array}$ & $\begin{array}{c}1.27 \\
( \pm 0.12)\end{array}$ & 52.8 & 52.2 & 1.60 & 1.58 & 17.3 & 12.0 \\
\hline 2. & 2.5 & $25 / 26.3$ & 1250 & $\begin{array}{c}1.21 \\
( \pm 0.08)\end{array}$ & $\begin{array}{c}1.46 \\
( \pm 0.17)\end{array}$ & 62.4 & 70 & 1.40 & 1.52 & 12.6 & 13.0 \\
\hline 3. & 2.5 & $25 / 26.3$ & 1500 & $\begin{array}{c}1.13 \\
( \pm 0,09)\end{array}$ & $\begin{array}{c}1.15 \\
( \pm 0.09)\end{array}$ & 49.5 & 56.2 & 1.25 & 1.33 & 14.7 & 12.7 \\
\hline 4. & 2.5 & $27 / 28.5$ & 1000 & $\begin{array}{c}1.25 \\
( \pm 0.11)\end{array}$ & $\begin{array}{c}1.28 \\
( \pm 0.11)\end{array}$ & 50.8 & 59.6 & 1.57 & 1.55 & 16.2 & 11.3 \\
\hline 5. & 2.5 & $27 / 28.5$ & 1250 & $\begin{array}{c}1.20 \\
( \pm 0.08)\end{array}$ & $\begin{array}{c}1.22 \\
( \pm 0.11)\end{array}$ & 73.8 & 60.6 & 1.50 & 1.41 & 13.7 & 13.5 \\
\hline 6. & 2.5 & $27 / 28.5$ & 1500 & $\begin{array}{c}1.23 \\
( \pm 0.10) \\
\end{array}$ & $\begin{array}{c}1.16 \\
( \pm 0.07) \\
\end{array}$ & 76.8 & 62.2 & 1.36 & 1.32 & 15.4 & 13.9 \\
\hline 7. & 2.5 & $29 / 30.3$ & 1000 & $\begin{array}{c}1.22 \\
( \pm 0.02)\end{array}$ & $\begin{array}{c}1.22 \\
( \pm 0.08)\end{array}$ & 82.6 & 66.4 & 1.24 & 1.44 & 10.4 & 9.1 \\
\hline 8. & 2.5 & $29 / 30.3$ & 1250 & $\begin{array}{c}1.25 \\
( \pm 0.11)\end{array}$ & $\begin{array}{c}1.17 \\
( \pm 0.13)\end{array}$ & 79.6 & 77.6 & 1.10 & 1.27 & 11.2 & 10.4 \\
\hline 9. & 2.5 & $29 / 30.3$ & 1500 & $\begin{array}{c}1.12 \\
( \pm 0.14)\end{array}$ & $\begin{array}{c}1.16 \\
( \pm 0.14)\end{array}$ & 85.0 & 73.4 & 1.10 & 1.16 & 12.3 & 15.4 \\
\hline 10. & 10 & $25 / 26.3$ & 1000 & $\begin{array}{c}1.22 \\
( \pm 0.07)\end{array}$ & $\begin{array}{c}1.22 \\
( \pm 0.10) \\
\end{array}$ & 78.2 & 63.4 & 1.49 & 1.54 & 16.3 & 15.4 \\
\hline 11. & 10 & $25 / 26.3$ & 1250 & $\begin{array}{c}1.17 \\
( \pm 0.07)\end{array}$ & $\begin{array}{c}1.14 \\
( \pm 0.08)\end{array}$ & 93.6 & 82.6 & 1.30 & 1.36 & 19.3 & 19.5 \\
\hline 12. & 10 & $25 / 26.3$ & 1500 & $\begin{array}{c}1.10 \\
( \pm 0.11)\end{array}$ & $\begin{array}{c}1.01 \\
( \pm 0.07)\end{array}$ & 91.4 & 82.6 & 1.15 & 1.24 & 19.5 & 19.5 \\
\hline 13. & 10 & $27 / 28.5$ & 1000 & $\begin{array}{c}1.23 \\
( \pm 0.08)\end{array}$ & $\begin{array}{c}1.16 \\
( \pm 0.11)\end{array}$ & 87.2 & 85.2 & 1.54 & 1.3 & 15.2 & 15.6 \\
\hline 14. & 10 & $27 / 28.5$ & 1250 & $\begin{array}{c}1.17 \\
( \pm 0.14)\end{array}$ & $\begin{array}{c}1.13 \\
( \pm 0.10) \\
\end{array}$ & 92.6 & 86.4 & 1.31 & 1.25 & 18.1 & 14.2 \\
\hline 15. & 10 & $27 / 28.5$ & 1500 & $\begin{array}{c}1.11 \\
( \pm 0.12)\end{array}$ & $\begin{array}{c}1.03 \\
( \pm 0.09)\end{array}$ & 93.0 & 75.4 & 1.15 & 1.11 & 18.0 & 20.9 \\
\hline 16. & 10 & $29 / 30.3$ & 1000 & $\begin{array}{c}1.21 \\
( \pm 0.09)\end{array}$ & $\begin{array}{c}1.19 \\
( \pm 0.13)\end{array}$ & 90.4 & 97 & 1.07 & 1.08 & 15.1 & 14.3 \\
\hline 17. & 10 & $29 / 30.3$ & 1250 & $\begin{array}{c}1.18 \\
( \pm 0.08)\end{array}$ & $\begin{array}{c}1.10 \\
( \pm 0.12)\end{array}$ & 84.0 & 96.8 & 1.06 & 1.05 & 19.1 & 14.0 \\
\hline 18. & 10 & $29 / 30.3$ & 1500 & $\begin{array}{c}1.18 \\
( \pm 0.07)\end{array}$ & $\begin{array}{c}1.09 \\
( \pm 0.10)\end{array}$ & 82.0 & 95.6 & 1.07 & 1.06 & 15.1 & 14.0 \\
\hline
\end{tabular}


The fraction in the $10 \%$ interval was in the $50-94 \%$ range in case of pellets with enalapril maleate and in the $52-97 \%$ range in case of hydrochlorothiazide pellets. Thus all size distributions can be regarded as good.

The most common parameter to describe the shape of pellets is the aspect ratio. Pellets of a mean aspect ratio was close to 1.2 were regarded insufficient [51].

The results show that the aspect ratio and the other shape parameters are the worst if the process parameters are at minimum level (Fig. 14a), but spherical-shaped pellets may be gained with some optimization. The aspect ratio was near 1 in the case of Samples 16-18 for both APIs where the liquid feed rate and the spheronization time is on a higher level (Fig. $14 b)$.

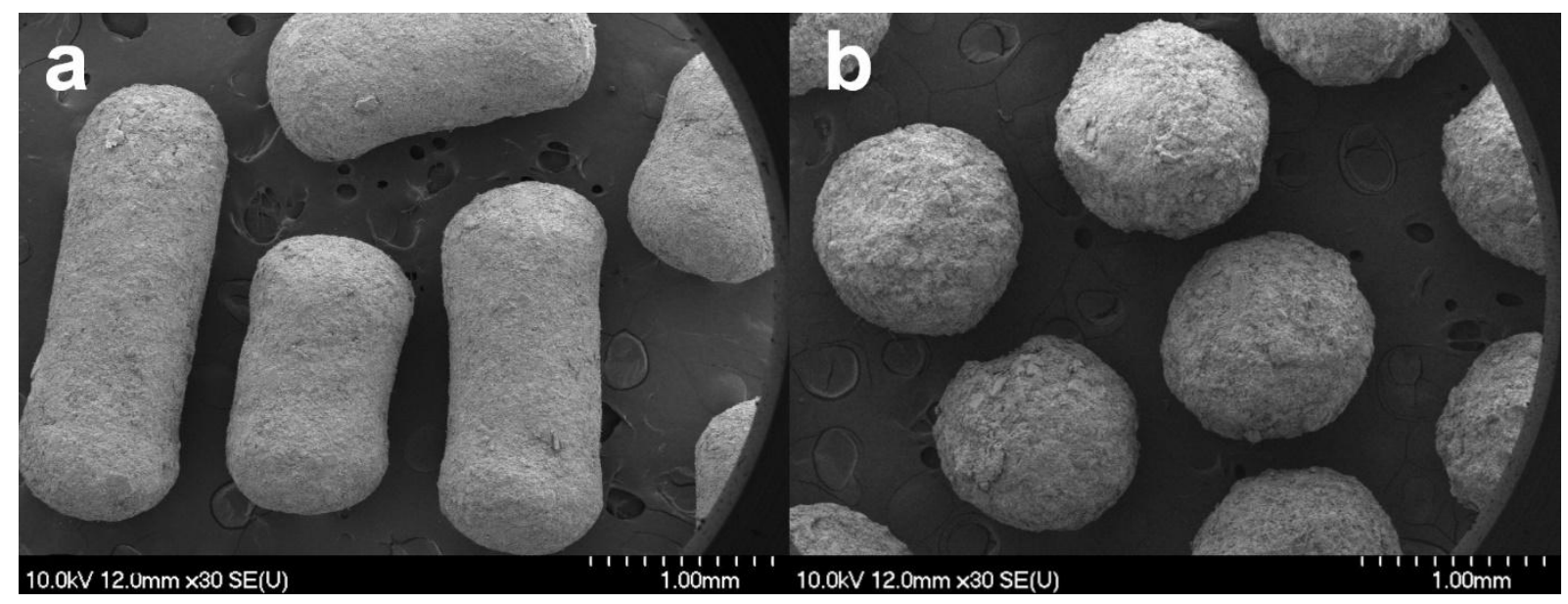

Figure 14.: SEM pictures of insufficient (a) and well (b) shaped pellets

\subsubsection{Factorial design}

The effect of the different process parameters as factors was studied on the basis of a mixed (2 and 3) level full factorial design. The different experimental settings and the corresponding physical properties are displayed in Table 13.

The response surfaces of the various optimization parameters may be described with the following general equation:

$$
\mathrm{y}=\mathrm{b}_{0}+\mathrm{b}_{1} \mathrm{x}_{1}+\mathrm{b}_{2} \mathrm{x}_{2}+\mathrm{b}_{22} \mathrm{x}_{2}{ }^{2}+\mathrm{b}_{3} \mathrm{x}_{3}+\mathrm{b}_{33} \mathrm{x}_{3}{ }^{2}+\mathrm{b}_{12} \mathrm{x}_{1} \mathrm{x}_{2}+\mathrm{b}_{13} \mathrm{x}_{1} \mathrm{x}_{3}+\mathrm{b}_{23} \mathrm{x}_{2} \mathrm{x}_{3}
$$

(where $\mathrm{x}_{1}$ :spheronization time, $\mathrm{x}_{2}$ :liquid feed rate, $\mathrm{x}_{3}$ : spheronization speed) 
The regression coefficients and statistical results are displayed in Table 14., significant factors are highlighted with red colour.

Table 14.: Effects of factors on the Aspect ratio (AR) and breaking hardness

\begin{tabular}{|c|c|c|c|c|}
\cline { 2 - 5 } \multicolumn{1}{c|}{} & \multicolumn{2}{c|}{ AR } & \multicolumn{2}{c|}{ Hardness } \\
\cline { 2 - 5 } \multicolumn{1}{c|}{} & EM & HCT & EM & HCT \\
\hline $\mathbf{R}^{2}$ & 0.9215 & 0.9525 & 0.7070 & 0.7996 \\
\hline MS Residual & 0.0047 & 0.0023 & 4.1575 & 3.6379 \\
\hline $\mathbf{b}_{\mathbf{0}}$ & $\mathbf{1 . 2 8 3}$ & $\mathbf{1 . 2 8 5}$ & $\mathbf{1 5 . 5 1 5}$ & $\mathbf{1 4 . 3 7 0}$ \\
\hline $\mathbf{b}_{\mathbf{1}}$ & $\mathbf{- 0 . 0 4 7}$ & $\mathbf{- 0 . 0 8 0}$ & $\mathbf{1 . 7 6 4}$ & $\mathbf{2 . 0 0 2}$ \\
\hline $\mathbf{b}_{\mathbf{2}}$ & $\mathbf{- 0 . 1 2 9}$ & $\mathbf{- 0 . 1 1 7}$ & $\mathbf{- 1 . 3 7 3}$ & -1.237 \\
\hline $\mathbf{b}_{\mathbf{2 2}}$ & $\mathbf{0 . 0 7 1}$ & 0.007 & 0.434 & 0.413 \\
\hline $\mathbf{b}_{3}$ & $\mathbf{- 0 . 1 0 7}$ & $\mathbf{- 0 . 0 9 9}$ & 0.381 & $\mathbf{1 . 5 6 1}$ \\
\hline $\mathbf{b}_{\mathbf{3 3}}$ & -0.004 & 0.005 & 0.104 & -0.204 \\
\hline $\mathbf{b}_{\mathbf{1}} \mathbf{b}_{\mathbf{2}}$ & 0.008 & -0.031 & 0.398 & -0.782 \\
\hline $\mathbf{b}_{\mathbf{1}} \mathbf{b}_{3}$ & -0.014 & 0.014 & 0.623 & -0.039 \\
\hline $\mathbf{b}_{\mathbf{2}} \mathbf{b}_{\mathbf{3}}$ & $\mathbf{0 . 0 6 9}$ & 0.030 & 0.154 & 0.153 \\
\hline
\end{tabular}

It can be seen from the statistical results that the aspect ratio is significantly influenced by all three factors, within standard 95\% CI $(\mathrm{p}<0.05)$ and the liquid feed rate $\left(\mathrm{x}_{2}\right)$ has the most considerable effect, while spheronization time $\left(\mathrm{x}_{1}\right)$ has the smallest, for both APIs.

The higher factor values resulted in smaller aspect ratio values and also in the formation of sphere-shaped pellets in both cases. Nevertheless, the considerable difference between the two APIs is that the aspect ratio of HCT pellets decreases linearly with the increment of the liquid addition rate, while EM exhibits a nonlinear dependence on this factor (Fig. 15a, b). The explanation of this difference may be the different solubility of the APIs, which exerts considerable effect on the pellet texture through the influencing of the distribution of the water inside the wet mass. 

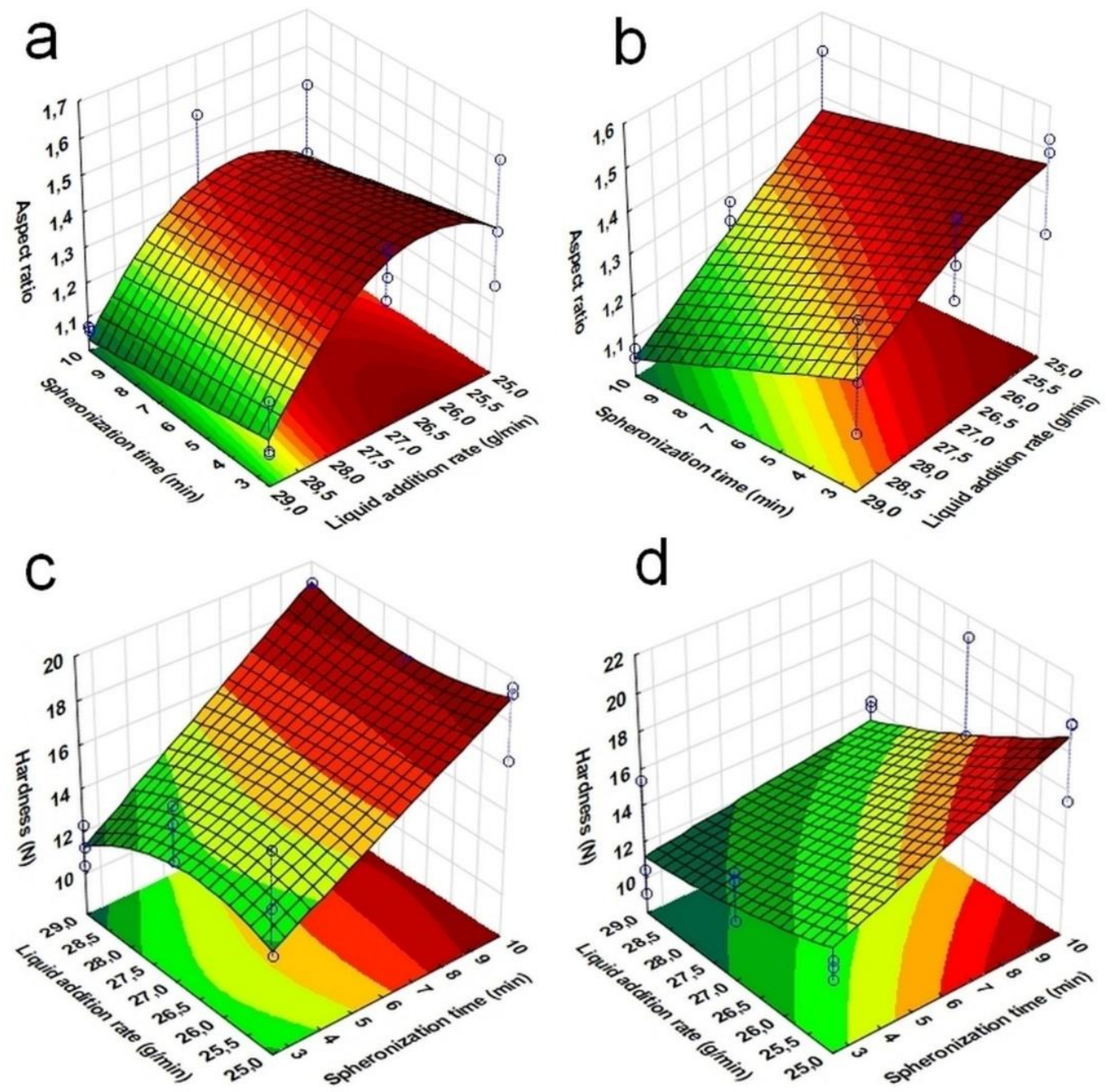

Figure 15.: Response surface on the aspect ratio of EM (a) and HCT (b), and hardness of EM (c) and HCT (d) pellets

The structural differences are well visible on the cross-sectional scanning electron micrographs (Fig. 16.). Although the low magnification images show compact spongiform texture for all investigated samples, the pellets with higher aspect ratio exhibit slightly higher apparent porosity. The increasing magnification reveals the differences of the sponge-like texture of the EC-MCC matrices. Besides the smooth surface of the embedded EM crystals surrounded with fibriform, filamentous, crumpled MCC grains, numerous rounded EC particles connected to them can be clearly identified in EM 1 pellets (Fig. 16c). Despite the different embedding mechanism of the API crystals, where the rounded particles are distributed more uniformly in the matrix, the general matrix texture of HCT 1 pellets is similar and the round EC grains may be identified (Fig. 16d). The different embedding can be due to the fact that smaller crystals are bound to the surface with a smaller force than to the matrix formers. The breaking surface of the pellets is generally splintered, which indicates 
strong cohesion between the particles, but numerous fibrous ruptures may be identified, which can be due to the elastic deformation of the EC grains during the breaking process (Fig. 16g, h).

Consequently, intact, rounded EC grains cannot be identified in EM 18 and HCT 18 pellets. This indicates that the high liquid feed rate induced structural changes in the EC grains, and the better deformation of these samples may be due to the plasticizing effect of the water.

Probably, if the better soluble EM bonds more water, that could be the reason for the nonlinear relation between the aspect ratio and liquid addition rate in these pellets.

The differences of the two APIs are also visible if we take into consideration the interactions between the factors. In the case of EM pellets, the interaction of the spheronization speed and the liquid feed rate is significant, and the other interactions have negligible effect. In contrast, the interaction of the liquid feed rate with the two spheronization parameters has equal weight for HCT pellets. In general, the spheronization speed has almost no effect on the shape of the particles at low liquid feed rates, which also supports the negative effect of the unplasticized EC grains on this parameter. The different texture and embedding mechanism of the API crystals have also significant effect on the the mechanical properties (hardness) of pellets. 


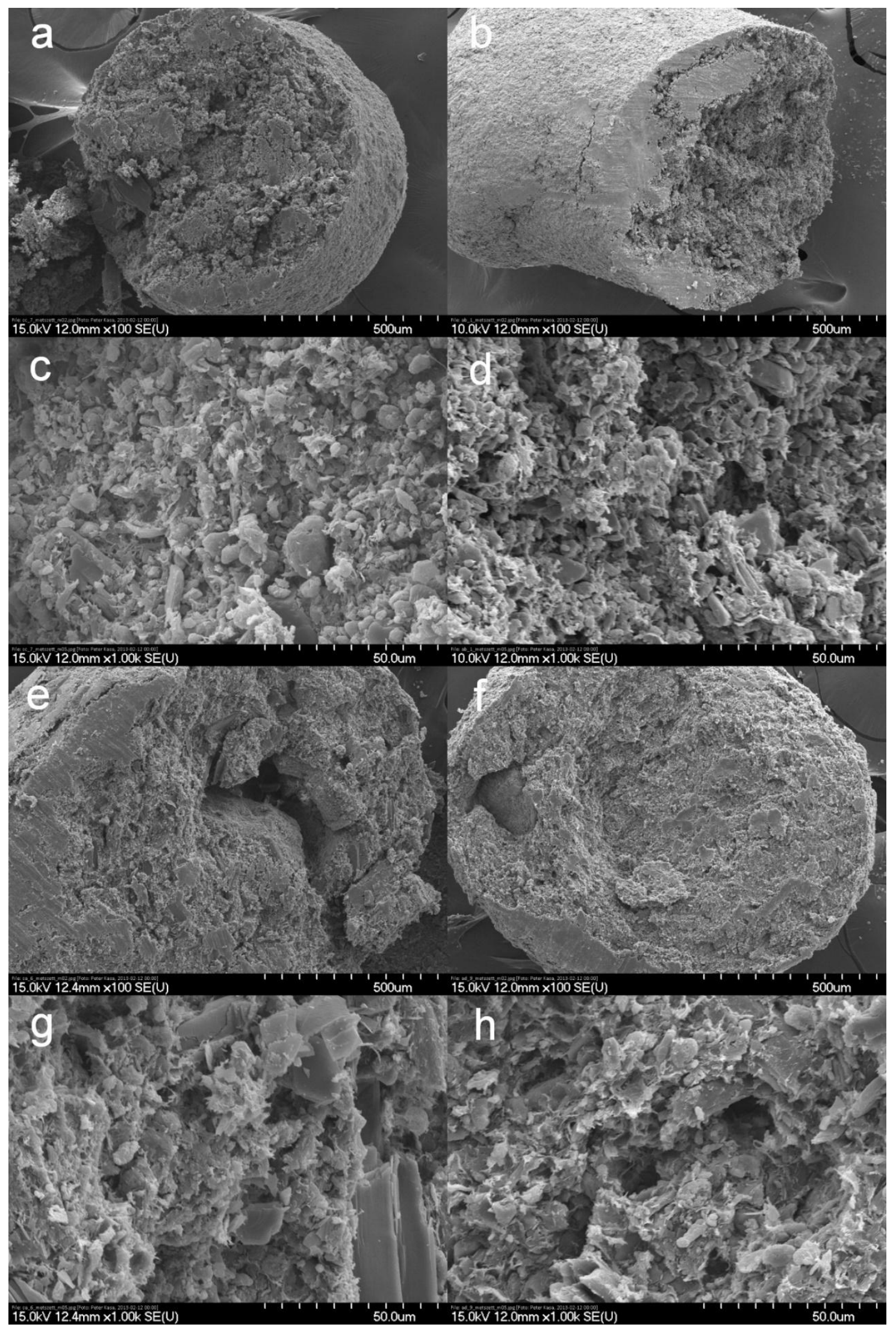

Figure 16.: Scanning electron micrographs of the cross sections of various pellets (EM 1 100x (a), HCT 1 100x (b), EM 1 1000x (c), HCT 1 1000x (d), EM 18 100x (e), HCT 18 100x (f), EM 18 1000x (g), HCT 18 1000x (h)) 


\subsubsection{Mechanical properties of pellets}

The general breaking process of the pellets is displayed in Figure 17. Each section of the process is marked by a coloured line.

The deformation of a pellet starts with a short period of elastic deformation. The green cursor shows the maximum value of this period. In the second stage, a short period of viscoelastic deformation occurs, which can be due to the presence and elastic properties of EC (from green cursor to black). The third stage involves the first cracks in the pellet (from black cursor to purple), influencing only the microstructure without any sign of macroscopic changes. In the fourth stage, as pressure increases, a structure change develops in the pellet (from purple cursor to red). Every solid body-bridge within the pellet will crack in this stage. In the end (from the red cursor), the final deformation of the pellet occurs.

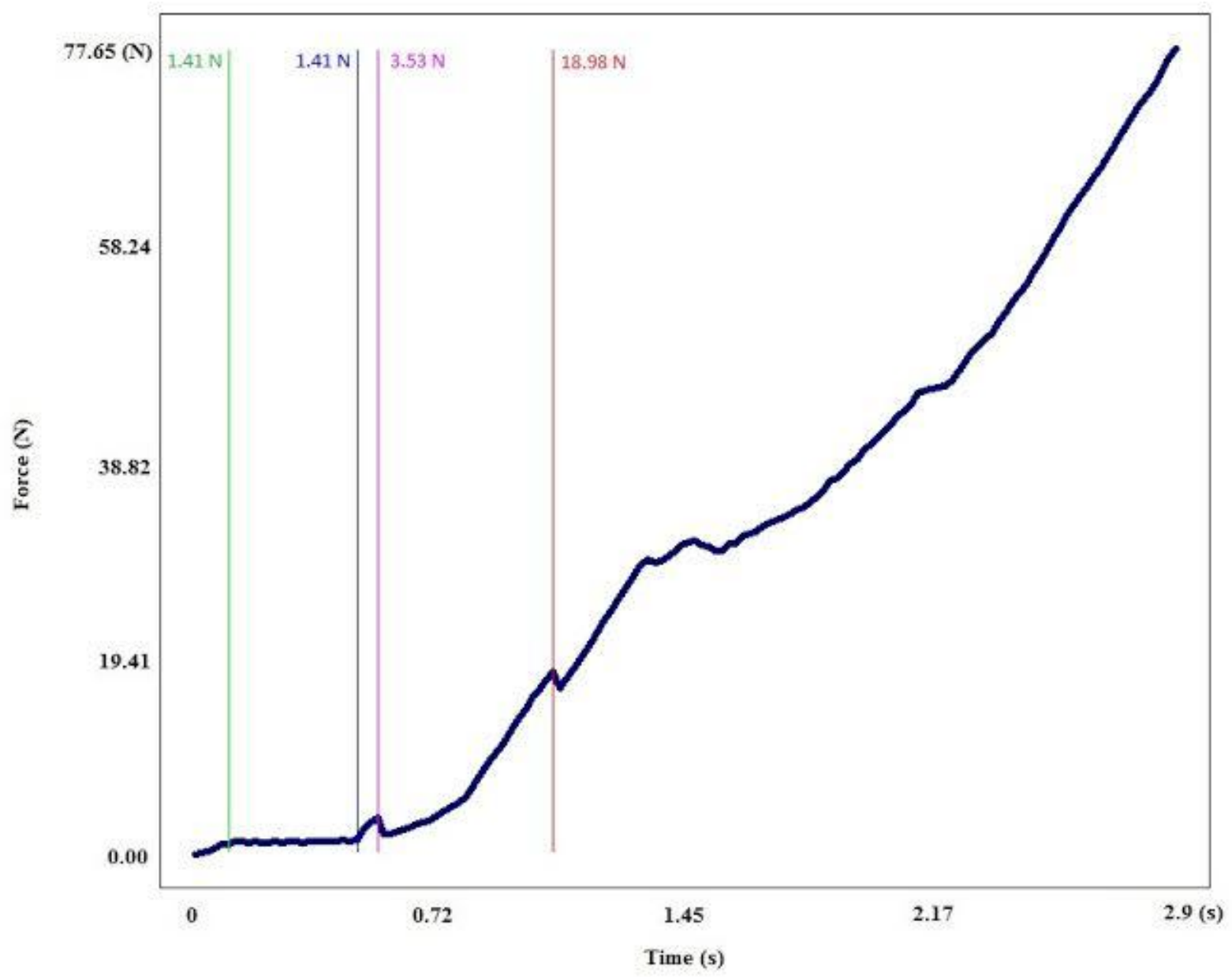

Figure 17.: General deformation process of the studied pellets

Various authors adopted different approaches to assume the correspondence between a given peak of such complicated deformation procedure and the real crushing strength value. In some 
cases the last one was chosen, whereas in other cases the highest one and yet in other works the first peak giving a preset drop of force was taken into account [77].

In present case the breaking hardness value is given by the force corresponding to the last peak of the force-time plot, since this was the starting point of the macroscopic deformation of the pellets. The maximal breaking strength of HCT pellets is lower in comparison with the corresponding EM ones (Table 13.) possibly due to the different embedding and distribution of API particles within the EC-MCC matrix. Furthermore, the statistical analysis revealed that although the pellet hardness is influenced most significantly by spheronization time, within 95\% CI $(\mathrm{p}<0.05)$ for both APIs, but amongst the other factors the liquid feed rate is significant for the EM and the spheronization speed for the HCT pellets (Table 14.). This indicates different behaviour of the various textures, which may be related to the different number and arrangement of solid bridges inside the matrix. The greater hardness of EM pellets is possibly related to the greater amount of dissolved particles due to the better solubility of the API, which results in more intense solid bridge formation after the drying and recrystallization of these particles.

\subsubsection{Dissolution}

The dissolution of the pellets containing hydrochlorothiazide lasts longer than that of pellets containing enalapril maleate (Fig. 18.).

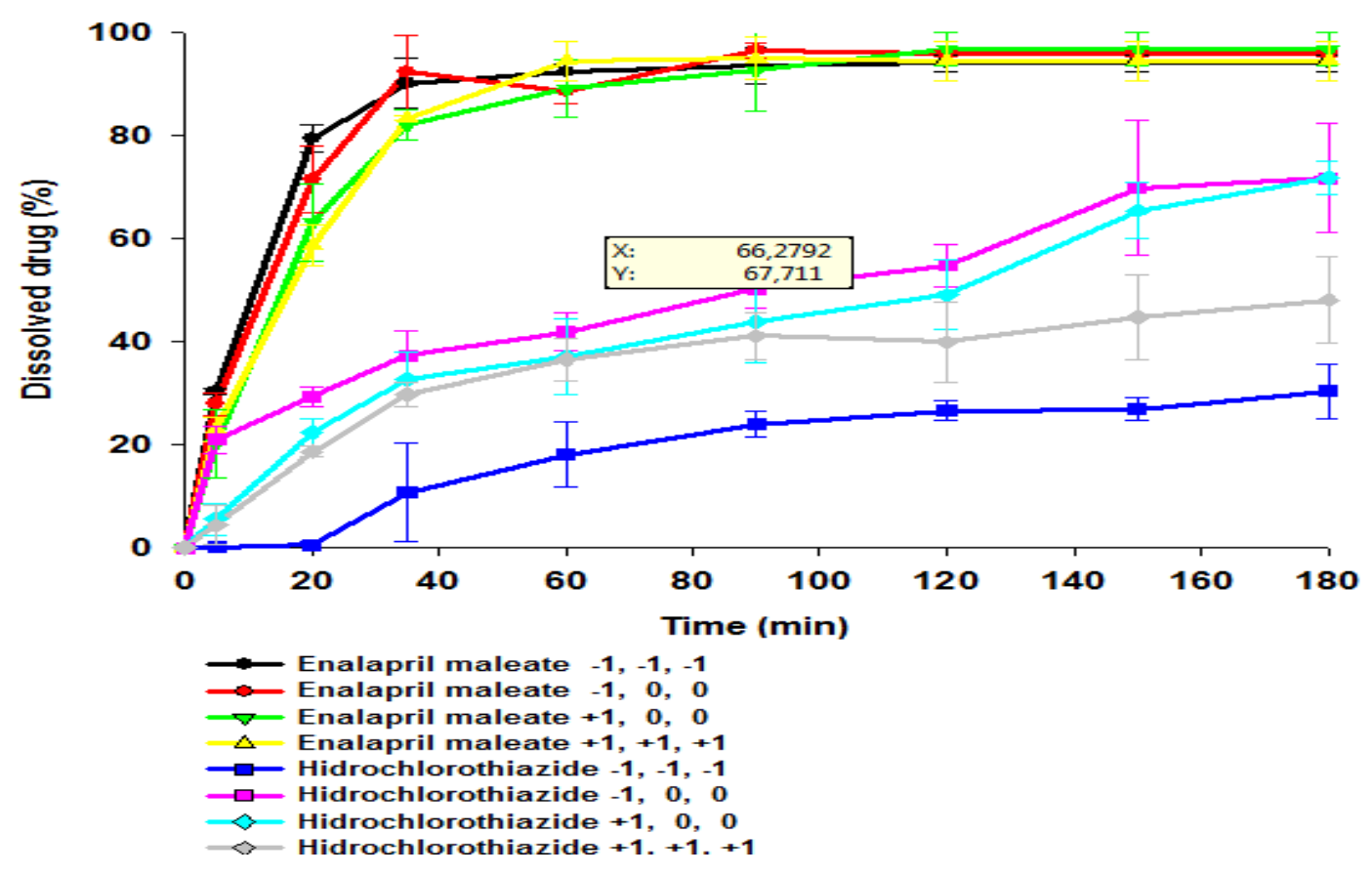

Figure 18.: The disssolution of the pellets 
In the case of pellets containing enalapril maleate, the dissolution of the active ingredient is the fastest when all three factors are on the lowest level, and the slowest when the factors are on the highest level. Shorter spheronization time results in faster dissolution. There are various release kinetics models that are used to describe the API release profiles in pharmaceutical studies [78]. The Noyes-Whitney model was found to be the most suitable for the fitting of the API dissolution curves in the case of enalapril maleate with a very good correlation $\left(\mathrm{R}^{2}=0.9836-0.9948\right)$. This model was offered by Noyes and Whitney as the following equation:

$$
\frac{d M}{d t}=K\left(C_{s}-C_{b}\right)
$$

where

$\frac{d M}{d t}$ is the dissolution rate

$M$ is the dissolved material,

$t$ is the time,

$k$ is the dissolution rate constant,

$C_{s}$ is the concentration of the API in the stagnant layer,

$C_{b}$ is the concentration of the API in the bulk of the solution at time $\mathrm{t}$ respectively.

This is first order ordinary differential equation. The solution of this equation is:

$$
M(t)=M_{0}\left(1-e^{-k t}\right)
$$

where

$M(t)$ is the dissolved mass of API at the time t,

$M_{0}$ is the full mass of API in the pellet,

$k$ is the dissolution rate constant respectively.

In the case of hydrochlorothiazide the semiempirical Korsmeyer - Peppas model and the Chapman-Richards were found to be the best model for the fitting the API dissolution curves $\left(\mathrm{R}^{2}=0.9900-0.9984\right.$ In the Korsymeyer-Peppas model the fractional release of API is exponentially related to the release time:

$$
\frac{M_{t}}{M_{0}}=k t^{n}
$$

where

$\frac{M_{t}}{M_{0}}$ is a fraction of API released at time $\mathrm{t}$,

$k$ is the release rate constant

$\mathrm{n}$ is a release exponent.

For more details of Korsmeyer-Peppas model see [78, 79]. 
The Chapman-Richards method based on Bernoulli differential equation which is used to describes the growth of an arbitrary quantity as the difference between its constructive growth and the destructive growth [80].

$$
\frac{d M}{d t}=\alpha M^{\beta}-\gamma M
$$

where

$M$ is the amount of quantity,

$\alpha M^{\beta}$ is constructive part

$\gamma M$ is the destructive part.

The general solution of this differential equation is the 3-parameter Chapman-Richards function:

$$
M(t)=M_{\infty}\left(1-e^{-k t}\right)^{\beta}
$$

where

$M_{\infty}, k, \beta$ are the regression parameters to be estimated.

In our case:

$M(t)$ is the dissolved API as a function of time,

$M_{\infty}$ is the total amount of the API,

$k$ is the dissolution rate

$\beta$ describes the shape of the curve, which is refers to the lag time of the dissolution.

Like RRSBW model, for $\beta=1$, implies the first order kinetics.

On the basis of dissolution examinations we can prove that the water solubility of the active ingredients significantly influences the dissolution. EC matrix does not inhibit the dissolution of the active ingredient, in case of EM with good dissolution properties (BCSIII). Approximately after 30 minutes, $80 \%$ of the acitve ingredient has already dissoluted from the pellets; in this case we cannot talk about sustained/modified release, this could only be reached by adding more EC to the system. In such case the adding of more EC would be necessary.

In the case of HCT (BSC IV) with poor dissolution properties, the active ingredient could not dissolute quickly from the matrix, but this was not our goal anyway. 
We can see it from the results that by keeping the formulation parameters on a low level, dissolution only begins after a delay period, lag time.

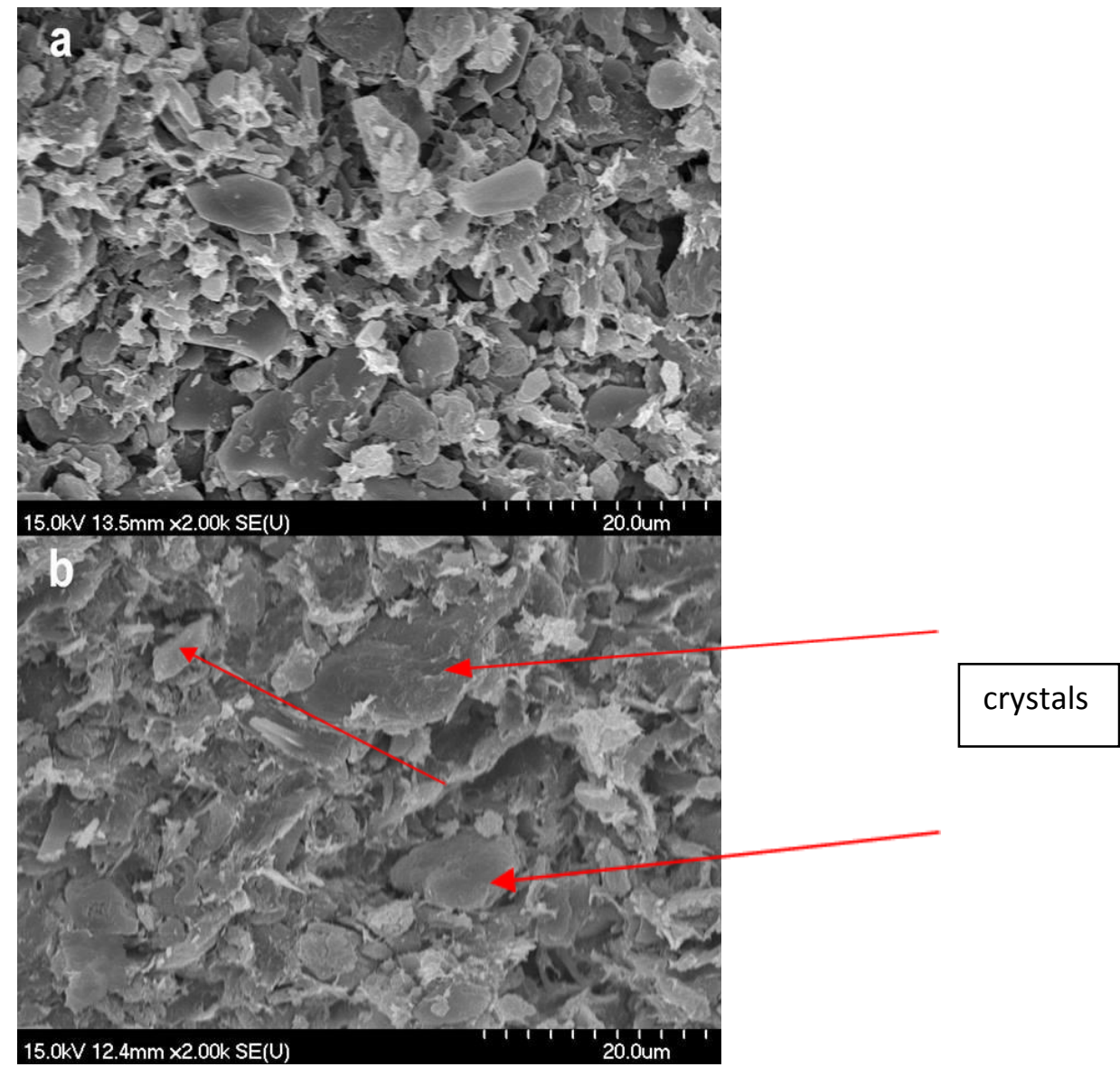

Figure 19.: Scanning electron micrographs of the cross sections of HCT pellets:HCT $12000 x$ (a) HCT $182000 x(b)$

In this case, owing to the smaller mechanical effect (slower spheronozation speed), a much looser structure develops; the interior part of the pellets is filled with pores (Fig. 19.). Consequently, an inner structure that is based on the protective effect of the EC film can develop, and makes dissolution modified.

By keeping the parameters on a higher level a more compact structure, with less pores develops in the inner part of the pellets (Fig. 19a). Owing to the faster liquid feed rate, EC cannot spread properly in the mass during extrudation, furthermore due to the bigger mechanical impact (spheronization speed), the film gets fractured, since elastic recovery also succeeds heres. Nude crystal surfaces can be seen, which meet with the dissolution medium earlier (Fig. 19b $\longrightarrow$ ). So, the protective effect of the EC cannot prevail so much, contrary to those pellets, where the spheronization speed was smaller, thus we experience faster dissolution in this case. 
In the other two cases, we can see the influencing effect of spheronization time. If the spheronization time is shorter, a looser structure develops, and the dissolution of the active ingredient starts earlier. Where the spheronization time is longer, the dissolution starts more difficulty, but this does not influence the structure to an extent that we should count with a lag time.

We can determine that spheronization time has a decisive influence on the commencement and degree of the dissolution. The other important parameter is not other than spheronization speed. Spheronization parameters do have a greater influnece in general on dissolution, than the parameters playing role in the formation of the wet mass that is to say liquid feed rate during extrusion.

The results draw our attention to the fact that during the preformulation examinations, in the case of poor water solubility active ingredients, designing has specific importance.

\subsection{Discussion}

It was confirmed, that the assurance of required pellet shape is problematic due to the elastic properties of EC. The use of EC-MCC mixture provides better process yield in comparison with the EC-MCC-PEO mixture applied by Mallipeddi et. al, [34, 35] since there is no hydrogel formation.

The amount of the granulation liquid play a key role in the pellet shaping. A high liquid addition rate is preferred because of the high water absorption capacity of MCC decreases the plasticizing effect of the granulation liquid on the EC particles.

The solubility of the applied API also has a considerable effect on the pellet properties. However, in contrast with the expectations, the amount of the granulation liquid could not be decreased in the case of well soluble material. Furthermore, this API affected the liquid distribution in the wetted mass negatively at low liquid addition rates, which resulted in a nonlinear relationship between the liquid feed rate and aspect ratio.

Spheronization parameters has a greater influence on dissolution than liquid feed rate. 


\section{FINAL CONCLUSIONS, NOVELTY, PRACTICAL USEFULNESS}

As previously described in Section: Aims, our goal was to study the application of the widely used ethylcellulose polymer as film forming- and matrix former agent, and with the use of them develop innovative dosage forms with and for combined APIs.

The important novelty and practical usefulness of this work may be summarized as follows:

- $\quad$ Different properties of film forming effects were observed among the used film forming agents and we have come to the conclusion that EC45 has better properties, furthermore we have determined the optimal concentration of plasticizer (triethyl citrate).

- $\quad$ Films with better quality can be prepared from EC45, the prepared films stayed stable until approximately $200^{\circ} \mathrm{C}$.

- $\quad$ The results of the FT-IR method supported all the examination data that were gained by other examination methods, such as thermostability and the incorporation of the plasticizer.

- PALS studies showed that $1 \%$ plasticizer is integrated between the polymer chains and has greater breaking strength, more concentration of the plasticizer results in larger free volume holes and lower breaking strength.

- $\quad$ Based on the above results, the composition prepared from EC45 polymer with $1 \%$ triethyl citrate as plasticizer is recommended for making MR coats. This composition can be used for diffusion coating to obtain a product with modified release.

- With the use of EC and MCC as matrix former, a monolithical matrix system was developed, containing enalapril maleate and hydrochlorothiazide as APIs. We could prepare pellets with optimal physico-chemical properties in both cases. If we want to produce an extended release system, it is essential to know the correct ratio of $\mathrm{MCC} / \mathrm{EC}$ to achieve monolithic matrix pellets.

- The results of our experiments show that the parameter values and factors influencing extrusion and spheronization depend first of all on the properties of the active ingredient with poor aquos solubility, thus preformulation and detailed 
planning is essential in the case of poor aquos solubility active ingredients; and furthermore the use of factorial design is essential for their determination. In the case of HCT-pellets, we managed to achive an extended drug release, opposite to EM; but in case of EM-pellets, the addition of more EC may achieve the modified release.

- $\quad$ Capsule dosage forms can be formed with the filling of pellets containing EM and HCT. (In Hungary there are only tablets with these API combination.) The formulation of capsules can be an alternative opportunity for patients with dysphagia, who can gulp capsules easier than tablets.

- The results and observations of the present study provide useful information for industrial technologists. 


\section{References}

1. Bertelsen P., Christensen F.N., Holm P., Jorgensen K.: Comparison of organic solventbased ethylcellulose coatings of $\mathrm{KCl}$ crystals applied by top and bottom spraying in fluidizedbed equipment, Int. J. Pharm. 111, 117-125 (1994)

2. Aleksovski A., Luštrik M., Šibanc R., Dreu R.: Design and evaluation of a specific, biphase extended release system based on differently coated mini-tablets, Eur. J. Pharm. Sci. 75, 114-122 (2015)

3. Dashevsky A., Kolter K., Bodmeier R.: pH-independent release of a basic drug from pellets coated with the extended release polymer dispersion Kollicoat ${ }^{\circledR}$ SR 30 D and the enteric polymer dispersion Kollicoat ${ }^{\circledR}$ MAE 30 DP, Eur. J. Pharm. Biopharm. 58, 45-49 (2004)

4. Gaber D.N., Nafee N., Abdallah O.J.: Mini-tablets versus pellets as promising multiparticulate modified release delivery systems for highly soluble drugs, Int. J. Pharm. 488, 86-94 (2015)

5. Dredán J., Zelkó R., Dávid Á.Z., Antal I.: Quantitative estimation of film forming polymer-plasticizer interactions by the Lorentz-Lorenz Law, Int. J. Pharm. 310, 25-30 (2006)

6. Piermaria J., Bosch A., Pinotti A., Yantorno O., Garcia M.A., Abraham A.G.: Kefiran films plasticized with sugars and polyols: water vapor barrier and mechanical properties in relation to their microstructure analyzed by ATR/FT-IR spectroscopy, Food Hydrocolloids 25, 1261$1269(2011)$

7. Papp J., Horgos J., Szente V., Zelkó R.: Correlation between the FT-IR characteristics and metoprolol tartrate release of methylcellulose-based patches, Int. J. Pharm. 392, 189-191 (2010)

8. Szabó B., Süvegh K., Zelkó R.: Effect of storage on microstructural changes of Carbopol polymers tracked by the combination of positron annihilation lifetime spectroscopy and FT-IR spectroscopy, Int. J. Pharm. 416, 160-163 (2011)

9. Szente V., Baska F., Zelkó R., Süvegh K.: Prediction of the drug release stability of different polymeric matrix tablets containing metronidazole, J. of Pharm.and Biomed. Anal. 54, 730-734 (2011)

10. Kitano H., Ichikawa K., Fukuda M., Mochizuki A., Tanaka.M.: The structure of water sorbed to polymethoxyethylacrylate film as examined by FT-IR Spectroscopy, J. of Coll. and Interface Science 242, 133-140 (2001)

11. Perez-Guaita D., Ventura-Gayete J., Pérez-Rambla C., Sancho-Andreu M., Garrigues S, De la Guardia M.: Evaluation of infrared spectroscopy as a screening tool for serum analysis: Impact of the nature of samples included in the calibration set, Microchem. J. 106, 202-211 (2013)

12. Lin S. Y., Yu H.L., Li M.J.: Formation of six-membered cyclic anhydrides by thermally induced intramolecular ester condensation in Eudragit E film, Polym. 40, 3589-3593 (1999)

13. Ferrarri C. P., Oliveira F.G., Chibebe S. C. F., Evangelista C. R.: In vitro characterization of coevaporates containing chitosan for colonic drug delivery, Carbohydr. Polym. 78, 557-563 (2009) 
14. Sovány T., Nikowitz K., Regdon G. Jr., Kása P. Jr., Pintye-Hódi K.: Raman spectroscopic investigation of film thickness, Polym. Test. 28, 770-772 (2009)

15. Nikowitz K., Kása P. Jr., Pintye-Hódi K., Regdon G. Jr.: Study of the preparation of a multiparticulate drug delivery system with a layering technique, Powder Techn. 205, 155-159 (2011)

16. Nikowitz K., Pintye-Hódi K., Regdon G. Jr.: Study of the recrystallization in coated pellets - Effect of coating on API crystallinity. Eur. J. Pharm. Sci. 48, 563-571 (2013)

17. Sansom L.N.: Oral extended-release products, Aust. Prescr. 22, 88-90 (1999)

18. Claxton A.J., Cramer J., Pierce C.: A systematic review of the associations between dose regimens and medication compliance, Clin. Ther. 23, 1296-1310 (2001)

19. Debunne A., Vervaet C., Remon J.P.: Development and in vitro evaluation of an entericcoated multiparticulate drug delivery system for the administration of piroxicam to dogs. Eur. J. Pharm. Biopharm. 54, 343-348 (2002)

20. http://www.pharmatutor.org/articles/film-coating-technology-over-view?page=0,1

21. Kovács L.: Vizes polimer diszperziók; Müszaki Könyvkiadó, Budapest, 1986

22. Bindschaedler C., Gurley R., Doelker E.: Theoritical concepts regarding the formation of films from aequeous microdispersions and application to coating, Labo-Pharma Probl. Techn. 31, 389-394 (1983)

23. Cole G., Hogen J.: Pharmaceutical coating technology, Taylor\&Francis Ltd., London, 1995

24. Buchholcz Gy., Erős I., Hódi K.: Gyógyszer-filmbevonó anyagok és eljárások, Fókuszban az Eudragit. Gyógyszerészet, 48, 651-658 (2004)

25. www.colorcon.com/product

26. Sharma V., Chopra H.: Role of taste and taste masking of bitter drugs In Pharmaceutical Industries An Overview, Int. J. Pharm. and Pharm. Sci. 2, 14-18 (2010)

27. Joshi S., Petereit H.U.: Film coatings for taste masking and moisture protection, Int. J. Pharm. 5, 395-406 (2013)

28. Do T.-A.L., Mitchell J.R., Wolf B., Vieira J.: Use of ethylcellulose polymers as stabilizer in fat-based food suspensions examined on the example of model reduced-fat chocolate, Reactive and Functional Polymers, 70, 856-862 (2010)

29. Tang E. S. K., Chan L.W., Heng P.W.S.: Coating of multiparticulates for sustained release, American Journal of Drug Delivery 3, 17-28 (2005)

30. Kondo K., Niwa T., Danjo K.: Preparation of sustained-release coated particles by novel microencapsulation method using three-fluid nozzle spray drying technique, Eur. J. Pharm. Sci. 51, 11-19 (2014)

31. Young-Hoon Y., Kab-Young K., Un-Kyu P.: Effects of two cellulose binders on the luminous properties of phosphor pastes, Ceramics International 38, 1599-1603 (2012)

32. Gravelle A. J., Davidovich-Pinhas M., Zetzl A.K., Barbut S., Marangoni A.G.: Influence of solvent quality on the mechanical strength of ethylcellulose oleogels, Carbohydr. Polym. $135,169-179$ (2016) 
33. Hamedelniel E. I., Bajdik J., Pintye-Hódi K.: Optimization of preparation of matrix pellets containing ethylcellulose. Chem. Eng. Process. 49, 120-124 (2010)

34. Mallipeddi R., Saripella K.K., Neau S.H.: Use of coarse ethylcellulose and PEO in beads produced by extrusion-spheronization, Int. J. Pharm. 385, 53-65 (2010)

35. Mallipeddi R., Saripella K.K., Neau S.H.: Use of fine particle ethylcellulose as the diluent in the production of pellets by extrusion-spheronization, Saudi Pharm. J. 22, 360-371 (2014)

36. Hamedelniel I. E., Bajdik J., Sovány T., Pintye-Hódi K.: Delayed release matrix pellet preparation containing an alkalizing pore-former agent, Chem. Eng. Res. Des. 89, 1006-1010 (2011)

37. Pearnchob N., Bodmeier R.: Coating of pellets with micronized ethylcellulose particles by a dry powder coating technique, Int. J. Pharm. 268, 1-11 (2003)

38. Sadeghi F., Ford J. L, Rajabi-Siahboomi A,: The influence of drug type on the release profiles from Surelease-coated pellets, Int. J. Pharm. 254, 123-135 (2003)

39. McConnell E. L., Short M. D., Basit A.W.: An in vivo comparison of intestinal $\mathrm{pH}$ and bacteria as physiological trigger mechanisms for colonic targeting in man., J. Control. Release $130,154-160(2008)$

40. Frohoff-Huélsmann M.A., Lippold B.C., McGinity J.W.: Aqueous ethyl cellulose dispersion containing plasticizers of different water solubility and hydroxypropyl methylcellulose as coating material for diffusion pellets. II: properties of sprayed films, Eur. J. Pharm. Biopharm. 48, 67-75 (1999)

41. Lecomte F., Siepmann J., Walther M., MacRae R.J., Bodmeier R.: Polymer blends used for the aqueous coating of solid dosage forms: importance of the type of plasticizer, $J$. Control. Releas. 99, 1-13 (2004)

42. Kangarlou S., Haririan I., Gholipour Y.: Physico-mechanical analysis of free ethyl cellulose films comprised with novel plasticizers of vitamin resources, Int. J. Pharm. 356, 153-166 (2008)

43. Lin S-Y., Chen K-S., Run-Chu L.: Organic esters of plasticizers affecting the water absorption, adhesive property, glass transition temperature and plasticizer permanence of Eudragit acrylic films, J. Controlled Release, 68, 343-350 (2000)

44. Felton L.A., McGinity J.W.: Influence of plasticizers on the adhesive properties of an acrylic resin copolymer to hydrophilic and hydrophobic tablet compacts, Int. J. Pharm. 154, 167-178 (1997)

45. Zelkó R., Orbán Á., Süvegh K., Riedl Z., Rácz I.: Effect of plasticizer on the dynamic surface tension and the free volume of Eudragit systems, Int. J. Pharm. 244, 81-86 (2002)

46. Jean Y.C.: Positron annihilation spectroscopy for chemical analysis: A novel probe for microstructural analysis of polymers, Microchem. J. 42, 72-102 (1990)

47. Sebe I., Szabó B., Zelkó R.: Bio-based pharmaceutical polymers, possibility of their chemical modification and applicability of modified polymers, Acta Pharm. Hung. 82, 138154 (2012)

48. Pethrick R. A.: Positron annihilation - A probe for nanoscale voids and free volume? Prog. in Polym. Sci. 22, 1-47 (1997) 
49. Gottnek M., Süvegh K., Pintye-Hódi K., Regdon G. Jr.: Effects of excipients on the tensile strength, surface properties and free volume of Klucel® free films of pharmaceutical importance, Rad. Phys. Chem. 89, 57-63 (2013)

50. Deb R., Abdul A.: Pellets and pelletisation techniques, Int. Res. J. Pharm. 4, 90-95 (2013)

51. Kleinebudde P.: Use of a power-consumption-controlled extruder in the development of pellet formulations., J. Pharm. Sci. 84, 1259-1264 (1995)

52. Bilgili E. Arastoopour H., Bernstein B.: Pulverization of rubber granulates using the solid-state shear extrusion (SSSE) process: Part I. Process concepts and characteristics, Powder Techn. 115, 265-276 (2001)

53. Even M.P., Bobbala S., Kooi K. L ., Hook S., Winter G ., Engert J.: Impact of implant composition of twin-screw extruded lipid implants on the release behavior, Int. J. Pharm. 493, $102-110(2015)$

54. Even M.P., Young K., Winter G., Hook S., Engert J.: In vivo investigation of twin-screw extruded lipid implants for vaccine delivery, Eur. J. Pharm. and Biopharm. 87, 338-346 (2014)

55. Colak B.Y., Peynichou P., Galland S., Oulahal N., Assezat G., Prochazka F., Degraeve P.: Active biodegradable sodium caseinate films manufactured by blown-film extrusion: Effect of thermo-mechanical processing parameters and formulation on lysozyme stability, Industrial Crops and Products 72, 142-151 (2015)

56. Herrera N., A. M. Salaberria, A. P. Mathew, Oksman K.: Plasticized polylactic acid nanocomposite films with cellulose and chitin nanocrystals prepared using extrusion and compression molding with two cooling rates: Effects on mechanical, thermal and optical properties, Composites Part A: Applied Sci. and Manufacturing 83, 89-97 (2016)

57. Hicks D.C., Freese H.L.: Extrusion and spheronizing equipment in: I. Ghebre- Sellassie (Ed.) Pharmaceutical Pelletization Technology, Marcel Dekker, New York, 1989 pp 71-84

58. Rowe R.C.: The characterization and quantification of the extrusion-spheronization process. Proc. $25^{\text {th }}$ Int. Colloq. Ind. Pharm. (1986)

59. Fielden K.E., Newton J.M., Rowe R.C.: A comparison of the extrusion and spheronization behaviour of wet powder masses processed by a ram extruder and a glinder extruder. Int. J. Pharm. 81, 225-233 (1992)

60. Hellen L., Yliruusi J., Palmroos P., Kristoffersen E.: Production capacity of the radial screen extruder, Eur. J. Pharm. Biopharm. 38, 485 (1992)

61. Kleinebudde P., Lindner H.: Experiments with an instrumented twin-screw extruder using a single-step granulation / extrusion process, Int. J. Pharm. 94, 49-58 (1993)

62. Mollan M.: Historical overview in: Pharmaceutical Extrusion Technology Marcel Dekker New York 2003.

63. Thiele W. Twin-screw extruder and screw design in: Pharmaceutical Extrusion Technology Marcel Dekker New York 2003.

64. Otsuka M., Gao J, Matsuda Y.: Effect of amount of added water during extrusionspheronization process on pharmaceutical properties of granules, Drug. Dev. Ind. Pharm. 20, 2977-2992 (1994) 
65. Newton J. M.: Extrusion/spheronization. In: D. Chulia, m- Deleuil, Y. Pourcelot, editors. Powder technology and pharmaceutical processes. Amsterdam: Elsevier; 1994

66. Noche C., Barochez B.H., Brossard C., Horvath S., Cuiné A.: Optimising the manufacturing process for contrilled release pellets, Pharm. Techn. Eur. 4, 39-46 (1994)

67. Thommes M., Kleinebudde P.: Use of K-carrageenan as alternative pelletisation aid to microcrystalline cellulose in extrusion/spheronisation. I. Influence of type and fraction filler, Eur. J. Pharm. Biopharm. 63, 59-67 (2006)

68. Lau C.L.S., Yu Q., Lister V.Y., Rough S.L., Wilson D.I., Zhang M.: The evolution of pellet size and shape during spheronisation of an extruded microcrystalline cellulose paste, Chem. Eng. Res. Des. 92, 2413-2424 (2014)

69. Sonaglio D., Bataille B., Ortigosa C., Jacob M.: Factorial design in the feasibility of producing Microcel MC 101 pellets by extrusion/spheronization, Int. J. Pharm. 115, 53-60 (1995)

70. Chatlapalli R., Rohera B. D.: Physical characterization of HPMC and HEC and investigation of their use as pelletization aids, Int. J. Pharm. 161, 179-193 (1998)

71. Ethocel Standard Premium ${ }^{\circledR}$ Application Data, Colorcon Ltd. Dartford, England

72. Bajdik J., Regdon G. jr., Marek T., Erős I., Süvegh K., Pintye-Hódi K.: The effect of the solvent on the film-forming parameters of hydroxypropyl-cellulose, Int J Pharm. 301, 192-198 (2005)

73. Bajdik J., Makai Z., Berkesi O., Süvegh K., Marek T., Erős I., Pintye-Hódi K.: Study of the effect of lactose on the structure of sodium alginate films, Carbohydr. Polym. 77, 530-535 (2009)

74. Bölcskei É., Süvegh K., Marek T., Regdon G. Jr., Pintye-Hódi K.:Testing of the structure of macromolecular polymer films containing solid active pharmaceutical ingredient (API) particles, Rad. Phys Chem. 80, 799-802. (2011)

75. Eldrup M., Lightbody D., Sherwood J.N.: The temperature dependence of positron lifetimes in solid pivalic acid, Chem. Phys. 63, 51-58 (1981)

76. Aygen, B., Kucuksu, M., Aydin, S., Ozercan, I.H.: Effect of enalapril-maleate on ghrelin levels in metabolic syndrome in rats, Peptides 67, 39-44 (2015)

77. Cespi M., Bonacucina G., Misici-Falzi M., Golzi R., Boltri L., Palmieri G.F.: Stress relaxation test for the characterization of the viscoelasticity of pellets, J. of Pharm. Biopharm. 67, 476-484 (2007)

78. Dash S., Murthy N. P., Nath L., Chowdhury P.: Kinetic modeling on drug release from controlled drug delivery systems, Acta Poloniae Pharmaceutica in Drug Res. 67, 217-223 (2010)

79. Korbely A, Kelemen A, Kasa P Jr, Pintye-Hodi K.: Effects of Processing on the Release Profiles of Matrix Systems Containing 5-Aminosalicylic Acid. AAPS Pharmscitech. 13, 1341-1347 (2012)

80. Buchholcz Gy., Kelemen A., Pintye-Hódi K: Modified-release capsules containing sodium riboflavin 5'-phosphate, Pharm. Dev. Techn. 20, 676-683 (2015) 


\section{AKNOWLEDGEMENT}

Firstly, I sincerelly thank my supervisor Dr. Géza Regdon Jr. for his endless patience, encouragement, and for letting me shape my research along the way. His keen eyes for details have contributed immensely to the quality of all my work.

My warmest gratitude goes to Prof. Dr. Klára Pintye-Hódi for her guidance, invaluable advice, encouragements discussion and for always keeping me on my toes. Her being there was an inspiration for me to pull through.

I take this opportunity to express my appreciation to Prof. Dr. Piroska Szabó-Révész, who granted me the opportunity to do research in the Department of Pharmaceutical Technology.

My warmest thank to Richter Gedeon Ltd., and Dr. Attila Bódis, to the financial support of my experiments in Szeged and in Düsseldorf.

I express my grateful thank to Professor Peter Kleinebudde and Dr. Markus Thommes, for providing me with possibility to work in their Institute.

My warmest thank to Dr. Tamás Sovány for his good advice, criticism and numerous discussion during my work.

My warmest thank to Dr. András Kelemen and Dr. Péter Kása Jr., for their good advice and help.

I express my kindest thanks to all my co-authors for their collaboration in this work.

I thank all members of the department for their help and friendship.

I owe my thanks to my family and my friends for their support and understanding attitude during these years. 


\section{ANNEX \\ Related articles}


I. 


\title{
Thermal study of ethyl cellulose coating films used for modified release (MR) dosage forms
}

\author{
Géza Regdon Jr. • Diána Hegyesi · Klára Pintye-Hódi
}

Received: 4 July 2011/Accepted: 12 September 2011/Published online: 23 September 2011

(C) Akadémiai Kiadó, Budapest, Hungary 2011

\begin{abstract}
The aim of our research was to investigate the effect of the length of the polymer chain and the concentration of triethyl citrate used as a plasticizer on the thermal stability of the film structure in the case of two ethyl cellulose films (EC 10 and EC 45) used for preparing MR dosage forms. The influence of storage time was studied by monitoring the changes in the thermoanalytical parameters and by performing TG-MS examinations. It was found that the decomposition of the plasticizer from the arising film structure is retarded and a more homogeneous sample, therefore a better film can be prepared from EC 45. Mass spectrography performed as a coupled technique also proved that the films stayed stable until approximately $200{ }^{\circ} \mathrm{C}$. Based on the above results, the composition prepared from EC 45 polymer with $5 \%$ triethyl citrate as plasticizer is recommended for making MR dosage forms.
\end{abstract}

Keywords Ethyl cellulose - Triethyl citrate - Free films · Physical-chemical investigations - MFT .

Glass transition temperature $\cdot$ DSC $\cdot$ TG-MS

\section{Introduction}

With the continuous development of biopharmacy and technology, the possibility arose to make controlled-release oral-modified release systems and thus to control the rate, place, or duration of drug release. Accordingly, modified,

G. Regdon Jr. $(\varangle) \cdot$ D. Hegyesi · K. Pintye-Hódi

Department of Pharmaceutical Technology,

University of Szeged, Eötvös utca 6, 6720 Szeged, Hungary

e-mail: geza.regdon@pharm.u-szeged.hu sustained, retarded, and periodic drug release can be achieved, and one possible way to realize this is to use a properly formed coat ( $\mathrm{pH}$-dependent dissolution, diffusion film, etc.). These solutions require film coats to meet higher expectations [1].

For this reason, it is indispensable to study the physicochemical and thermal behaviour of free films as part of the preformulation studies for developing a film coat composition, which is particularly important for the investigation of the stability of the preparations. Thermoanalysis is a very well used method in the preformulation tests of solid dosage forms [2-7].

There are some publications in literature on the thermoanalytical examination of free films or film-coated preparations, e.g. on the study of Eudragit containing polymethacrylate films [8-11], chitosan films [12], gelatin and poly(vinyl alcohol) containing films [13], biodegradable films [14-16] or cellulose-based films [9, 10, 17-19].

From amongst cellulose derivatives, EC is an ideal polymer for coating modified release (MR) preparations, yet few authors have studied its thermal properties in spite of the fact that more up-to-date preparations to be administered once/twice a day are of outstanding importance in choosing the therapy for reasons of patient compliance.

The aim of our experiments was to perform the preformulation tests of two EC film forming polymers with different chain lengths and different molecular weights (Ethocel Standard Premium $10^{\circledR}$, Ethocel Standard Premium $45^{\circledR}$, Colorcon Ltd.), and to study the thermal properties of the free films made from them. As polymer does not dissolve in water only in an organic solvent, $96 \%$ alcohol was used as a solvent. Polymers are best characterized by the viscosity of their solutions, the viscosity of Ethocel Standard Premium $10^{\circledR}$ and Ethocel Standard Premium $45^{\circledR}$ is $9-11$ and $41-49 \mathrm{cP}$, respectively. 
Viscosities are for $5 \%$ solutions measured at $25{ }^{\circ} \mathrm{C}$ in an Ubbelohde viscosimeter, and the solvent is $80 \%$ toluene and $20 \%$ alcohol [20]. We studied the effect of the length of the polymer molecule and the plasticizer used on important thermal properties such as, e.g. glass transition temperature, mass loss due to decomposition or thermal stability.

The polymer film has to form a uniform and continuous coat on the surface of the core to be coated; therefore, it has to have proper elasticity. In most of the cases films prepared only from a film forming polymer are rigid and break easily, so the use of plasticizers is indispensable to increase the elasticity of the coat. The quantity and quality of plasticizers can be checked with various physical-chemical investigations.

It is especially important to know the effect of the concentration of the plasticizer on the properties of the film structure, e.g. minimal film forming temperature (MFT), $\operatorname{Tg}$ [21] and the influence of storage time on the physicalchemical properties so that the polymer film can form an intact, properly elastic and uniform coat on the surface of the core. Plasticizers have to be used to ensure the proper elasticity of the coating. Plasticizers reduce the rigidity of the film. The molecules of the plasticizer are built in amongst the polymer chains, thereby preventing their interaction. Therefore, the polymer chains may shift along each other and the elasticity of the polymer film will increase.

With the examination of free films, we aimed to investigate the effect exerted not only by the chain length of the film forming polymer used and by the viscosity of its solution but also by the concentration of the plasticizer used on the thermal properties of the arising film structure to find the composition necessary for making films with optimal physical-chemical properties.

\section{Materials}

Ethyl cellulose is a water insoluble cellulose ether which is prepared from cellulose, it is a partly $O$-ethylated cellulose, its ethoxy content (-OC2H5) is between 44 and $51 \%$. Two different products of Colorcon Ltd. were used for the experiments, namely, EC labelled Ethocel Standard Premium $10^{\circledR}$ and Ethocel Standard Premium $45^{\circledR}$ (Colorcon Ltd, Dartford, England), which differed in the viscosity of their solutions and also in the length of the polymer chains. As polymer does not dissolve in water only in an organic solvent, 96\% alcohol was used as a solvent.

Plasticizers have the capacity to alter the physical properties of a polymer film. Triethyl citrate, which was used as a plasticizer ( $\mathrm{Ph}$. Eur.), is the ethyl ester of citric acid, and it belongs in the group of organic esters.

\section{Methods}

Investigation of solutions

For the experiments, alcoholic solutions with $10 \%$ polymer content were prepared without plasticizer and with 1-3-5\% triethyl citrate concentration. An MFT bar apparatus (Rhopoint Instrumentation Ltd.) was applied to determine the MFT and the film forming time of a $75-\mu \mathrm{m}$ thick layer of solution at different temperatures. We had already worked out a method for determining film formation time earlier [19]. Six parallel measurements were performed.

Preparation of free films

The solutions were sprayed on glass and Teflon surfaces placed in a rotating vessel, the conditions of spraying are presented in Table 1 . The temperature of the drying air was set according to the MFT values presented in Table 2. During spraying, we continuously checked the temperature of the drying air, which was controlled with a laser temperature controller. The properties of the prepared free films were determined after preparation (fresh) and also after 2 and 4 weeks of storage $\left(40{ }^{\circ} \mathrm{C} / 50 \mathrm{RH} \%\right)$ to monitor changes.

\section{Thermoanalytical measurements}

The thermoanalytical examinations of the materials were carried out with a Mettler Toledo DSC 821e and TG/DSC1 instrument. During the DSC measurements, the start temperature was $-40{ }^{\circ} \mathrm{C}$, the end temperature was $300{ }^{\circ} \mathrm{C}$ and the applied heating rate was $10^{\circ} \mathrm{C} \mathrm{min}^{-1}$. Argon atmosphere was used, and nitrogen was used as drying gas. $10 \pm 1 \mathrm{mg}$ of sample was measured into aluminium pans (40 $\mu \mathrm{l})$. The data were calculated from the average of three parallel measurements and were evaluated with STARe Software.

For the TG measurements, the start temperature was $+25^{\circ} \mathrm{C}$, the end temperature was $400{ }^{\circ} \mathrm{C}$, and the applied heating rate was $10{ }^{\circ} \mathrm{C} \mathrm{min}{ }^{-1}$. Nitrogen atmosphere was used. $10 \pm 1 \mathrm{mg}$ of sample was measured into aluminium pans $(100 \mu \mathrm{l})$. The data were calculated from the average

Table 1 Parameters of the preparation of free films

\begin{tabular}{ll}
\hline Parameter & Value \\
\hline Rotation rate of vessel & $22 / \mathrm{min}$ \\
Rate of liquid feeding & $5 \mathrm{ml} / \mathrm{min}$ \\
Pressure of spraying air & $1.5 \mathrm{bar}$ \\
Diameter of nozzle & $0.8 \mathrm{~mm}$ \\
Temperature of drying air & According to MFT
\end{tabular}


Table 2 MFT values of EC 10 and EC 45 films

\begin{tabular}{llllrl}
\hline & & \multicolumn{2}{l}{ Concentration of plasticizers } \\
\cline { 3 - 6 } & & $0 \%$ & $1 \%$ & $3 \%$ & $5 \%$ \\
\hline EC 10 films & MFT $\left({ }^{\circ} \mathrm{C}\right)$ & 26.1 & 20.7 & 20.3 & 17.7 \\
EC 45 films & MFT $\left({ }^{\circ} \mathrm{C}\right)$ & 24.4 & 13.1 & 16.8 & 18.8 \\
\hline
\end{tabular}

of three parallel measurements and were evaluated with STARe Software.

Mass spectrometric examinations

The stability examination of the films was supplemented with gas analysis. The TG instrument was coupled to a Thermo Star (Pfeiffer) quadruple mass spectrometer (maximum $500 \mathrm{amu}$ ) for gas analysis. The measurements were carried out in nitrogen atmosphere. Ions with various mass numbers were determined with the SEM MID measurement module of the Quadera software. The obtained results were exported and then plotted in one coordinate system with the TG curves using the Mettler Toledo Star software.

\section{Results and discussion}

Before the preparation of free films, the minimum film forming temperature of EC films of various compositions were determined (see Table 2), so that the temperature of the drying air during spraying could be set accordingly. After the evaluation of the data shown in the table, it was found that the use of plasticizer decreased the value of the MFT in each case. The increase of triethyl citrate concentration decreased the MFT value proportionally to concentration in the case of EC 10 films and according to the minimum curve in the case of EC 45 films. The possible physical-chemical structural changes in the background of this phenomenon were already reported in another article [22].

The condition of the formation of a proper film structure is to know the glass transition temperature of the film forming polymer, which was determined with a DSC instrument. Both the structure and the glass transition temperature of the film are influenced greatly by the properties and concentration of the plasticizers used, therefore their role was studied.

The DSC curves of EC 10 fresh films containing various quantities of triethyl citrate are shown in Fig. 1. The glass transitions are indicated on the curve, and it is clear that the $\mathrm{Tg}$ value decreases with the increase of the plasticizer concentration.

The numerical data of glass transition are summarized in Table 3 . The data clearly reveal that the $T g$ value in fresh films is not yet decreased by $1 \%$ of plasticizer but is definitely decreased by 3 and $5 \%$ of plasticizer.

Table 3 Changes in the $T g$ values of EC 10 fresh films as a function of plasticizer concentration

\begin{tabular}{lllll}
\hline & \multicolumn{4}{l}{ Triethyl citrate concentration } \\
\cline { 2 - 5 } & $0 \%$ & $1 \%$ & $3 \%$ & $5 \%$ \\
\hline Glass transition temperature & 126.4 & 126.9 & 118.6 & 105.1 \\
$(T g) /{ }^{\circ} \mathrm{C}(\mathrm{SD})$ & $( \pm 2.22)$ & $( \pm 2.74)$ & $( \pm 7.89)$ & $( \pm 8.95)$ \\
\hline
\end{tabular}

Fig. 1 DSC curves of EC 10 fresh films

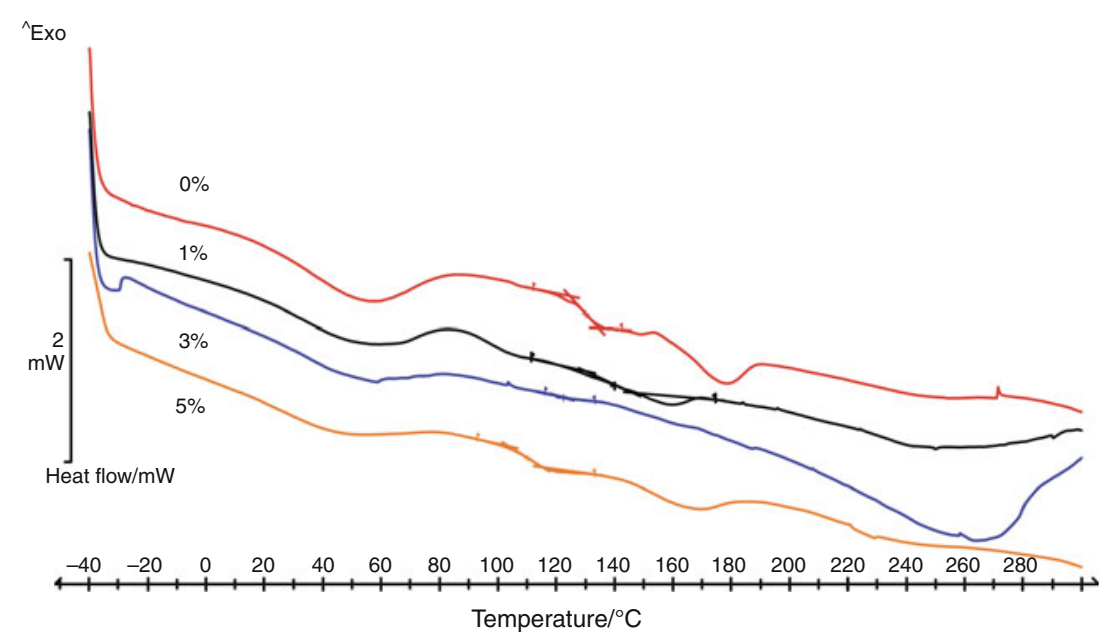


Fig. 2 DSC curves of EC 45 fresh films

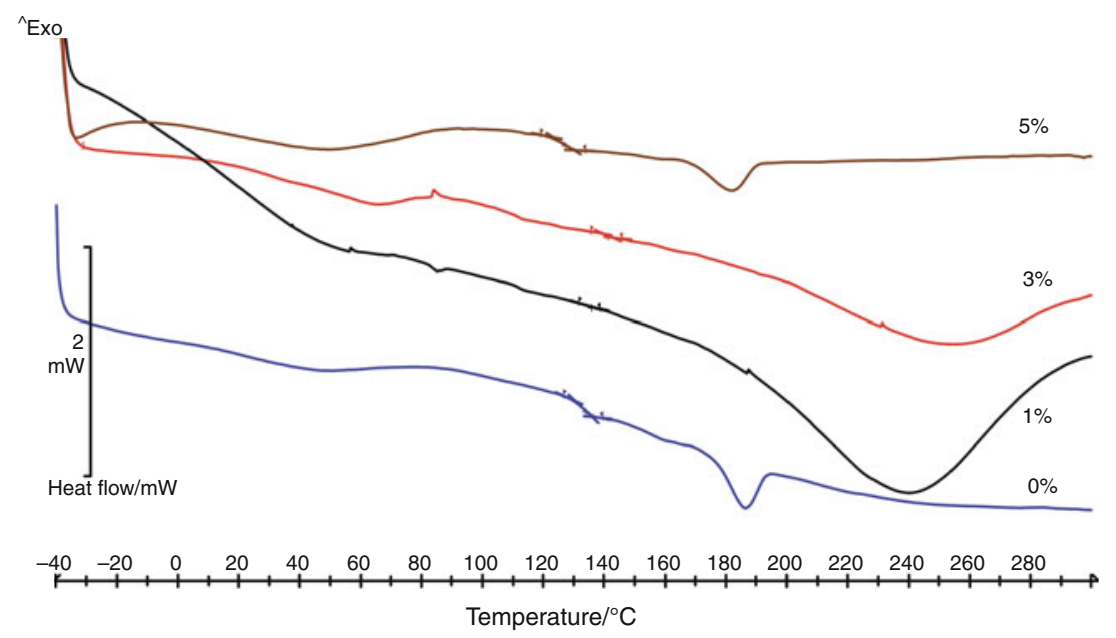

Table 4 Changes in the $T g$ values of EC 45 fresh films as a function of plasticizer concentration

\begin{tabular}{lllll}
\hline & \multicolumn{4}{l}{ Triethyl citrate concentration } \\
\cline { 2 - 5 } & $0 \%$ & $1 \%$ & $3 \%$ & $5 \%$ \\
\hline Glass transition & 133.4 & 135.9 & 141.5 & 128.7 \\
temperature $(\mathrm{Tg}) /{ }^{\circ} \mathrm{C}$ & $( \pm 0.56)$ & $( \pm 0.23)$ & $( \pm 0.43)$ & $( \pm 0.91)$ \\
$(\mathrm{SD})$ & & & & \\
\hline
\end{tabular}

Figure 2 shows the DSC curves of EC 45 fresh films containing various quantities of triethyl citrate. The numerical data of glass transition are summarized in Table 4. It is clear from the data that the $T g$ value in fresh films is increased by $3 \%$ plasticizer, but is decreased by $5 \%$ of plasticizer in the case of EC 45 films, which is again due to structural changes.

The comparison of the glass transition temperature values of the two film forming polymers shows that the glass transition temperature of films prepared from the shorter-chain EC 10 polymer is slightly lower than for longer-chain EC 45 films. The reason for this is that in the "looser" structure transition can take place at a lower temperature than in the "more compact" structure formed by longer-chain polymers. The numerical data also show that in fresh films containing plasticizer the $T g$ value could
Table 6 Mass change of EC 10 and EC 45 films as a function of plasticizer concentration

\begin{tabular}{lllrll}
\hline & & \multicolumn{4}{c}{ Triethyl citrate concentration } \\
\cline { 3 - 6 } & & $0 \%$ & $1 \%$ & \multicolumn{1}{c}{$3 \%$} & $5 \%$ \\
\hline Mass decrease/\% & EC 10 films & 1.12 & 8.94 & 21.23 & 30.16 \\
& EC 45 films & 1.22 & 10.56 & 20.48 & 31.70 \\
\hline
\end{tabular}

Table 7 Mass change of EC 10 and EC 45 films as a function of plasticizer concentration after 4 weeks of storage

\begin{tabular}{lllrll}
\hline & & \multicolumn{4}{c}{ Triethyl citrate concentration } \\
\cline { 3 - 6 } & & $0 \%$ & $1 \%$ & $3 \%$ & $5 \%$ \\
\hline Mass decrease/\% & EC 10 films & 2.59 & 1.16 & 21.00 & 27.03 \\
& EC 45 films & 0.53 & 11.51 & 20.25 & 28.14 \\
\hline
\end{tabular}

be decreased by $3 \%$ plasticizer in the case of "looser" EC 10 films prepared from shorter-chain polymers, whilst $5 \%$ plasticizer was needed for "stronger" EC 45 films made from longer-chain polymers.

We also investigated whether the glass transition temperature, which is the most typical feature of the film structure, changed as a function of storage time for the free films we prepared.

Table 5 Changes in the $T g$ values of EC 10 and EC 45 films as a function of storage time

\begin{tabular}{|c|c|c|c|c|}
\hline & \multirow{3}{*}{$\begin{array}{l}\text { Triethyl citrate } \\
\text { concentration }\end{array}$} & \multicolumn{3}{|l|}{$\mathrm{Tg} /{ }^{\circ} \mathrm{C}$} \\
\hline & & \multicolumn{3}{|l|}{ Storage time } \\
\hline & & Fresh & 2 weeks & 4 weeks \\
\hline \multirow[t]{2}{*}{ EC 10 films } & $0 \%$ (SD) & $121.9( \pm 6.4)$ & $126.9( \pm 1.58)$ & $107.1( \pm 2.08)$ \\
\hline & $5 \%(\mathrm{SD})$ & $108.3( \pm 7.11)$ & $104.2( \pm 6.16)$ & $101.1( \pm 11.1)$ \\
\hline \multirow[t]{2}{*}{ EC 45 films } & $0 \%(\mathrm{SD})$ & $131.9( \pm 1.16)$ & $135.7( \pm 4.85)$ & $132.7( \pm 1.47)$ \\
\hline & $5 \%(\mathrm{SD})$ & $127.5( \pm 0.74)$ & $127.9( \pm 2.16)$ & $128.5( \pm 0.16)$ \\
\hline
\end{tabular}


Fig. 3 TG Curves of EC 10 and EC 45 films containing 5\% triethyl citrate and their MS evaluation

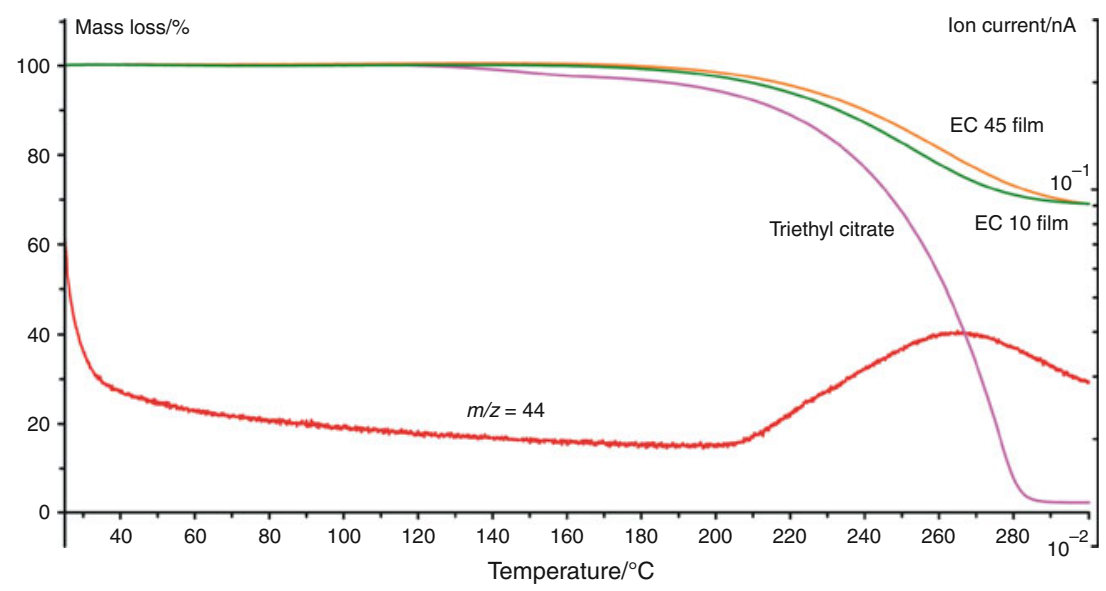

The time course of the glass transition values is presented for the films without plasticizer and with the highest concentration in the case of both film forming polymers (see Table 5). The data show that EC 10 films underwent greater change during storage and they were less stable than EC 45 films, so EC 10 films are less suitable for forming MR dosage forms.

The thermal stability values of the fresh films were examined, and the results are summarized in Table 6. The analysis of the TG curves (Fig. 3) revealed that the two different film forming polymers are thermally stable, a mass decrease of only 0.5 and $1.2 \%$ could be detected until 100 and $300{ }^{\circ} \mathrm{C}$, respectively. The decomposition process starts only later and a mass loss of about $10-20-30 \%$ can be detected, depending on the concentration of the plasticizer. There is practically no difference between the thermal stabilities of the two polymers, so mass change depends only on the plasticizer concentration.

The thermal behaviour of triethyl citrate and of films containing 5\% plasticizer is shown in Fig. 3. The TG curves show that the decomposition of triethyl citrate starts as early as over $120^{\circ} \mathrm{C}$ and becomes more intensive over $200{ }^{\circ} \mathrm{C}$, and the material is fully decomposed before reaching $300{ }^{\circ} \mathrm{C}$. The shape of the curves is a proof for triethyl citrate probably being built in the structure of the EC film, because its decomposition from the film starts only later, at about $180-200{ }^{\circ} \mathrm{C}$.

Similarly, the results of the MS examinations are shown in Fig. 3, based on the analysis of the gases which evolve from the EC 10 film. Carbon dioxide gas $(\mathrm{m} / \mathrm{z}=44)$ starts to evolve at $200{ }^{\circ} \mathrm{C}$ and reaches its highest concentration at $260-270{ }^{\circ} \mathrm{C}$.

The films were also examined after 4 weeks of storage (see Table 7), and the results were practically the same as those for the fresh film. The only exception was the EC 10 film containing $1 \%$ plasticizer, which is probably due to the inhomogeneity of the sample.
As a summary of the thermal investigations, it can be stated that the decomposition of the plasticizer from the arising film structure is retarded, and the polymer molecule itself stays stable until $300{ }^{\circ} \mathrm{C}$. A more homogeneous sample, therefore a better film can be prepared from EC 45 , but mass change depends basically on the material quality of the plasticizer. Mass spectrography performed as a coupled technique also proved that the films stayed stable until approximately $200^{\circ} \mathrm{C}$.

\section{Conclusions}

It was found that the glass transition temperature of films prepared from the shorter-chain EC 10 polymer with a "looser" structure is slightly lower than for longer-chain, more "compact" EC 45 films. In fresh films containing plasticizer, the $T g$ value could be decreased by $3 \%$ plasticizer in the case of "looser" EC 10 films prepared from shorter-chain polymers, while 5\% plasticizer was needed for "stronger" EC 45 films made from longer-chain polymers. EC 45 films were more stable during storage. The thermal stabilities of the two polymers are approximately the same.

The thermal investigations revealed that the decomposition of the plasticizer from the arising film structure is retarded. A more homogeneous sample, therefore a film of better quality (pore-free, properly elastic) can be prepared from EC 45. Mass spectrography performed as a coupled technique also proved that the films stayed stable until approximately $200{ }^{\circ} \mathrm{C}$. Based on the above results, the composition prepared from EC 45 polymer with $5 \%$ triethyl citrate as plasticizer is recommended for making MR coats.

Acknowledgements This study was supported by TÁMOP-4.2.1/ B-09/1/KONV-2010-0005 (Hungary). 


\section{References}

1. Bertelsen P, Christensen FN, Holm P, Jorgensen K. Comparison of organic solvent-based ethylcellulose coatings of $\mathrm{KCl}$ crystals applied by top and bottom spraying in fluidized-bed equipment. Int J Pharm. 1994;111:117-25.

2. Beretzky Á, Kása P Jr, Pintye-Hódi K, Bajdik J, Szabó-Révész P, Erös I. Pelletization of needle-shaped phenylbutazone crystals. J Therm Anal Calorim. 2002;69:529-39.

3. Zelkó R, Orbán Á, Nagy J, Csóka G, Rácz I. Coating polymerplasticizer interaction in relation to the enthalpy relaxation of polymer. J Therm Anal Calorim. 2002;68:531-7.

4. Aigner Z, Szepesi E, Berkó S, Novák C, Regdon G Jr, Kata M. Investigation of ethacrynic acid and random-methyl- $\beta$-cyclodextrin binary complexes. J Incl Phenom Macro. 2002;42:219-26.

5. Kiekens F, Zelkó R, Remon JP. Effect of the storage conditions on the tensile strength of tablets in relation to the enthalpy relaxation of the binder. Pharm Res. 2000;17:490-3.

6. Peres-Filho MJ, Gaeti MPN, Oliveira SR, Marreto RN, Lima EM. Thermoanalytical investigation of olanzapine compatibility with excipients used in solid oral dosage forms. J Therm Anal Calorim. 2011;104:255-60.

7. Bhattacharjya $S$, Wurster DE. Investigation of the drug release and surface morphological properties of film-coated pellets, and physical, thermal and mechanical properties of free films as a function of various curing conditions. AAPS Pharm Sci Tech. 2008;9:449-57.

8. Melo EJ, Alves BRV, Freitas AA, Muniz EC, Cavalcanti OA. Influence of the addition of alpha or gamma-cyclodextrin on the formation of free films in the polymethacrylates eudragit (R) FS30D. Latin Am J Pharm. 2010;29:919-26.

9. Bley O, Siepmann I, Bodmeier R. Characterization of moistureprotective polymer coatings using differential scanning calorimetry and dynamic vapor sorption. J Pharm Sci. 2009;98:651-64.

10. Regdon G Jr, Kósa A, Erős I, Pintye-Hódi K. Study of thermoanalytical behaviour of some coating films. J Therm Anal and Calorim. 2007;89:793-7.

11. Bajdik J, Pintye-Hódi K, Regdon G Jr, Fazekas P, Szabó-Révész $\mathrm{P}$, Erős I. The effect of storage on the behaviour of Eudragit NE free film. J Therm Anal Calorim. 2003;73:607-13.
12. Zen-aldeen EA, Hussein AK, Ibrahim MA, Amin MA. Physicomechanical properties and release characteristics of ketorolac tromethamine from chitosan films: effect of inclusion of different polyols plasticizers. Bull Pharm Sci. 2008;31:229-47.

13. Mendieta-Taboada O, Sobral PJD, Carvalho RA, Habitante AMBQ. Thermomechanical properties of biodegradable films based on blends of gelatin and poly(vinyl alcohol). Food Hydrocolloids. 2008;22:1485-92.

14. Langmaier F, Mokrejs P, Mladek M. Heat-treated biodegradable films and foils of collagen hydrolysate crosslinked with dialdehyde starch. J Therm Anal Calorim. 2010;102:37-42.

15. Nunes PS, Bezerra MS, Costa LP, Cardoso JC, Albuquerque RLC Jr, Rodrigues MO, Barin GB, Amaral da Silva F, Araújo AAS. Thermal characterization of usnic acid/collagen-based films. J Therm Anal Calorim. 2010;99:1011-4.

16. Mokrejs P, Langmaier F, Janacova M, Mladek M, Kolomaznik K, Vasek V. Thermal study and solubility tests of films based on amaranth flour starch-protein hydrolysate. J Therm Anal Calorim. 2009;98:299-307.

17. Sahin NO, Arslan H. Formulation study for enteric microspheres of tenoxicam using cellulose acetate phthalate part-II: modulation of ulcerogenic effect. Asian J Chem. 2007;19:5718-26.

18. Regdon G Jr, Zsellér B, Pintye-Hódi K. Physical-chemical investigations of Metolose coating films. Composite Interfaces. 2010;17:581-94.

19. Bajdik J, Regdon G Jr, Marek T, Erős I, Süvegh K, Pintye-Hódi $\mathrm{K}$. The effect of the solvent on the film-forming parameters of hydroxypropyl-cellulose. Int J Pharm. 2005;301:192-8.

20. Ethocel Standard Premium ${ }^{\circledR}$ Application Data, Colorcon Ltd. Dartford, England.

21. Bley O, Siepmann J, Bodmeier R. Importance of glassy-to-rubbery state transitions in moisture-protective polymer coatings. Eur J Pharm Biopharm. 2009;73:146-53.

22. Marek T, Süvegh K, Kéry I, Zelkó R, Regdon G Jr, Pintye-Hódi $\mathrm{K}$, Vértes A. The effect of plasticizer on the ageing of Metolose films. Rad Phys Chem. 2007;76:165-8. 
II. 


\title{
Study of the effect of plasticizer on the structure and surface characteristics of ethylcellulose free films with FT-IR spectroscopy
}

\author{
Diána Hegyesi a , Tamás Sovány ${ }^{\text {a }}$, Ottó Berkesi ${ }^{\text {b }}$, Klára Pintye-Hódi a , Géza Regdon Jr. a,* \\ a University of Szeged, Department of Pharmaceutical Technology, Eötvös u. 6., H-6720, Szeged, Hungary \\ b University of Szeged, Department of Physical Chemistry and Materials Science, Aradi Vértanúk tere 1., H-6720, Szeged, Hungary
}

\section{A R T I C L E I N F O}

Article history:

Received 25 January 2013

Accepted 9 February 2013

Available online 16 February 2013

\section{Keywords}

Free films

Ethylcellulose

Preformulation study

Plasticizer

Contact wetting angle

FT-IR

\begin{abstract}
A B S T R A C T
The investigation of free films is an essential part of the preformulation studies, because it is necessary to know, weather the given formulation is suitable to coat the corpus or not. As preformulation, the relationships between surface properties, and the structure of ethylcellulose free films containing different amount of plasticizer were studied. The structure analysis, and the incorporation of the plasticizer was performed with the use of FT-IR analysis. The results showed that the films are suitable to produce diffusion coatings.
\end{abstract}

(c) 2013 Elsevier B.V. All rights reserved.

\section{Introduction}

Ethylcellulose is suitable to prepare modified release (MR) coatings. It has a great significance in the therapy, where the patient compliance could be considerably improved with the use of preparations administered once/twice daily [1]. The improvements of the effectiveness of the therapy and the increasing of patient compliance have an increasing importance in the last decades. This necessitates to control the rate, place, or duration of drug release. One of the many possibilities is the use of coated dosage forms, however to achieve the required effect ( $\mathrm{pH}$-dependent dissolution, diffusion film, etc.) is necessary to use a properly formed coat. These solutions require film coats to meet higher expectations.

The polymer film has to form a uniform and continuous coat on the surface of the core to be coated; which is properly based on the properties of the polymer. However, the special requirements, or the achievement of the best performance or the need to decrease the costs often necessitates the modification of the basic properties of films. Most of the properties such as the minimal film forming temperature, the surface characteristics and the mechanical properties can be modified with the use of different plasticizers [2-5]. These molecules are built in amongst the polymer chains, thereby preventing their interaction. Therefore, the polymer chains may shift along each other and the

\footnotetext{
* Corresponding author. Tel.: + 36 62545576; fax: + 3662545571 .

E-mail address: geza.regdon@pharm.u-szeged.hu (G. Regdon).
}

elasticity will increase which will reduce the rigidity of the film. Moreover, the functional groups of the plasticizer and the interactions between the materials will affect the surface characteristics and adhesive properties of the films [5,6]. So it is essential to know the effect of the concentration of the plasticizer on the properties of the film structure, which is particularly important for the investigation of the composition and process parameters of the preparations, in particular, because of the difference of the plasticizer uptake in different systems $[7,8]$. There are several methods for the prediction of the polymer-plasticizer interactions [9], but the real microstructure and the incorporated amount of the plasticizer could be studied with the use of Fourier transform infrared (FT-IR) spectroscopy [10-16].

The aim of our research was to investigate the effect of the length of the polymer chain and the concentration of triethyl citrate used as a plasticizer on the thermal stability of the film structure in the case of two ethylcellulose films (EC10 and EC45) used for preparing MR dosage forms.

\section{Materials and methods}

\subsection{Materials}

Two grades of ethylcellulose (Ethocel standard premium 10 and Ethocel standard premium 45, Colorcon, UK) were used. The polymers were dissolved in $96 \%$ ethanol (Merck, Hungary). The films were plasticized with triethyl citrate (Ph. Eur.). 


\subsection{Preparation}

$10 \%$ alcoholic solution of the ethylcellulose polymers were mixed with magnetic stirrer for $1 \mathrm{~h}$ without plasticizer and after the addition of 1,3 or $5 \%$ of triethyl citrate, respectively. The solutions were sprayed onto Teflon and glass surfaces in a conventional coating pan. The temperature of the drying air was set in accordance to the minimal film forming temperature (MFT) of the films (Table 1). The process parameters of the spraying are given in Table 2.

\subsection{Minimal film forming temperature}

For the experiments alcoholic solutions with $10 \%$ polymer content were prepared without plasticizer and with 1-3-5\% triethyl citrate concentration. An MFT bar apparatus (Rhopoint Instrumentation Ltd.) was applied to determine the MFT and the film forming time of a $75 \mu \mathrm{m}$-thick layer of solution at different temperatures. The results were calculated as an average of six parallel measurements.

\subsection{Measurement of the contact wetting angle}

Contact wetting angle was examined with a Dataphysics OCA-20 equipment, it was determined by means of drop contour analysis. The SCA-20 software belonging to the equipment can be used for calculating the surface/interfacial tension $(\gamma)$ and the surface free energy of solid materials according to Wu's theory, which gives the dispersion and polar components of surface free energy, too. Contact wetting angle was determined in fresh films and in films after storage with sessile drop method. The liquids used for contact-angle measurements were water and diiodomethane/methylene iodide.

\subsection{Measurement with FT-IR spectroscopy}

A Bio-Rad Digilab Division FTS65A/896 FT-IR Spectrometer with a Harrick's Meridian $^{\mathrm{TM}}$ SplitPea Single Reflection Diamond ATR Accessory was used to record the spectra. The measurements were performed in the range of $4000-400 \mathrm{~cm}^{-1}$ at $4 \mathrm{~cm}^{-1}$ optical resolution and 256 scans were taken to achieve good signal to noise ratio. Three spectra were averaged for each composition, measured at three different places of the same film.

\section{Results and discussion}

The results showed that there are considerable differences in the behaviour according to the chain length of the applied polymers. For example the film integrity and the mechanical properties significantly improve with the increasing chain length. However, longer chains resulted in higher lipophilicity, probably due to the relatively increased proportion of the ethyl ether groups. The incorporation of triethyl citrate into the structure will affect not only the mechanical and thermal properties but also the surface characteristics of films (Table 3 ).

The results of the surface energy measurements suggest that the kinetics and probably the mechanism, of incorporation of the plasticizer differ depending on the chain length of the polymer. A significant change can be observed in the surface properties of films after the addition of $1 \%$ of plasticizer. However its effect is stabilized after this amount in the

Table 1

Minimal film forming temperature of the samples.

\begin{tabular}{llr}
\hline Plasticizer & \multicolumn{2}{c}{ Minimal film forming temperature $\left({ }^{\circ} \mathrm{C}\right)$} \\
\cline { 2 - 3 } & EC10 & EC45 \\
\hline $0 \%$ & 26.1 & 24.4 \\
$1 \%$ & 20.7 & 13.1 \\
$3 \%$ & 20.3 & 16.8 \\
$5 \%$ & 17.7 & 18.8 \\
\hline
\end{tabular}

Table 2

Parameters of the preparation of free films.

\begin{tabular}{ll}
\hline Parameter & Value \\
\hline Rotation rate of vessel & $22 / \mathrm{min}$ \\
Rate of liquid feeding & $5 \mathrm{ml} / \mathrm{min}$ \\
Pressure of spraying air & $1.5 \mathrm{bar}$ \\
Diameter of nozzle & $0.8 \mathrm{~mm}$ \\
\hline
\end{tabular}

case of EC10 films, while in the case of EC45 the stabilization is visible only after $3 \%$. The properties of the fully plasticized films are statistically the same $(p>0.05)$, which suggest that the plasticizer binds differently to the different types of EC-s. To clarify this phenomenon the structure of the films was investigated by FT-IR spectrometer. Better mechanical properties of the EC45 films provided better quality for the spectra, so the results are explained according to these data. The spectra of the blank and plasticized films have generally the same shape (Fig. 1), no significant shift of peaks can be observed, only a small widening of the symmetric and asymmetric valence vibration of the ether bonds are present in the $1000-1200 \mathrm{~cm}^{-1}$ wavenumber range. This suggests that the incorporation of plasticizer is based on secondary bindings.

The presence of the plasticizer can be clearly identified based on the bands of the ester groups. The most intensive peaks at $1750 \mathrm{~cm}^{-1}$, belong to the $\mathrm{C}=0$ valence vibrations. They are clearly present in the original FT-IR spectra. The signs of ternary OH groups at $1200 \mathrm{~cm}^{-1}$ and the $\mathrm{COC}$ vibration of the ester groups are overlapped with the other ether vibration signals are only can be identified in the subtracted spectra (Fig 2.).

The peaks in the subtracted spectra of EC45 films are significantly increased with increasing of the amount of plasticizer from 1 to $3 \%$, but after than a slight decrease can be observed, which is in good agreement with the surface energy measurements and also with the change of the minimal film forming temperature of the samples. This suggests that some of the main characteristics of the films are determined by the bounded fraction of the plasticizer. The slight decrease of the bounded fraction with increasing triethyl citrate amount probably can be due to the mass effect, which means that the increasing amount of the material will change the preferences of the intermolecular bindings, and will hinder the incorporation of the plasticizer into the structure of the polymer film. Meanwhile, there was no sign of inhomogeneity inside the film, the unbounded fraction of the plasticizer is probably evaporated/ flew out from the system with the small droplets of the solvent. These particles could be presented on the surface of the coating pan, but no measurements were performed to the detection of the plasticizer in the pollution.

\section{Conclusions}

The structure of films and the incorporation of plasticizer can be followed with the use of FT-IR. The results support that only a limited amount of plasticizer can be incorporated with physico-chemical bindings into the structure of polymer films and this proportion will basically determine some of the main properties of the preparations.

Table 3

Surface properties of EC films.

\begin{tabular}{llllll}
\hline \multirow{2}{*}{ Plasticizer } & \multicolumn{2}{l}{$\gamma(\mathrm{mN} / \mathrm{m})$} & & \multicolumn{2}{l}{ Polarity $(\%)$} \\
\cline { 2 - 3 } \cline { 5 - 6 } & EC10 & EC45 & & EC10 & EC45 \\
\hline \multirow{2}{*}{$0 \%$} & 56.17 & 49.54 & & 28.45 & 22.22 \\
& $( \pm 0.60)$ & $( \pm 0.96)$ & & $( \pm 0.90)$ & $( \pm 1.68)$ \\
$1 \%$ & 53.42 & 49.36 & & 26.13 & 18.13 \\
& $( \pm 0.55)$ & $( \pm 1.68)$ & & $( \pm 0.68)$ & $( \pm 2.38)$ \\
$3 \%$ & 53.92 & 54.71 & & 29.95 & 30.31 \\
& $( \pm 1.09)$ & $( \pm 1.03)$ & & $( \pm 0.98)$ & $( \pm 1.21)$ \\
$5 \%$ & 53.59 & 53.48 & & 28.66 & 27.54 \\
& $( \pm 0.89)$ & $( \pm 1.00)$ & & $( \pm 0.98)$ & $( \pm 1.06)$ \\
\hline
\end{tabular}




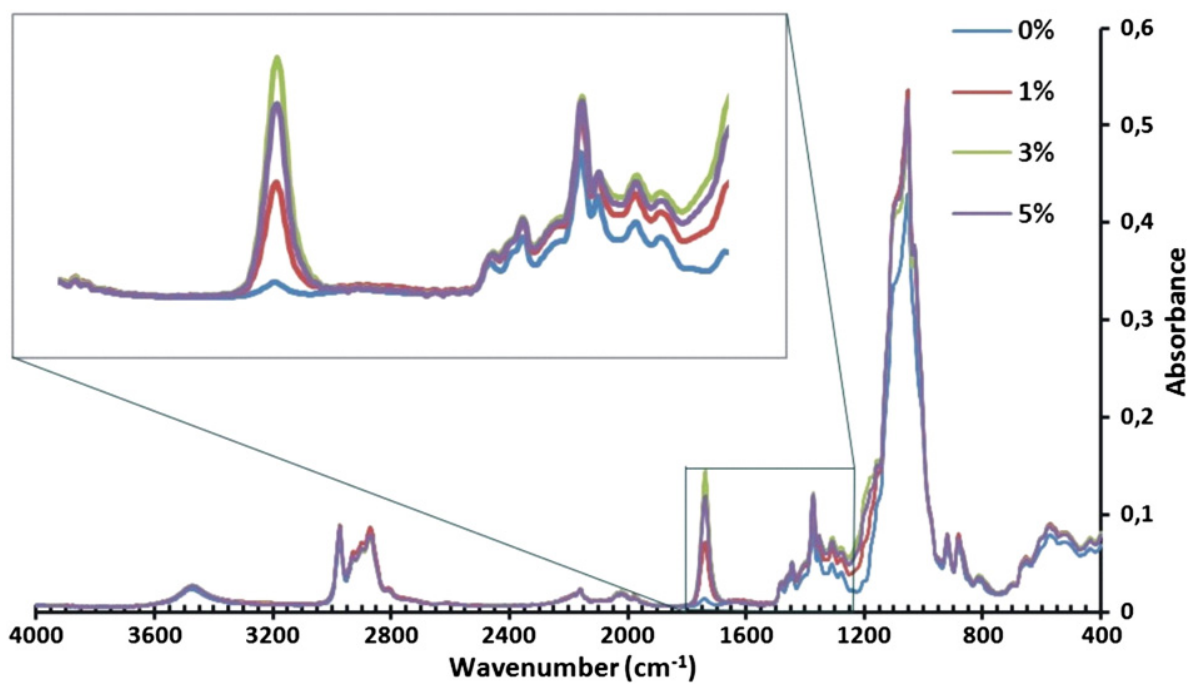

Fig. 1. FT-IR spectra of the EC45 films.

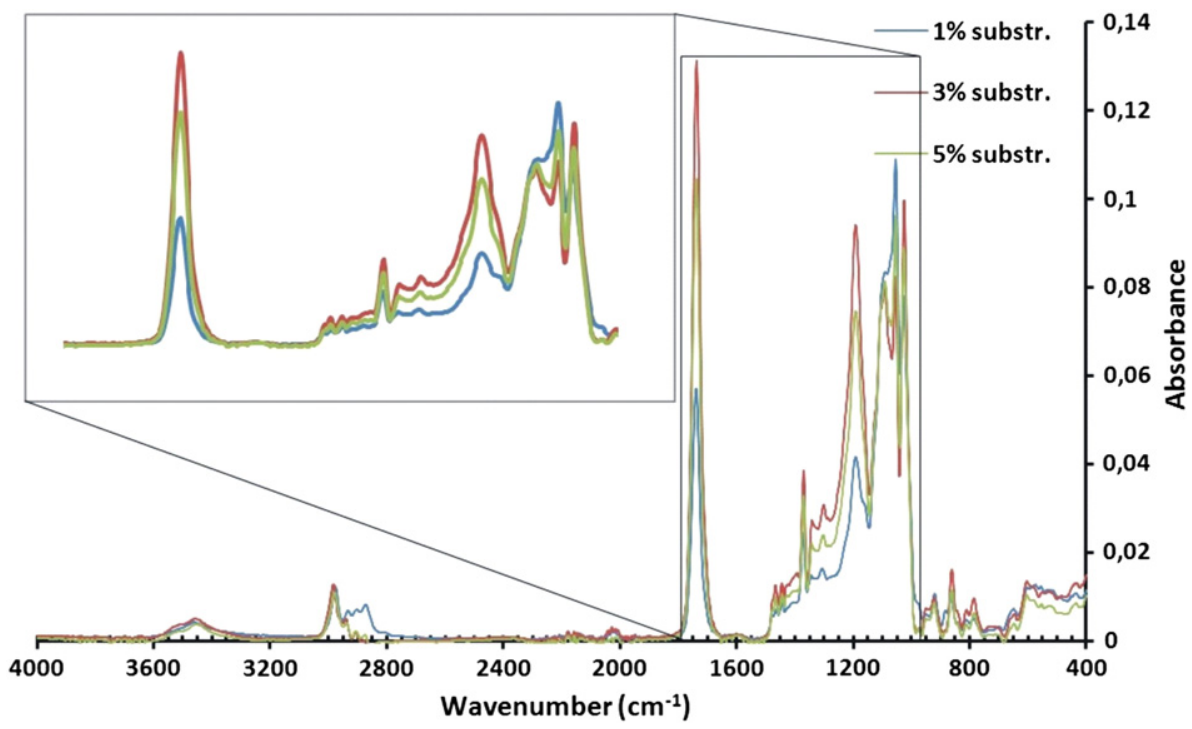

Fig. 2. Subtracted spectra of the plasticized EC45 films.

The analysis of the film structure can explain some unexpected disturbances in the film properties and can help in the development of suitable preparations.

\section{Acknowledgements}

The publication/presentation is supported by the European Union and co-funded by the European Social Fund. Project title: "Broadening the knowledge base and supporting the long term professional sustainability of the Research University Centre of Excellence at the University of Szeged by ensuring the rising generation of excellent scientists." Project number: TÁMOP-4.2.2/B-10/1-2010-0012. The EC samples were kindly supplied by the Colorcon Ltd.

\section{References}

[1] A.J. Claxton, J. Cramer, C. Pierce, A systematic review of the associations between dose regimens and medication compliance, Clin. Ther. 23 (2001) 1296-1310.

[2] M.A. Frohoff-Huélsmann, B.C. Lippold, J.W. McGinity, Aqueous ethyl cellulose dispersion containing plasticizers of different water solubility and hydroxypropyl methyl-cellulose as coating material for diffusion pellets II: properties of sprayed films, Eur. J. Pharm. Biopharm. 48 (1999) 67-75.
[3] F. Lecomte, J. Siepmann, M. Walther, R.J. MacRae, R. Bodmeier, Polymer blends used for the aqueous coating of solid dosage forms: importance of the type of plasticizer, J. Control. Release 99 (2004) 1-13.

[4] S. Kangarlou, I. Haririan, Y. Gholipour, Physico-mechanical analysis of free ethyl cellulose films comprised with novel plasticizers of vitamin resources, Int J. Pharm. 356 (2008) 153-166.

[5] S.-Y. Lina, K.-S. Chenb, L. Run-Chu, Organic esters of plasticizers affecting the water absorption, adhesive property, glass transition temperature and plasticizer permanence of Eudragit acrylic films, J. Control. Release 68 (2000) 343-350.

[6] L.A. Felton, J.W. McGinity, Influence of plasticizers on the adhesive properties of an acrylic resin copolymer to hydrophilic and hydrophobic tablet compacts, Int. J. Pharm. 154 (1997) 167-178.

[7] J. Siepmann, O. Paeratakul, R. Bodmeier, Modeling plasticizer uptake in aqueous polymer dispersions, Int. J. Pharm. 165 (1998) 191-200.

[8] R. Bodmeier, O. Paeratakul, Plasticizer uptake by aqueous colloidal polymer dispersions used for the coating of solid dosage forms, Int. J. Pharm. 152 (1997) 17-26.

[9] J. Dredán, R. Zelkó, Á.Z. Dávid, I. Antal, Quantitative estimation of film forming polymer-plasticizer interactions by the Lorentz-Lorenz Law, Int. J. Pharm. 310 (2006) 25-30.

[10] J. Piermaria, A. Bosch, A. Pinotti, O. Yantorno, M.A. Garcia, A.G. Abraham, Kefiran films plasticized with sugars and polyols: water vapor barrier and mechanical properties in relation to their microstructure analyzed by ATR/FT-IR spectroscopy, Food Hydrocolloids 25 (2011) 1261-1269.

[11] J. Papp, J. Horgos, V. Szente, R. Zelkó, Correlation between the FT-IR characteristics and metoprolol tartrate release of methylcellulose-based patches, Int. J. Pharm. 392 (2010) 189-191. 
[12] B. Szabó, K. Süvegh, R. Zelkó, Effect of storage on microstructural changes of Carbopol polymers tracked by the combination of positron annihilation lifetime spectroscopy and FT-IR spectroscopy, Int. J. Pharm. 416 (2011) 160-163.

[13] V. Szente, F. Baska, R. Zelkó, K. Süvegh, Prediction of the drug release stability of different polymeric matrix tablets containing metronidazole, J. Pharm. Biomed. Anal. 54 (2011) 730-734.

[14] H. Kitano, K. Ichikawa, M. Fukuda, A. Mochizuki, M. Tanaka, The structure of water sorbed to polymethoxyethylacrylate film as examined by FT-IR spectroscopy, J. Colloid Interface Sci. 242 (2001) 133-140.
[15] D. Perez-Guaitaa, J. Ventura-Gayete, C. Pérez-Rambla, M. Sancho-Andreu, S. Garrigues, M. de la Guardia, Evaluation of infrared spectroscopy as a screening tool for serum analysis: impact of the nature of samples included in the calibration set, Microchem. J. 106 (2013) 202-211.

[16] P.L.R.M. Palaniappan, V. Vijayasundaram, The FT-IR study of the brain tissue of Labeo rohita due to arsenic intoxication, Microchem. J. 91 (2009) 118-124. 
III. 


\title{
Characterization of ethylcellulose free films by positron annihilation spectroscopy and mechanical testing
}

\author{
Diána Hegyesi ${ }^{\text {a,b }}$, Károly Süvegh ${ }^{c}$, András Kelemen ${ }^{\mathrm{d}}$, Klára Pintye-Hódi ${ }^{\mathrm{a}}$, Géza Regdon Jr. a,* \\ a Department of Pharmaceutical Technology, University of Szeged, Eötvös utca 6., H-6720 Szeged, Hungary \\ b Richter Gedeon Ltd., Gyömröi út 17-19., H-1103 Budapest, Hungary \\ c Laboratory of Nuclear Chemistry, Eötvös Loránd University, P.O. Box 32, H-1518 Budapest 112, Hungary \\ d Department of Applied Informatics, University of Szeged, Boldogasszony sgt. 6., H-6720 Szeged, Hungary
}

\section{A R T I C L E I N F O}

\section{Article history:}

Received 29 January 2014

Accepted 10 February 2014

Available online 16 February 2014

\section{Keywords:}

Ethylcellulose

Free films

PALS

Mechanical test

Triethyl citrate

\begin{abstract}
A B S T R A C T
The distribution of the plasticizer triethyl citrate between the chains of the polymer ethylcellulose was determined in order to explain the mechanical properties. A knowledge of these properties is indispensable for preformulation studies. As preformulation, the relationship between the mechanical properties and the distribution of the plasticizer was studied. The distribution was investigated with positron annihilation lifetime spectroscopy, and the mechanical properties with breaking hardness tests. Two kinds of ethylcellulose were used. The best film-former with plasticizer was chosen with the optimal concentration. Selection of the optimum type and concentration of the plasticizer is essential in the formulation of pellets and coated dosage forms.
\end{abstract}

(C) 2014 Elsevier B.V. All rights reserved.

\section{Introduction}

Film coating is a method widely used for the development of solid dosage forms. In the process of film coating, a thin stable polymer film coat is created on the surface of a solid dosage form, such as tablets, capsules, pellets or crystals.

The numerous polymers available for coating ensure different dissolution profiles. Cellulose esters, cellulose acetatephthalate and hydroxypropylmethylcellulose phthalate are enteric polymers used to form colonic drug delivery systems [1]. Methylcellulose, hydroxyethylcellulose and some polymethacrylate products (e.g. Eudragit $\AA$ E) are polymers that dissolve in the gastric juice [2]. We earlier studied Eudragit ${ }^{\circledR}$ L 30D-55, an aqueous dispersion of anionic polymers with methacrylic acid functional groups [3].

Acryl-Eze, an aqueous system, which contains a 1:1 copolymer of methacrylic acid and methyl methacrylate, is often used for the enteric coating of dosage forms [4-6].

In the present study, ethylcellulose was used as film former. Ethylcellulose is an ideal polymer for the formation of products allowing modified drug release. It is insoluble at any $\mathrm{pH}$ that occurs in organism, but in the presence of the gastric juice it undergoes swelling. It is then permeable for water and permits extended modified drug release

\footnotetext{
* Corresponding author. Tel.: + 36 62545576; fax: + 3662545571.

E-mail address: geza.regdon@pharm.u-szeged.hu (G. Regdon).
}

[7-10]. This makes it suitable for improved patient compliance. Only a small number of ethylcellulose polymers have been approved for general pharmaceutical application and are used in extended release solid dosage formulations. Several types of such ethylcellulose exist, e.g. Ethocel 4, Ethocel 10 and Ethocel 45, which differ in the length of the polymer chains, the rate of dissolution, and the viscosity of their solution.

The purpose of the polymer film is to form a uniform and continuous coat on the surface of the core, and it must therefore have appropriate elasticity. In most cases, films prepared from a film-forming polymer alone are rigid and break easily, and the use of a plasticizer is therefore indispensable to increase the elasticity of the coat. The quantity and quality of plasticizers can be determined by means of various physicalchemical investigations [11].

Before the film coating, preformulation studies are necessary in order to study the physicochemical and thermal properties of the free films, e.g. the glass-transition temperature, the minimum film-forming temperature, the surface properties, the breaking strength and deformability and the structure of the film-former polymer. The thermal behaviour of ethylcellulose free films was studied earlier [12]. Ethocel 45 films proved to be more stable than Ethocel 10 films during storage. In our previous work [13], we made use of FT-IR spectroscopy, to study the structure of free films containing ethylcellulose, and the effects of the plasticizer on the structure and surface characteristics of the films. The results indicated that only a limited amount of plasticizer can be incorporated into the structure of the polymer film through physical-chemical binding, 
the proportion basically determining some of the main properties of the product. The mechanical properties of the resulting film depend on the distribution of the plasticizer. It is necessary to know its breaking strength, because the film is exposed to intense mechanical stress during the technological process.

In the present work, the distribution of the plasticizer and the supramolecular structure of free films were studied by means of positron annihilation lifetime spectroscopy (PALS), which furnishes direct information about the dimensions and contents of free-volume holes in amorphous materials. The magnitude of the free volume can be measured with the aid of PALS as electron density changes in the lifetime of the ortho-positron depend on the free volume of the polymer [14-16]. This method is most commonly applied to study polymers. Investigation of cellulose-based polymers by PALS has revealed that substitution on cellulose has little effect on the lifetime, but a major effect on the probability of formation of the ortho-positron (o-Ps) [17,18].

\section{Experimental}

Two different forms of ethylcellulose were used in the experiments: Ethocel Standard Premium 10 and Ethocel Standard Premium 45 (Colorcon Ltd, Dartford, England). Triethyl citrate was used as a plasticizer (Ph. Eur.).

\subsection{Preparation of free films}

The free films were prepared by spraying, as described previously [13]. The temperature of the drying air was set at the minimum filmforming temperature. The process parameters of the spraying are given in Table 1.

\subsection{Positron lifetime measurements}

PALS measures the time for which a positron can exist in a material. This lifetime depends on the properties of the particular material. The method is based on the fact that electrons and positrons annihilate each other to form photons. The properties of the resulting radiation correspond exactly to the relevant properties of the electron and the positron preceding the annihilation. PALS is an important method in the structural characterization of polymers, and its role is currently increasing in pharmaceutical technology [19-21]. Together with other properties, this method measures the size distribution of free-volume holes in polymers.

The use of positrons in polymers is based on the formation of the positronium, a bound state of an electron and a positron, in which the role of the positron resembles that of the proton in a hydrogen atom. The lifetime of the positronium before its annihilation is determined by the properties of the material in which it is formed. The exact dependence can be approximated by means of a simple model. The freevolume model regards the free volume in polymers as formed of uniform spherical voids [21]. Although the model is simple, it provides a possibility to derive a connection between the measured lifetime and the size distribution of the free-volume holes:

$\tau=\frac{1}{2}\left[1-\frac{R}{R+\Delta R}+\frac{1}{2 \pi} \sin \left(\frac{2 \pi R}{R+\Delta R}\right)\right]^{-1}$

Table 1

Process parameters for preparation of free films.

\begin{tabular}{lc}
\hline Parameter & Value \\
\hline Rotation rate of vessel (rpm) & 22 \\
Rate of liquid feeding (ml/min) & 5 \\
Pressure of spraying air (bar) & 1.5 \\
Diameter of nozzle (mm) & 0.8 \\
\hline
\end{tabular}

where $\tau$ is the lifetime of the ortho-positronium in nanoseconds, $R$ is the radius of the voids in Angströms, and $\Delta R$ is a constant. This formula indicates that $\tau$ increases with $R$. On a molecular scale, the $R$ values correspond well with the BET and neutron scattering results.

The positron source applied for the measurements was made of carrier-free ${ }^{22} \mathrm{NaCl}$ with an activity of $10^{5} \mathrm{~Bq}$, sealed between two very thin Kapton foils. The source was placed between two pieces of polymeric mixture previously treated identically. Positron lifetime spectra were recorded by a conventional fast-fast coincidence system based on $\mathrm{BaF}_{2} / \mathrm{XP2020Q}$ detectors and Ortec electronics.

Spectra were recorded in 4096 channels of a computer-based multichannel analyser card (Nucleus). The time resolution of the spectrometer was $\sim 220$ ps. Each spectrum related to $1.5 \times 10^{6}$ annihilation events. Samples were measured repeatedly and the data given below are averages of the repeated measurements.

\subsection{Mechanical properties of free films}

The breaking strength of the films was tested with an indentation hardness tester. This device and the software were developed in our institute. The tester contains a special specimen holder and a jowl. The loading indicates stress in the sample and it can deform. These devices are connected with a computer through an interface. Thus, not only can the ultimate deformation force be measured, but also the process (force-time and force-displacement curves) can be followed. The specimen, and hence the free film is located horizontally in the holder and the jowl moves vertically. The measuring range was $0-200 \mathrm{~N}$, the speed of the stamp was $20 \mathrm{~mm} / \mathrm{min}$, the sampling rate was $50 \mathrm{~Hz}$, the output was $0-5 \mathrm{~V}$, and the sensitivity was \pm 0.1 digit. The sensor was a Unicell force-measuring instrument, calibrated with the C9B $20 \mathrm{kN}$ cell.

\section{Results}

\subsection{Positron lifetime measurement}

The PALS results revealed that there was no significant difference between the two types of ethylcellulose samples (Fig. 1), which were influenced very similarly by the plasticizer. A significant difference was observed only at the highest concentration of the plasticizer.

The positron lifetime initially decreased slightly at the lowest plasticizer concentration. This is a consequence of the distribution of the plasticizer molecules between the polymer chains, filling the free-volume holes, occupying sites formerly available for the positronium atoms, providing a higher electron density. The lifetime of the positronium

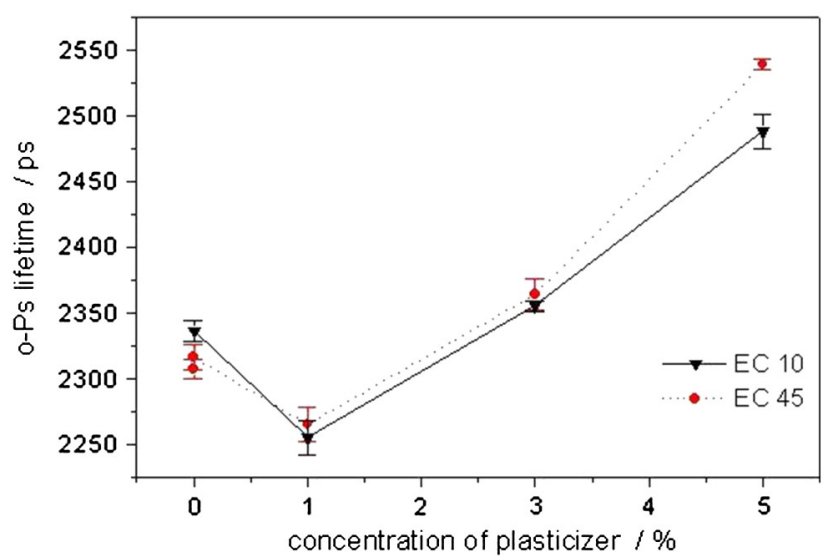

Fig. 1. Positron lifetime plotted against concentration. 
Table 2

Breaking strength of Ethocel 10 free films.

\begin{tabular}{lllll}
\hline \multicolumn{5}{l}{ Plasticizer concentration } \\
\cline { 2 - 5 } & $0 \%$ & $1 \%$ & $3 \%$ & $5 \%$ \\
\hline Storage conditions & 5.66 & \multicolumn{3}{l}{ Breaking strength $(\mathrm{N})$} \\
Fresh films & $( \pm 1.55)$ & $( \pm 2.58)$ & $( \pm 1.00)$ & $( \pm 1.31)$ \\
& 5.68 & 9.46 & 4.38 & 4.18 \\
After 1 week & $( \pm 1.83)$ & $( \pm 2.56)$ & $( \pm 1.15)$ & $( \pm 0.83)$ \\
& 5.28 & 9.41 & 4.82 & 4.81 \\
After 2 weeks & $( \pm 1.99)$ & $( \pm 2.63)$ & $( \pm 1.66)$ & $( \pm 1.43)$ \\
After 4 weeks & 5.02 & 9.12 & 4.9 & 4.45 \\
& $( \pm 1.52)$ & $( \pm 2.47)$ & $( \pm 1.6)$ & $( \pm 0.69)$ \\
\hline
\end{tabular}

Table 3

Breaking strength of Ethocel 45 free films.

\begin{tabular}{|c|c|c|c|c|}
\hline & \multicolumn{4}{|c|}{ Plasticizer concentration } \\
\hline & $0 \%$ & $1 \%$ & $3 \%$ & $5 \%$ \\
\hline Storage conditions & \multicolumn{4}{|c|}{ Breaking strength $(\mathrm{N})$} \\
\hline Fresh films & $\begin{array}{l}10.47 \\
( \pm 1.94)\end{array}$ & $\begin{array}{l}31.06 \\
( \pm 1.32)\end{array}$ & $\begin{array}{l}12.73 \\
( \pm 2.14)\end{array}$ & $\begin{array}{l}8.46 \\
( \pm 1.5)\end{array}$ \\
\hline After 1 week & $\begin{array}{l}11.04 \\
( \pm 2.58)\end{array}$ & $\begin{array}{l}34.34 \\
( \pm 3.49)\end{array}$ & $\begin{array}{l}13.63 \\
( \pm 3.06)\end{array}$ & $\begin{array}{l}8.74 \\
( \pm 1.82)\end{array}$ \\
\hline After 2 weeks & $\begin{array}{l}10.89 \\
( \pm 2.96)\end{array}$ & $\begin{array}{l}32.99 \\
( \pm 3.09)\end{array}$ & $\begin{array}{l}12.1 \\
( \pm 1.82)\end{array}$ & $\begin{array}{l}8.63 \\
( \pm 1.64)\end{array}$ \\
\hline After 4 weeks & $\begin{array}{l}10.37 \\
( \pm 2.47)\end{array}$ & $\begin{array}{l}30.13 \\
( \pm 3.31)\end{array}$ & $\begin{array}{l}12.59 \\
( \pm 2.11)\end{array}$ & $\begin{array}{l}8.51 \\
( \pm 0.71)\end{array}$ \\
\hline
\end{tabular}

atoms therefore decreases. The structure of the film was changed as a result of the admixture of the plasticizer. At higher concentrations, the plasticizer initiated a large-scale rearrangement of the polymer chains, leading to the formation of larger free-volume holes, as indicated by the longer lifetimes.

It should be emphasised that the PALS data did not indicate any major structural change up to a plasticizer concentration of $1 \%$. The large-scale rearrangement of the polymer chains necessitated a higher concentration.

\subsection{Mechanical properties}

The pellet deformation process was evaluated by determining the breaking hardness and studying the deformation curve. The breaking strength results are presented in Tables 2 and 3. The addition of $1 \%$ plasticizer to Ethocel 10 resulted in a 2-fold higher breaking strength of the

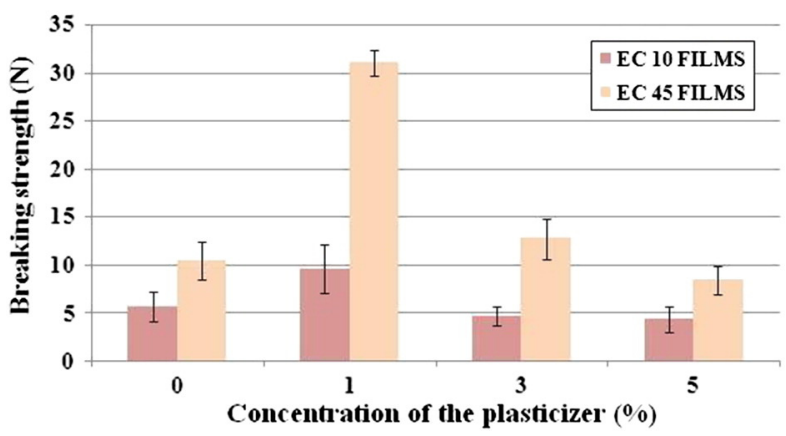

Fig. 2. Breaking strength of Ethocel 10 and Ethocel 45 free films.
Table 4

Fitted results of change in breaking strength in time with the following model: $F(t)=$ $F_{0}+a t$.

\begin{tabular}{llll}
\hline Plasticizer concentration & $F_{0}$ & $a$ & $\mathrm{R}^{2}$ \\
\hline $0 \%$ & 11.300 & -0.2286 & 0.9860 \\
$1 \%$ & 35.77 & -1.41 & 0.9998 \\
$5 \%$ & 8.80 & -0.0743 & 0.9730 \\
\hline
\end{tabular}

film. The addition of larger amounts of the plasticizer resulted in a decrease in the breaking hardness. The reason for this is the influence of the moisture content of the plasticizer on the elasticity of the film.

The addition of $1 \%$ plasticizer to Ethocel 45 resulted in a 3 -fold higher breaking strength of the film.

The breaking strengths of the two kinds of ethylcellulose films are compared in Fig. 2. It may be seen that the breaking strengths of the films prepared from the shorter-chain Ethocel 10 polymer with its looser structure were lower than those for the longer-chain, more compact Ethocel 45 films. Ethocel 45 formed a significantly stronger structure.

The addition of $3 \%$ plasticizer resulted in a small increase in the breaking strength, whereas higher concentrations of the plasticizer caused decreases in the breaking strength.

The changes in the breaking strength as a function of time are shown in Tables 2 and 3. In the case of the Ethocel 45 film the breaking strength was highest after 1 week at all plasticizer levels. In contrast, the case of Ethocel 10 film, a similar effect was found only at $1 \%$ plasticizer. The reason for this is the loss of the moisture content from the system. The rate of evaporation of moisture depends on the film structure.

The breaking strength of the Ethocel 45 film after 1 week varied linearly with time with a very good correlation, except in the case of the $3 \%$ plasticizer (Table 4).

Fig. 3 illustrates the above effects for the Ethocel 45 film containing $1 \%$ plasticizer, with $\mathrm{R}^{2}=0.9998$.

The Ethocel 10 films exhibited a similar linear property only at a low concentration of the plasticizer. The reason for this is that the breaking strength depends on the moisture content of the system and the length of the polymer chains.

Study of the deformation curve with the aid of our software revealed that the loading did not cause deformation of the film (Fig. 4, section a). After a very short viscoelastic deformation, when the breaking strength did not change significantly, the breaking curve displayed an elastic tendency (section b). This was followed by a further elastic section (section c), at the end of which breaking occurred.

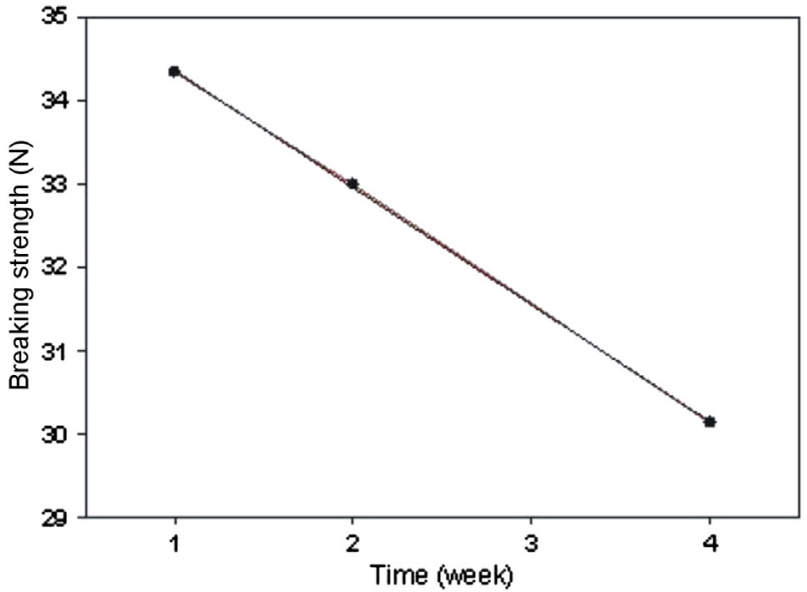

Fig. 3. Fitted hardness curve of Ethocel 45 films with $1 \%$ plasticizer. 


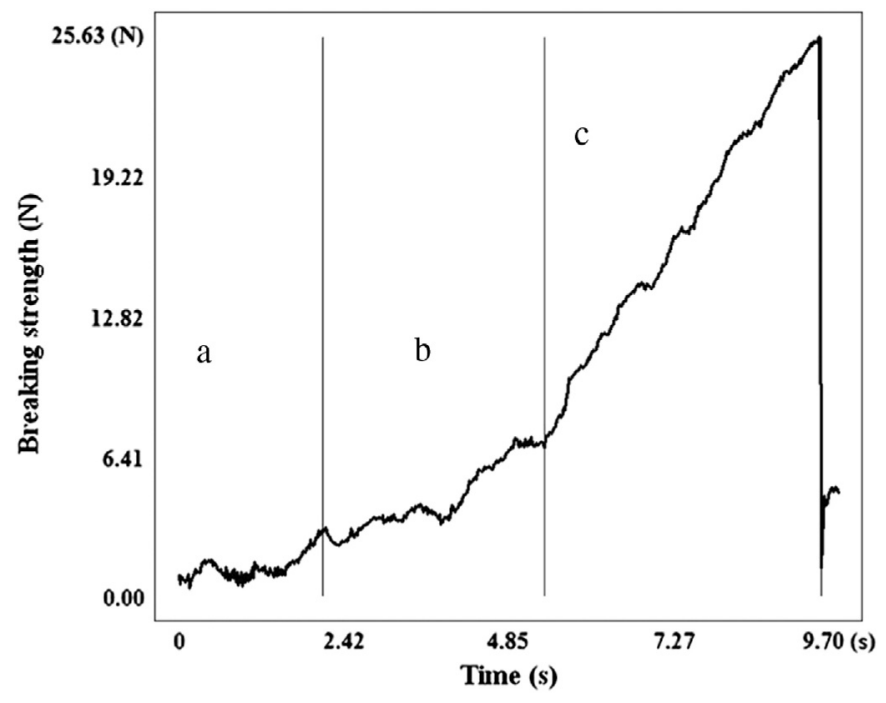

Fig. 4. Deformation curve of the free films.

\section{Conclusions}

The mechanical properties of ethylcellulose polymers and the effects of the incorporation of a plasticizer agreed with our expectations and former results. PALS studies demonstrated that up to a concentration of $\sim 1 \%$ the incorporated plasticizer is integrated between the polymer chains. At higher concentrations, the large-scale rearrangement of the polymer chains begins, resulting in larger free-volume holes and lower breaking strengths. The mechanical properties were clearly revealed to depend on the concentration of the plasticizer. These results allow the choice of the better film-former polymer: Ethocel 45 with its longer chains. The moisture content of the $1 \%$ plasticizer proved suitable for these ethylcellulose films. After a storage time of 1 week, the breaking strength decreased linearly, the film losing its moisture content continuously.

The ideal concentration of the plasticizer in these film-formers was $1 \%$. This concentration resulted in strong, mechanically resistant, stable films. This composition can be used for diffusion coating to obtain a product with modified release.

\section{Acknowledgements}

This publication is supported by the European Union and co-funded by the European Social Fund (project number: TÁMOP 4.2.2. A-11/1/ KONV-2012-0047).

Purchase of two types of ethylcellulose was supported by Colorcon Ltd.

\section{References}

[1] C.P. Ferrarri, F.G. Oliveira, S.C.F. Chibebe C.R. Evangelista, In vitro characterization of coevaporates containing chitosan for colonic drug delivery, Carbohydr. Polym. 78 (2009) 557-563.

[2] S.Y. Lin, H.L. Yu, M.J. Li, Formation of six-membered cyclic anhydrides by thermally induced intramolecular ester condensation in Eudragit E film, Polymer 40 (1999) 3589-3593.

[3] É. Bölcskei, K. Süvegh, T. Marek, G. Regdon Jr., K. Pintye-Hódi, Testing of the structure of macromolecular polymer films containing solid active pharmaceutical ingredient (API) particles, Radiat. Phys. Chem. 80 (2011) 799-802.

[4] T. Sovány, K. Nikowitz, G. Regdon Jr., P. Kása Jr., K. Pintye-Hódi, Raman spectroscopic investigation of film thickness, Polym. Test. 28 (2009) 770-772.

[5] K. Nikowitz, P. Kása Jr., K. Pintye-Hódi, G. Regdon Jr., Study of the preparation of a multiparticulate drug delivery system with a layering technique, Powder Technol. 205 (2011) 155-159.

[6] K. Nikowitz, K. Pintye-Hódi, G. Regdon Jr. Study of the recrystallization in coated pellets - effect of coating on API crystallinity, Eur. J. Pharm. Sci. 48 (2013) 563-571.

[7] I.E. Hamedelniel, J. Bajdik, T. Sovány, K. Pintye-Hódi, Delayed release matrix pellet preparation containing an alkalizing pore-former agent, Chem. Eng. Res. Des. 89 (2011) 1006-1010

[8] N. Pearnchob, R. Bodmeier, Coating of pellets with micronized ethylcellulose particles by a dry powder coating technique, Int. J. Pharm. 268 (2003) 1-11.

[9] F. Sadeghi, J.L. Ford, A. Rajabi-Siahboomi, The influence of drug type on the release profiles from Surelease-coated pellets, Int. J. Pharm. 254 (2003) 123-135.

[10] E.L. McConnell, M.D. Short, A.W. Basit, An in vivo comparison of intestinal pH and bacteria as physiological trigger mechanisms for colonic targeting in man, J. Control. Release 130 (2008) 154-160.

[11] D. Hutchings, S. Clarson, A. Sakr, Studies of the mechanical properties of free films prepared using an ethylcellulose pseudolatex coating system, Int. J. Pharm. 104 (1994) 203-213.

[12] G. Regdon Jr., D. Hegyesi, K. Pintye-Hódi, Thermal study of ethyl cellulose coating films used for modified release (MR) dosage forms, J. Therm. Anal. Calorim. 108 (2012) 347-352.

[13] D. Hegyesi, T. Sovány, O. Berkesi, K. Pintye-Hódi, G. Regdon Jr., Study of the effect of plasticizer on the structure and surface characteristics of ethylcellulose free films with FT-IR spectroscopy, Microchem. J. 110 (2013) 36-39.

[14] R. Zelkó, Á. Orbán, K. Süvegh, Z Riedl, I. Rácz, Effect of plasticizer on the dynamic surface tension and the free volume of Eudragit systems, Int. J. Pharm. 244 (2002) 81-86.

[15] Y.C. Jean, Positron annihilation spectroscopy for chemical analysis: a novel probe for microstructural analysis of polymers, Microchem. J. 42 (1990) 72-102.

[16] I. Sebe, B. Szabó, R. Zelkó, Bio-based pharmaceutical polymers, possibility of their chemical modification and applicability of modified polymers, Acta Pharm. Hung. 82 (2012) 138-154.

[17] R.A. Pethrick, Positron annihilation - a probe for nanoscale voids and free volume? Prog. Polym. Sci. 22 (1997) 1-47.

[18] M. Gottnek, K. Süvegh, K. Pintye-Hódi, G. Regdon Jr., Effects of excipients on the tensile strength, surface properties and free volume of Klucel ${ }^{\circledR}$ free films of pharmaceutical importance, Radiat. Phys. Chem. 89 (2013) 57-63.

[19] J. Bajdik, G. Regdon Jr., T. Marek, I. Erős, K. Süvegh, K. Pintye-Hódi, The effect of the solvent on the film-forming parameters of hydroxypropyl-cellulose, Int. J. Pharm. 301 (2005) 192-198.

[20] J. Bajdik, Z. Makai, O. Berkesi, K. Süvegh, T. Marek, I. Erős, K. Pintye-Hódi, Study of the effect of lactose on the structure of sodium alginate films, Carbohydr. Polym. 77 (2009) 530-535.

[21] M. Eldrup, D. Lightbody, J.N. Sherwood, The temperature dependence of positron lifetimes in solid pivalic acid, Chem. Phys. 63 (1981) 51-58. 